Western University Scholarship@Western

Digitized Theses

Digitized Special Collections

1971

\title{
The Thermal Decomposition Of Perchloric Acid
}

Robert Gilbert

Follow this and additional works at: https://ir.lib.uwo.ca/digitizedtheses

\section{Recommended Citation}

Gilbert, Robert, "The Thermal Decomposition Of Perchloric Acid" (1971). Digitized Theses. 496.

https://ir.lib.uwo.ca/digitizedtheses/496

This Dissertation is brought to you for free and open access by the Digitized Special Collections at Scholarship@Western. It has been accepted for inclusion in Digitized Theses by an authorized administrator of Scholarship@Western. For more information, please contact tadam@uwo.ca,

wlswadmin@uwo.ca. 
The author of this thesis has granted The University of Western Ontario a non-exclusive license to reproduce and distribute copies of this thesis to users of Western Libraries. Copyright remains with the author.

Electronic theses and dissertations available in The University of Western Ontario's institutional repository (Scholarship@Western) are solely for the purpose of private study and research. They may not be copied or reproduced, except as permitted by copyright laws, without written authority of the copyright owner. Any commercial use or publication is strictly prohibited.

The original copyright license attesting to these terms and signed by the author of this thesis may be found in the original print version of the thesis, held by Western Libraries.

The thesis approval page signed by the examining committee may also be found in the original print version of the thesis held in Western Libraries.

Please contact Western Libraries for further information:

E-mail: libadmin@uwo.ca

Telephone: (519) 661-2111 Ext. 84796

Web site: http://www.lib.uwo.ca/ 
THE THERMAI DECOMPOSTTION OF PERCHLORIC ACID

\author{
by \\ Robert Gilbert \\ Department of Chemistry
}

\begin{abstract}
Submitted in partial fulfillment of the requirements for the degree of

Doctor of Philosophy
\end{abstract}

Faculty of Graduate Studies

The University of Westerm Ontario

London, Canada

August, 1970

(c) Lobert Gilbert I97. 


\section{ABSTRACT}

The kinetics of the thermal decomposition of perchloric acid vapour in pyrex reaction vessels has been investigated betureen 279 and $471^{\circ} \mathrm{C}$ with initial perchloric acid concentrations of $1 \times 10^{-4}$ to $1.5 \times 10^{-3}$ mole litre ${ }^{-1}$ using a flow technique. Four reaction vessels of different dimensions were used and the effect of ageing, annealing: coating and packing reaction vessels was observed. The major reaction products over this temperature range are chlorine, oxygen and water, although there was evidence for the formation of small amounts of hydrogen chloride in a side reaction. The decomposition was essentially first order at all tempergtures although significant deviations from first order kinetics were observed at high conversions in the intermediate temperature region. Strong suriace effects were observed, particularly at low temperatures. Hiti certain surfaces, sigmoid shaped decomposition curpes yere observed and these were ascribed to se? Gecomposition on these surfaces.

Piree different kinetic models Here discussed. While a chain aconanism may be involved, it is more probable that 
perchloric acia aecomposes unimolecularly in tine gas phase and heterogeneously on sparsely populated sites on the pyrex surface. The rate constant for the gas phase decomposition is given by $\mathrm{k}\left(\mathrm{sec}^{-1}\right)=1.3 \times 10^{12} \exp (-41,200 / \mathrm{RT})$ and the specific rate constant for the heterogeneous decomposition on freshly annealed pyrex is given by $\mathrm{k}\left(\mathrm{sec}^{-1} \mathrm{~cm}^{-2}\right)=3.5 \times 10^{2} \exp (-15,100 / \mathrm{RI})$. The surface concentration of active sites deperas on the history of the pyrex.

The effect on the decomposition of perchloric acid of five Harshaw catalysts ( $\mathrm{Cu}-0203, \mathrm{Fe}-0301, \mathrm{Al}-0104, \mathrm{Cu}-0803$ and $\mathrm{Mn}-0201$ ) was investigated. AII were positive catalysts and the major reaction products were chlorine, oxygen and water. The decomposition on the rirst four was clearly first order and Arrhenius parameters were obtained for these. The activation energies were $54.0,28.5,28.8$ and $39.0 \mathrm{kcal} \mathrm{mole} \mathrm{e}^{-1}$, respectively and a compensation effect was observed.

A preliminary study of the reaction of perchloric acid with the model fuels, hydrogen, methane, ethane and ethylene was made under fuel-rich conditions. Hydrogen reacted directly with perchloric acid on the pyrex surface to give mainly hydrogen chloride and water while methane, ethane and ethylene reacted with the decomposition intermediates of perchloric acid to give carbor monoxide ana byarogen chloride as the main products. 


\section{ACKINOWLEDGMEN}

I would like to express my gratitude to Dr. P.W.M. Jacobs for his constant encouragement, guidance and heip throughout this work. I $3 m$ also indebted to the graduate students, post-doctoral fellows, faculty members, visitors and technical staff who have contributed to my education at Western.

During the course of this research I received financial support from the Ontario Government in the form of a Province of Ontario Graduate Fellowship and from the National Research Council in the form of an N.R.C. Bursary. I would like to thank both these sponsors.

I owe a debt of thanks to my parents who have been a scurce of encouragement throughout my education and to my wife, I owe a special thank you, for not only typing this thesis, but for her constant understanding and help. 
TABLE OF COINTENTS

page

Certificate of Examination . . . . . . . . . ii

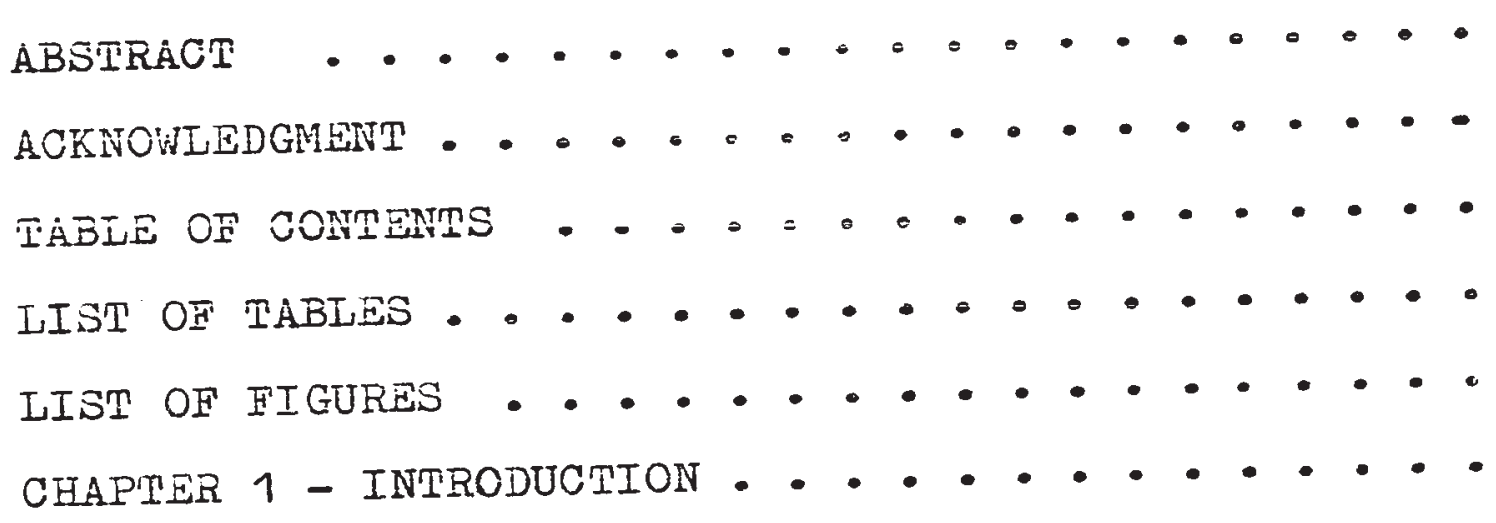

iii

$\mathrm{v}$

vi

viii

1.1 Thermal Decomposition of Ammonium Perchlorate . . . . . • • • • •

1.2 Physical Properties of Perchloric ... 4 Acid • • • • • • • • • • • • • 4

1.3 Thermal Decomposition of Gaseous .... 5

1.4 Thermal Decomposition in the ..... 17

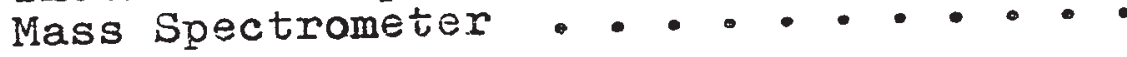

x

1

1.5 Catalytic Decomposition of Perchloric ficid ........ 20

1.6 Percbloric Acid Flames . . . . . . 23

1.7 Reaction of Perchloric Acid witis Amonia............. 28

1.8 Reactions of Chlorine Oxides..... 30

GAAPTER 2 - EXPERIMETTAI . . . . . . . . 36

2. i Outline 


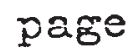

2.2 Materials . . . . . . . . 38

2.3 Apparatus .......... . . 39

2.4 Analysis ............ 43

2.5 Computing . . . . . . . . . 48

CHAPTER 3 - RESULTS ............. • 50

3.1 Decomposition of Perchloric Acid . . . 50
in Pyrex Reaction Vessels.... 50

3.2 Decomposition of Perchloric Acid
in the Presence of Added Catalysts . . 62

3.3 Reaction of Perchloric Acid . . . . 67

with Fuels . $\cdot$. • • • • • • •

CHAPTER 4 - DISCUSSION •. • • • • • • • . 72

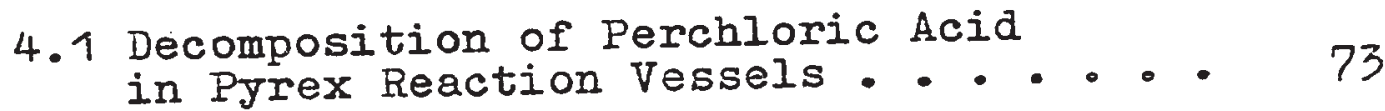

4.2 Decomposition of Perchloric Acid
in the Presence of Added Catalysts . . 92

4.3 Reaction of Perchloric Acid...... 96

with Fuels . • . • • • • • 96

4.4 Conclusions ........ . . 99

REFERENCES .................. 153

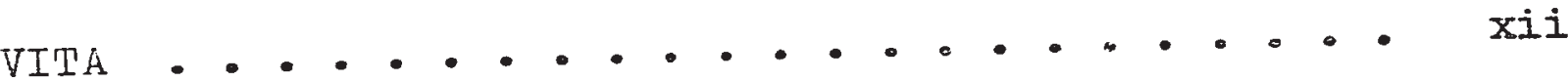


EIST OF TABLES

TABIE

page

Cataigst Parameters........... 104

2 Reaction Vessei Farameters . . . . = : . 105

3 First Order Rate Constants for

Decomposition - Annealed Reaction

Vesseì I

4 Effect of Initial Acia Concentration

on the First Order Rate Constant at

$374.4 \mathrm{C}$ - innealed Reaction Vessel I . . 107

5 First Order Rate Constants for

Decomposition - Aged Reaction ..... 108

Vessel I. • • • • • • • • • •

6 Eifect of Initial Acid Concentration

on the First Order Rate Constant at

$311.9^{8} \mathrm{C}$ - Agea Reaction Vessel I . . .

109

7 First Orảer Rate Constants for

Decomposition - Aged Reaction

Vessel I Packed with Glass Wool . •. • . 110

8 First Orajer Zate Constants for

Decomposition - Washed Reaction ..... 111

9 Pirst 0xder zate Constants for

Vessel I Facked with Glass Wool . $\cdot \cdot \cdot \cdot 112$

10 Effect of Tritiai Acid Goncentration on the Eirsi Grder Rate Constant at $362.0^{\circ} \mathrm{C}$ - Ieshed Reaction Vessel II 。.. 113

11 First Order Eate Constants for

Decomposition - Reaction Vessel II .... 114

viii 
12 Effect of Carrier Gas on the Pirst

Order Rate Constant at Three

Temperatures - Washed Reaction

Vessel II

13 First Order Rate Constants for

Decomposition - Reaction Vessel III *... 116

14 First Order Rate Constants for

Decomposition - Annealed Reaction

VesseI IV

15 First Order Rate Constants

Catalytic Decomposition on $\mathrm{Cu}-0203$

16 First Order Rate Constants Catalytic Decomposition on $\mathrm{Fe}-0301$

17 First Order Rate Constants Catalytic Decompositiox on Al-0104

18 First Crder Rate Constants Catalytic Decomposition on $\mathrm{Cu}-0803$

19 Arrhenius Parameters Catalytic Decomposition

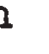

20 General Results for Hydrogen

Reaction in Uncoated Reaction Vessel III . . . . . . . . . . .

21 Percentage Decomposition for a $146.5 \mathrm{C}$ in Unicoated Reaction Vessel III . 124

22 General Reaults íor Hyarogen Reaction in Boric Acid Coated Reaction VesseI III

23 Percentage Decomposition for a Residence Tine of 0.10 min at $146.5^{\circ} \mathrm{C}$ in Boric Acid Coated Reaction Vessel III. 
1 Schematic Diagram of Flow System . • • - 127

2 Perchloric acid Saturator . . . . . 128

3 Reaction Vessel I . . . . . . . . 129

4 Reaction Vessel III . . . . . . . 130

5 Sampling System . . . . . . . . . 131

6 First Order Rate Plots - Annealed.... .132

7 Arrhenius Plot for First Order Rate 1 . . 133

8 First Oxder Rate Plots at $364.4^{\circ} \mathrm{C}$ for Three Initial Acia Concentrations.... .134

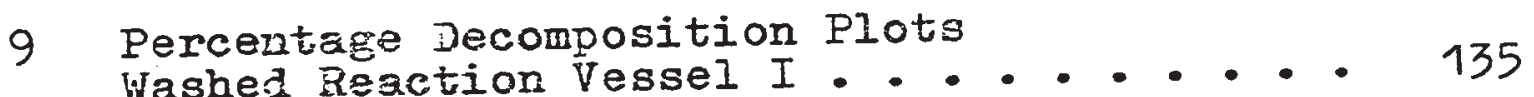

10 First Order Rate Plots - Washed
Reaction Vessel I Packed with Glass Wool • • 136

11 Arrhenius Plot for First Order Rate

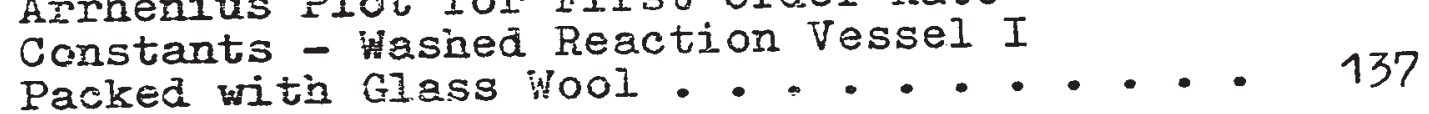

12 First Orier Rate Plots - Washed . . . . . 138

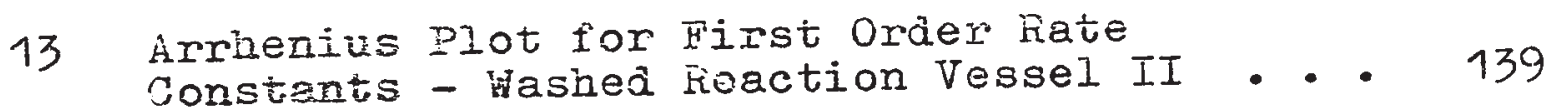

14 Tirst Oraer Piots - Coated and..... .140

15 Percentaze Decomposition Plots ....... 141 
FIGUPS

page

16 First Orcier Rate Plots - Annealed Reaction Vessel IV.......... 142

17 First Orcier Rate Plots - Cu-0203 . . . . 143

18 Arrhenius Plot of First Order Rate

19 First Orcer Rate Plots - Fe-0301..... 145

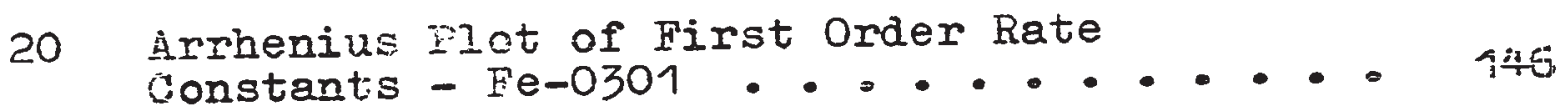

21 First Order Rate PIots - AI-0104..... 147

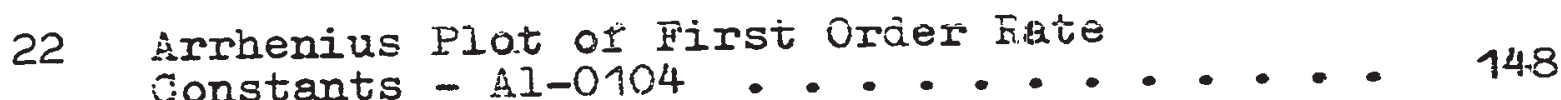

23 First Order Rate Plots - Cu-0803... . . 149

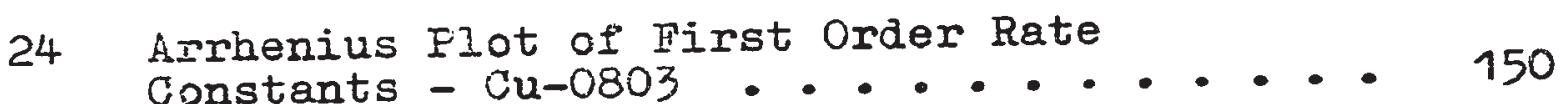

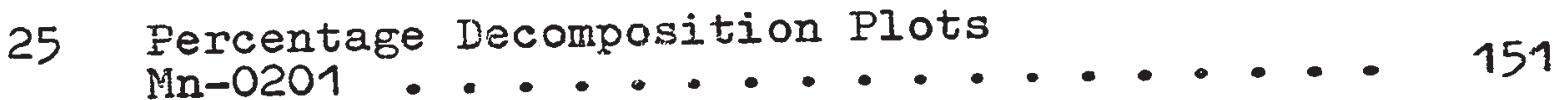

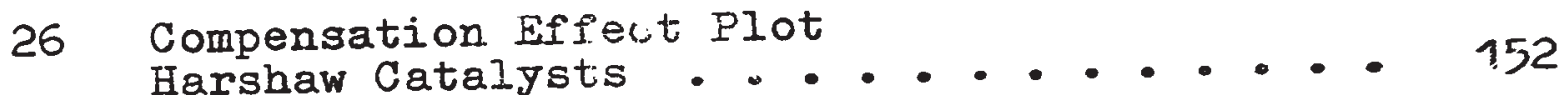


CHAPTER 1

INTRODUCTION

Much of the current interest in the thermal decomposition of perchloric acid has arisen for technological reasons. Many of the solid fuel rocket propellants in use today are based on ammonium perchlorate (AP) and under certain conditions the thermal decomposition of AP controis the rate of propellant burning. This has motivated an extensive study of this complicated reaction. At the present time the mechanism of the decomposition has not been fully elucidated and this is in part due to the lack of information on the possible intermediate reactions. The wort described in this thesis was carried out to obtain further informetion on one such reaction, namely the thermal decomposition of perchloric acia. 1.1 Thermal Decomposition of Ammonium Perchlorate

It is beyond the scops of this thesis to review all the work on AP and so just a urief outline is given. More detailed presentations can be found in a number of reviews ${ }^{1-4}$, in particular the comprehensive review by Jacois and whicehead?.

$A F$ is stable at coom temperature but decomposes at measurable rates ot temperatures greater than about $150^{\circ} \mathrm{C}$ 
to give entirely gaseous products. At decomposition temperatures below approximately $300^{\circ} \mathrm{C}$, AP undergoes an autocatalytic reaction which ceases after about 30\% decomposition. This is usually called the lov temperature reaction. The residue is quite stable at these temperatures unless rejuvenated by sublimation, recrystallisation or mechanical disturbance. At temperatures above $350^{\circ} \mathrm{C}$, the high temperature decompcsition occurs; this reaction is not autocatalytic and decomposition is complete. Concurrently with these decomposition reactions, $\triangle P$ also undergoes dissociative sublimation.

Catalysts may profoundly affect the decomposition. The shape of the decomposition-time curve may be modified; the extent of reaction may be altered anci the overall rate of decomposition may be changed.

A unified reaction scheme for the decomposition of AP has been proposed ${ }^{1}$.

$$
\begin{aligned}
& \mathrm{IHE}_{4}+\mathrm{ClO}_{4}-\frac{1}{\rightleftharpoons} \mathrm{HiI}_{3}(\mathrm{a})+\mathrm{EIClO}_{4}(\mathrm{a}) \stackrel{2}{\longrightarrow} \text { products }
\end{aligned}
$$

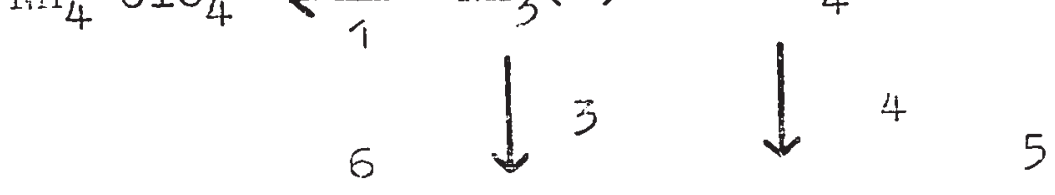

$$
\begin{aligned}
& \text { sublimate } \longleftarrow \mathrm{NH}_{3}(g)+\mathrm{HiClO}_{4}(8) \longrightarrow \text { products }
\end{aligned}
$$

The primary step (step 1) is proton trenstex to give adsorbed amonia and perchloric acia on the surface of the crystal. mhis step is reversible. The low temperature decomoosition invoives the reaction of these adsorbed 
species $($ seo 2). The adsorbed perchloric acid probably decomposes and the chlorine oxides, produced as intermejistas, oxisse the ammonia. phe reaction is thus in part, at jeast, heterogeneous. The failure of the low : temperature reaction to go to completion may be caused by the accumiation of ammonia on the surface, which supresses tie reversible proton transfer process. Et aijer temperatures, the ammonia vill desorb and a situation jevelops in which the ammonia and perchloric acid woiecules are both desorbing into the gas phase ratier tian reaction at the surface (steps 3 and 4 ). At low amiinit pressures, they diffuse sufficiently rapidly out of ize heated reaction zone before substantial decomposition of percbloric acid can occur. The ammonia ani peron oric acid then recombine on any coid surface to complete the sublimation process (step 6). As the ambient messure increases, the rate of diffusion of ammonia and percisoric acid through the gas phase decreases and their resiaence iime in the reactor is surficiently lone for decomocsition of perchloric acid and the subsequent oxidetion of a-monia to occur (step 5 ).

izezent catalysts may affect the mechanism in differen: : Eys. At catalyst may change the position of the proton insesfer equilibrium or affect the heteroceneous

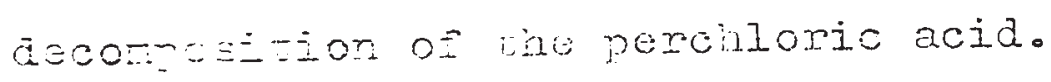


1.2 Phrsical Properties of Perchloric Acid

The yeneral properties of $\mathrm{FilO}_{4}{ }^{5-9}$ have been reviewed by a nlimber of people, notably by Pearson ${ }^{5}$. Eniydrous perchloric acid is a colourless, mobile liquid with a Ireezing poini of $-100^{\circ} \mathrm{C}$. It is thermally unstable and at room temperature decomposes within a few hours. It is in fact notoriously explosive but appareñtiy this is aue to chlorine oxide impurities ${ }^{10}$. It is stabje in aqueous solution and forms an azeotropic mixture of $72.4 \%$ by weight of the acid. There is eviaence for the formation of six different hydrates but only the monohyarate, a white crystalline solid isomorphous :ith AP, is vell characterisel. The stability of the aqueous solution is associated with the dissociation of the essentially covalent peschloric acia molecule to give a stable perchlorate ion. In the gas phase, perchloric acid is monomeric and in the vapour from $72 \%$ acid, there is no association betreen tire acid molecules and water. This makes $72 \%$ acid a useful, safe source of perchloric acid molecules; although of course vater molecules are also present.

the perchloric acid molecule is tetrahedral in shape with a JI-o bond length of $1.408 \&$ and a Cl-OH bond length of $1.630 \% 11$, The $110-010_{3}$ bond is the weairest. Usine the heats of rormation available for gaseous perchloric acid, caseous hydroxy and chlorine trioyide radicais, Lery ${ }^{10}$ calculated the bond dissociation enered, $\left(10-010_{3}\right)$, 
to $48.3 \mathrm{kcal} \mathrm{mole}^{-1}$. Heati and Majer ${ }^{12}$ in a mass spectrometric study of the vapour of $72 \%$ perchloric acid obtained a value of $46 \pm 5 \mathrm{kcal}$ mole $e^{-1}$ from a measurement of the appearance potential of the $\mathrm{ClO}_{3}^{+}$ions:

$$
A\left(\mathrm{ClO}_{3}^{+}\right)=D\left(\mathrm{IOO}-\mathrm{CIO}_{3}\right)+\mathrm{I}\left(\mathrm{ClO}_{3}\right)
$$

The value used for the ionization potential, $i\left(\mathrm{ClO}_{3}\right)$, was that of Dibeler ${ }^{13}$.

Fisher ${ }^{14}$ calculated the bond aissociation energy, $\nu\left(\mathrm{iI}-\mathrm{CClO}_{3}\right)$, to be approximately $112 \mathrm{kcal}$ mole ${ }^{-1}$ using a value of $59 \mathrm{kcal}$ mole $\mathrm{k}^{-1}$ for the heat of formation of the $\mathrm{ClO}_{4}$ radical, obtainea in his mass spectrometric study of aichlorine heptoxide.

whe bond dissociation energy, $D\left(\mathrm{HOO}_{2} \mathrm{CI}-\mathrm{C}\right)$ is not known but from a consideration of the G1-0 bond strength in other molecules, ileath and riajer ${ }^{12}$ estimated a value of about 60 zcal mole $e^{-1}$.

1.3 Thermal Decomposition of Gaseous Perehloric Acid

The literature, on the themochemistry end themal decomposition of perchloric acid up to 1963, has been reviewed by pearson and cummings ${ }^{15}$. In addition, the reviens citec in ت̈ection 1.2 contain discussions of the decomposition. The more recent i.iterature has been discussed by Pearson 15 in his review "Perchlorate Oxidizers". wuch of the work in se themel decomposition is, however, described ony in technical reouts, wicin ane rot readily 
available. This work will therefore be described in some detail and the results critically discussed.

Perchioric acid may jecompose in the vapour phase to form either chlorine or hürosen chloride ${ }^{5}$ according to the equations:

$$
\begin{aligned}
& \mathrm{IClO}_{4} \longrightarrow 1 / 2 \mathrm{Cl}_{2} \div 1 / 2 \mathrm{H}_{2} \mathrm{O}+7 / 4 \mathrm{O}_{2} \\
& \mathrm{HClO}_{4} \longrightarrow \mathrm{ECI} \div 2 \mathrm{C}_{2}
\end{aligned}
$$

The enthalpy chane For Equation 1.1 is $-28 \mathrm{kcal}$ mole anả for equation 1.2 it is $-21 \mathrm{rcal}$ mole $\mathrm{e}^{-1}$.

The first investigation of the thexmal decomposition of perchloric acia was reported by sibbett and Lobato 17 in 1960. They studied the decomposition of the anhydrous acid vapour at $200^{\circ} \mathrm{O}$ and $220^{\circ} \mathrm{O}$ rith initial acid pressures of 8.8 to 373.3 torr. They sugsested that the reaction could be represented entìrely by equation 1.1, although analyses of the reaction products by mass spectrometry, infra-red spectrometry ans oy gas chromatographic techniques were not consiajerej io be completely successful. rinis equation corresponus to a product gas containing $18.2 \%$ vater, 18.2\% chlorine anz $33.6 \%$ oxygen (percentares are by volume). The product Bas anelysea as $75-85 \%$ oxygen, 10-13\% chlorine, 5-10, water an $1-2 \%$ nyarogen chloride. Eydrogen and chiorine oajaross coula not be achieved. It was sureested that the nrocen chloride ras formed 
photochemicaliy by the secondary reaction of chlorine and water, and that some of the water and chiorine remained adsorbed in the surface.

Anhydrous perchloric acid was used, a fresh sample was made for each run. The apparatus was entirely pyrex and without taps. The decomposition was followed by overall pressure measurement, initially by a pressure transducer and then by a differential manometer linked through a Bourdon gauge. The reaction was started by raising an oil-bath around the reaction bath. Unfortunately this method makes it difficult to obtain a time origin and to follow the early part of the reaction. At $200^{\circ} \mathrm{C}$, it appears pressure measurements began after about 25 to $30 \%$ decomposition. The method of obtaining kinetics by initial rates could not be used.

The kinetics were complex. Assuming the stoichiometric equation given to be true, first order and second order integrated rate graphs were drawn for two different initial acia concentrations. At $200^{\circ} \mathrm{C}$ the reaction appeared to be second order up to 70-80\% decomposition and subsequently first order up to 95\% decomposition. The two second order rate constants which were obtained at the different initial acid concentrations agreed to about $8 \%$ and the two pseudo-first order constants agreed to about 5\%. The effect of surface was investieated at $200^{\circ} \mathrm{C}$ by packing the reaction vessel with gyrex beads thus approx- 
imately doubling the surface area. Whe kinetics showed. the sane form. The second order rate pristant increased by about $50 \%$ and the first order rate constant increased by a factor of about 5. The first order constant thus appeared to be more sensitive to surface.

Incident light was also shown to affect the kinetics, increasing the second order rate constant markedily ana reducine the first order constant sligitly. A quantitative study was not made of tile effect of temperature but for a run at $220^{\circ} \mathrm{C}$ with an initial acid pressure or 373 torr the second order rate constant had increased slightly while the first order rate constant had trebled. They suggested that perchloric acid reacts bimolecularly to form a complex which decomposes unimolecularig.

$$
2 \mathrm{iCIO}_{4} \stackrel{\mathrm{k}_{1}}{\rightleftharpoons \mathrm{k}_{1}} \mathrm{CI}_{2} \mathrm{O}_{7} \cdot \mathrm{H}_{2} \mathrm{O} \stackrel{\mathrm{k}_{2}}{\longrightarrow} \mathrm{CI}_{2}+7 / 2 \mathrm{O}_{2}+\mathrm{H}_{2} \mathrm{O} \text { (1.3 }
$$

The $\mathrm{Cl}_{2} \mathrm{O}_{7} \cdot \mathrm{H}_{2} \mathrm{O}$ complex was considered to be much more stable than chlorine heptoxide which is known to decompose rapidily at $120^{\circ} \mathrm{C}$.

Whe small temperature coeficient of the initial second order rate constant was explained by the fact that this rate constant also contains the equilibrium constant for the formation of $\mathrm{CI}_{2} \mathrm{O}_{7} \cdot \mathrm{H}_{2} \mathrm{O}$. The surface effect was said to be due to the first order step involving free racical chain initiation on the surface. 
Eovever, it is not clear that the mechanisi proposed, eren though it contains bimolecular and unimolecular steps :ouiz result in an overall rate which would apparently crange from second to first order. The explanation of the staii temperature coefficient for the second order rate consiari implies $k_{2}<k_{1}$ and so the reaction rould therefore be expected to be alvajs second order.

Sijoett and Geller ${ }^{15,19}$ extended this study to a temperature range of approximately $160-260^{\circ} \mathrm{C}$. The data coulc be fitted to second oruer kinetics for the initial part of the reaction and to first order kinetics for the final part of the reaction for the entire temperature range. Is the temperature was increased the region of apparent second order kinetics decreased. The effect of tinree different surface to volume ratios were observed at $200^{\circ} \mathrm{S}$. The rate constants obtaine $\mathrm{A}$ from the first and secoua order regions vere apparently proportional to the supface area although neither plots of rate constant acainst surface area passed through the origin. For certain runs the rate of chlorine production vas measured spectroprotometrically. This was compared to the rate derived from the overall, rate of pressure increase assumine ecuation 1.1 to represent the stoichiometry. Although there was a lareg anownt of scatter in the spectrophotoando data, there vas a ceneral agreenent rith the cuptes chlorine production rate. 
A number of reaction schemes and rate equations were considered. The rate equation used was,

$$
-\frac{d A}{d t}=2 k_{1} A^{2}+\frac{k_{2}^{A B}}{1+K_{B} B}
$$

Where $A$ is the concentration of perchloric acid, $B$ is the concentration of water, $k_{1}$ and $k_{2}$ are rate constanis and $K_{B}$ is an equilibrium constant. The rate equation was integrated numerically using a computer. whe overall pressure increase could be obtained using the stoichiometric equation. The value of $k_{1}$ was taken as the observed initial second order rate constant. To obtain values for $k_{2}$ and $k_{B}$, the second term in equation 1.4 was integrated separately between the limits of time zero and time $t$. Although this second term is clearly dominant towards the ena of the decomposition, it is preceded by a period in which the first term is dominant. It is therefore difficult to see the physical significance of this integration. Usine tine values of $k_{1}, k_{2}$ and $k_{B}$ obtained by this method, quite a good fit was cbtained.

sibbett and Gelier wrote the followink reaction scheme.

$$
\begin{aligned}
& 2 \mathrm{ICIO}_{4} \stackrel{\mathrm{I}}{\mathrm{N}} \longrightarrow \mathrm{H}_{2} \mathrm{O}+\mathrm{CI}_{2}+7 / 2 \mathrm{O}_{2} \text { (1.5 } \\
& \mathrm{II}_{2} \mathrm{O}+\mathrm{HCIO}_{4} \stackrel{\mathrm{k}_{2}}{\longrightarrow} \mathrm{HClO}_{4}=\mathrm{H}_{2} \mathrm{O}
\end{aligned}
$$




$$
\mathrm{HClO}_{4} \cdot \mathrm{H}_{2} \mathrm{O} \longrightarrow 3 / 2 \mathrm{H}_{2} \mathrm{O}+1 / 2 \mathrm{CI}_{2}+7 / 4 \mathrm{O}_{2}(1.7
$$

They obtained the above rate equation by considering two different Langmuir-Hinshelwood-Rideal mechanisms. However only one of these appears to be a valid derivation. If both the reaction steps are heterogeneous and the water and perchloric acid adsorb on different sites, the following rate equation results,

$$
-\frac{d A}{d t}=\frac{2 k_{1}^{\prime} K_{A}^{2} A^{2}}{\left(1+K_{A} A\right)^{2}}+\frac{k_{2}^{\prime} K_{A} K_{B} \dot{A} B}{\left(1+K_{A}^{A}\right)\left(1+K_{B} B\right)}
$$

where $k_{1}^{\prime}$ and $k_{2}^{\prime}$ are true rate constants and $K_{A}$ and $K_{B}$ are equilibrium constants for the adsorbtion of perchloric acid and water, respectively. The equation assumes that adsorbed and gaseous species are in equilibrium. If the perchloric acid coverage is always low, i.e. $\mathrm{K}_{\mathrm{A}} \mathrm{A} \ll 1$, then this rate equation agrees with the rate equation used, where $\mathrm{k}_{1}=\mathrm{k}_{1}^{\prime} \mathrm{K}_{\mathrm{A}}^{2}$ and $\mathrm{k}_{2}=\mathrm{k}_{2}^{\prime} \mathrm{K}_{\mathrm{A}} \mathrm{K}_{\mathrm{B}}$.

The alternative mechanism, considered that watex and perchloric acid adsorbed on the same sites, but that the second reaction is between adsorbed water molecules and gaseous perchloric acid molecules. The foloring equation results

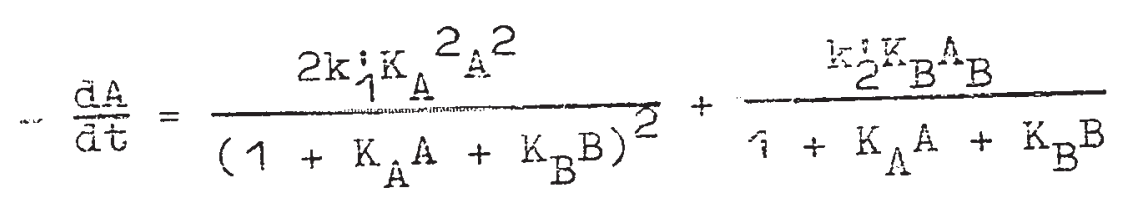


This also assumes equjlibrium between gaseous and adsorbed species is always maintained. However this equation cannot be reduced to the one used for this would require $K_{B} \ll 1$ in the first expression and not in the second expression.

It therefore appears that only the former mechanism proposed by Sibbett and Gelier leads to the rate oquation, which they used.

For a surface/volume ratio of 4.7 , they obtained for $k_{1}$ a preexponential factor or $9.7 \times 10^{7} \mathrm{~min}^{-1}$ and an activation energy of $12.3 \mathrm{kcal}$ mole ${ }^{-1}$; for $\mathrm{k}_{2}$ a preexponential factor of $1.95 \times 10^{5} \mathrm{~min}^{-1}$ and an activation energy of $20.5 \mathrm{kcal}$ mole $\mathrm{e}^{-1}$; and for $\mathrm{K}_{\mathrm{B}}$ a preexponential factor of $9.8 \times 10^{3}$ and a heat of adsorption of $13.3 \mathrm{kcal} \mathrm{mole} \mathrm{e}^{-1}$. The value of $13.3 \mathrm{kcal}$ mole $e^{-1}$ for the heat of adsorption of water on pyrex agrees with other literature values. Both preexponential factors and activation energies varied slightly with surface area.

The mechanism which involves adsorption on different sites gave $k_{1}=k_{1}^{\prime} K_{A}^{2}$ and $k_{2}=k_{2}^{\prime} K_{A} K_{B}$ and hence the observed activation energies, $E_{1}$ and $E_{2}$ can be related to the true activation energies, $E_{1}^{\prime}$ and $E_{2}^{\prime}$ by the equations:

$$
\begin{aligned}
& E_{1}=E_{1}^{\prime}-2 \lambda_{A} \\
& E_{2}=E_{2}-\lambda_{A}-\lambda_{B}
\end{aligned}
$$


$\lambda_{\hat{A}}$ represents the heat of adsorption oi perchloric acid on pyrex and $\lambda_{B}$ represents the heat of adsorption of water on pyrex. Using the observed vaiues for $E_{1}$ and $E_{2}$, gives the two expressions:

$$
\begin{aligned}
& E_{1}^{\prime}=12.3+2 \lambda_{A} \quad\left(\text { kcal mole } e^{-1}\right) \\
& E_{2}^{\prime}=33.8+\lambda_{A} \quad\left(\text { kcai mol } e^{-i}\right)
\end{aligned}
$$

Neither activation energy can be calculated. Sibbett

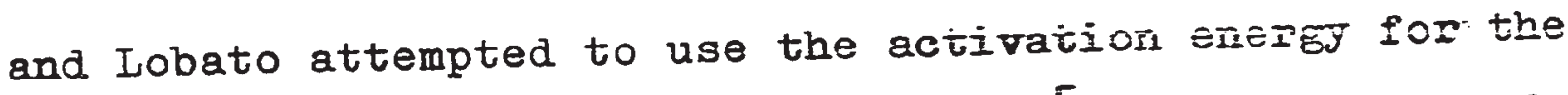
liquid phase decomposition and Pearson ${ }^{5}$ usea the value for the homogeneous gas phase decomposition, to obtain the heat of adsorption of perchloric acid and also to compare the two proposed mechanisms (one of which is invalid). Neither approach is strictly valia for the true activation energies refer to the heterogeneous reaction on pyrex. Howevex, $E_{1}$ must be less than tine homogeneous gas phase activation energy of about $45 \mathrm{kcal}$ mole $\mathrm{e}^{-1}$. This gives an upper limit of $16.4 \mathrm{kcal}$ mole $\mathrm{k}^{-1}$ for the heat of adsorption $0 \vec{i}$ perchloric acid on pyrex and an upper limit of $50.2 \mathrm{kcei}$ mole $\mathrm{H}^{-1}$ for the actiretion erergy of the heterogeneous reaction of perchlcric acia and water.

The thermal decomposition of percinoric acia has also been investigated by Levy ${ }^{10}$ between $200^{\circ} \mathrm{o}$ and $439^{\circ} \mathrm{C}$. Between $200^{\circ} \mathrm{C}$ and $350^{\circ} \mathrm{C}$, anhyarous percinicric acid was used and the kinetics were determined by sootrophotometrically 
following the rate of chlorine production. Fim $350^{\circ} \mathrm{C}$ to $439^{\circ} \mathrm{C}, 72 \%$ acid was used and the kinetics were determined by a flow technique.

In order to check the stoichiometry of the decomposition samples of the anhydrous acid were decomposed at $210^{\circ} \mathrm{C}$ and $400^{\circ} \mathrm{C}$ and the products reacted with standard sodium hydroxide. Titrations for hypochlorite ion End chloride ion indicated that no byarogen chioriae was romed and that the stoichiometric equation in fact corresponaed to equation $\hat{1} .1$.

Levy studied the low temperature region thoroughly. The rate of chlorine production was found to obey first order kinetics initially. At $250^{\circ} \mathrm{C}$ the decomposition fitted first order kinetics for the first $50 \%$ of the decomposition and at $350^{\circ} \mathrm{C}$ for the first 90\%. Reproducibility of the rate could not be achieved from run to rum. At $300^{\circ} \mathrm{C}$ increasing the initial acid concentration by a factor of ten appeared to increase the first order rate constant by only about 50\%, demonstrating the predominantly first order nature of the decomposition. Increasing the suriace to volume ratio by about tihree and a half times aid not seen to increase the rate between $248^{\circ} \mathrm{C}$ and $350^{\circ} \mathrm{C}$. However the general lack of reproducibility of restits guggested that the reaction was heterogeneous and sensitive to the nature of the suriace. phe high temperature region was not stuaied so 
thoroughly. Levy used a filow system and absorbed some of the products in standard sodium hydroxide. First order rate constants were calculated from each flow run. Abcut 12 runs were carried out. At $367^{\circ} \mathrm{C}$ the calculated first order rate constant varied only siightIy when a threefold increase in acid concentration was used and the amount of decomposition increased from $5 \%$ to $18 \%$. The ratio of chlorine produced as calculated from the hyposhlorite concentration, to chlorine produced as calculated from the chloride concentration, in the standard sodium hydroxide trap, varied by about 20\%. However this was not considered significant. It should also be pointed out that using Levy's data for the percentage aecomposition for given residence times, a rormal calculation of rate constunts give values slightly different to Lev's values.

While the rate constants for the low temperature region are very scattered they correspond roughly to an activation energy of $10 \mathrm{kcal}$ mole $\mathrm{e}^{-1}$. Levy suggested that this was the heterogeneous decomposition although the absence of effects due to increasing the surface area were not explained. No mechanism was proposed.

For the bigh temperature region Levy obtained an activation energy of $45.1 \mathrm{kcal}$ mole $\mathrm{k}^{-1}$ and a proexponential faco tor of $5.8 \times 10^{-13} \mathrm{sec}^{-1}$. However there was a fair amount of scatter in the data. By selecting the points Levy considered to be most reliable ac activation energy of 
$43.6 \mathrm{kcal}$ mole $\mathrm{e}^{-1}$ and a preexponential factor of $1.6 \times 10^{13}$ $\mathrm{sec}^{-1}$ can be obtained.

Ievy proposed the following mechanism for the high temperature decomposition,

$$
\mathrm{HClO}_{4} \longrightarrow \mathrm{OH}+\mathrm{ClO}_{3}
$$

followed by the fast steps

$$
\begin{aligned}
\mathrm{OH}+\mathrm{HClO}_{4} & \longrightarrow \mathrm{H}_{2} \mathrm{O}+\mathrm{ClO}_{4} \\
\mathrm{ClO}_{4} & \longrightarrow 1 / 2 \mathrm{Cl}_{2}+2 \mathrm{O}_{2} \\
\mathrm{ClO}_{3} & \longrightarrow 1 / 2 \mathrm{Cl}_{2}+3 / 2 \mathrm{O}_{2}
\end{aligned}
$$

The preexponential factor obtained lies within the acceptable limits for a unimolecular reaction and the activation energy is also about $3 \mathrm{kcal}$ mole $\mathrm{k}^{-1}$ less than the calculated $\mathrm{HO}-\mathrm{ClO}_{3}$ bond dissociation energy. The last two reaction steps are clearly overall steps, the intermediate steps being much more complicated.

Solymosi 20 , in his study of the catalytic decomposition or perchloric acia observed the uncatalysed decomposition in the rainge 390 to $440^{\circ} \mathrm{C}$. Using apparatus similar to Jevy's he measured the extent of decomposition at different temperatures for a constant flow rate and a constant initial acia concentration. A. value ô $44 \mathrm{kcal}$ mole 1 was obtained for the activation energy. Gritsan and Parifilov 21 have very recently reported 
a study of the kinetics of chlorine dioxide formation and consumption during the thermal decompesition of perchloric acid, in the range 230 to $440^{\circ} \mathrm{C}$. Unfortunately at the time of completion of this thesis, it had not been possible to obtain a copy of this paper.

1.4 Thermal Decomposition in the Mass Spectrometer

The mass spectrum of $72 \%$ perchloric acid has been recorded by several authors $12,22-26$. The spectrum is in part due to electron impact and in part due to thermal cracking. The effects of thermal decomposition are probably least in the spectrum obtained by Cordes and $\mathrm{Smith}^{24}$. The three principal peaks correspond to $\mathrm{ClO}_{3}{ }^{+}, \mathrm{HClO}_{4}{ }^{+}$and $\mathrm{ClO}_{2}{ }^{+}$. The $\mathrm{ClO}_{3}{ }^{+}$ion is produced by electron impact on perchloric acid itself. In his attempts to observe the mass spectrum of chlorine hexoxide, Fisher ${ }^{14}$ also obtained the mass spectrum of anhyarous perchloric acid. It was the same as for the $72 \%$ acid but without the water peak. Heath and Majer ${ }^{12}$ investigated the heterogeneous decomposition of perchloric acid vapour on a hot platinum wire, placed adjacent to the ionization chamber of the mass spectrometer. The mass spectra showed that the hot platinum wire caused the reaction;

$$
\mathrm{HClO}_{4} \longrightarrow \mathrm{HCl}+2 \mathrm{O}_{2}
$$

Peargon 15 has suggested that 2 the temperatures and pressures used in these studies, the Descon process 


$$
2 \mathrm{H}_{2} \mathrm{O}+2 \mathrm{OI}_{2}=4 \mathrm{HCI}+\mathrm{O}_{2} \quad(1=15
$$

woula account for the large quantities of hydrogen chloride. Fisher 22 has studied the intermediates formed in the thermal decomposition of perchloric acid. He. leaked perchloric acid into the mass spectrometer through a heated pyrex reactor. The resiaence times in this region were of the order of milliseconds and the pressures were between $10^{-2}$ and $10^{-3}$ torr. He observed the change in the mass spectrum as the temperature of the reaction zone uas increased. The acid decomposition exhibited three zones. The first at $800^{\circ} \mathrm{C}$ was associated with the decomposition of perchloric acid; the second at $950^{\circ} \mathrm{C}$ was associated with the decomposition of chlorine dioxide and the third at $1100^{\circ} \mathrm{C}$ was associated with the decomposition of the Cllo radical. Chlorine and hydrogen chloride did not increase until the higher temperature regions were obtained. It was suggested that chlorine trioxide should be a stable radical and at least as resistant to heterogeneous decomposition on the walls as the lower oxides. Fisher inerefore considerea the alternative primary step for the decomposition of perchloric acid,

$$
\mathrm{FiIO}_{i,} \longrightarrow \mathrm{HO}_{2}+\mathrm{ClO}_{2} \quad(1.16
$$

to be more probable than equation 1.3 The enthalpy change is $\div 31.1 \mathrm{kcal}$ mole $e^{-1}$ as compared to $+48.3 \mathrm{kcal} \mathrm{mole^{-1 }}$ 
for equation 1.10. However, as a large reorganisation of the molecule is involved, the activation energy may be expected to be excessive. This may be greatly lowered if the reaction is heterogeneous.

In his mass spectrometric studies of the thermal decomposition of chlorine heptoxide and chlorine hexoxide, chlorine trioxide and chlorine tetroxide were also net observed. It therefore appears that neither rauical can survive the few wall collisions which must take place in the inlet system.

As, at the pressures used, bimolecular reactions may be ignored, the following mechanism for the decomposition was proposed

$$
\begin{aligned}
& \mathrm{HClO}_{4} \longrightarrow \mathrm{OH}+\mathrm{ClO}_{3} \\
& \mathrm{ClO}_{3} \longrightarrow \mathrm{ClO}_{2}+\mathrm{O} \\
& \mathrm{ClO}_{3} \longrightarrow \mathrm{ClO}+\mathrm{O}_{2} \\
& \mathrm{ClO}_{2} \longrightarrow \mathrm{CI}+\mathrm{O}_{2} \\
& \mathrm{ClO}_{2} \longrightarrow \mathrm{ClO}+\mathrm{O} \\
& \mathrm{ClO} \longrightarrow \mathrm{Cl}+\mathrm{O}
\end{aligned}
$$

Cl, O dimerize

$\mathrm{Cl}, \mathrm{ClO}, \mathrm{OH} \underset{\mathrm{WaII}}{\longrightarrow} \mathrm{HCl}, \mathrm{ClOH}, \mathrm{H}_{2} \mathrm{O}$

$(1.24$ 
The clo radical was the main intermediate and it was postulated that this arose mainly from the chiorine trioxide radical which has only transitory existence. Chlorine dioxide was apparently a poor source of 010 radicals. Fisher suggested that ClO radicals are responsible for the enhanced reactivity of perchloric acid flames.

Pellet and Saunders ${ }^{25}$ in their study of the neterogeneous decomposition of AP-Catalyst mixtures using pulsed laser mass spectrometry, observed that the perchloric acid which is a primary product, underwent a rapia neierogeneoús decomposition on the substrate. Hydrogen chloride and chlorine dioxide were major products. Guillory and King ${ }^{26}$ have observed similar behaviour. They both suggest that the heterogeneous primary step is in fact equation 1.16. 1.5 Catalytic Decomposition of Perchloric Acid

Sibbett and Geller ${ }^{18}$, in their investigation of the decomposition of anhydrous perchloric acia also observed the effect at $200^{\circ} \mathrm{C}$, of adding a pellet of aiumina. They observed an increase in the decomposition rate. The initial second order rate constant was increased but their. pseudo-first order rate constent was anchanged. clearly alumina can catalyse the reaction.

Solymosi, Börcsơx and Lázár 20 have reportea a preliminery investigation of the effect of a number of oxide catalysts on the decomposition of perchioric acia. The used all the catalysts, they had used in studies of AP 
catalysis, namely chromium oxide, cupric oxide, ferric oxide, zinc oxide, titanium dioxide and alumina. Neitrer elumina nor titanium oxide catalyse the decomposition of AP.

A flow technique was used, similar to that used by Levy in his study of the homogeneous decomposition of perchloric acid. A constant flow of nitrogen, saturated yith perchloric acid was passed over a small pellet of the: catalyst. The chlorine produced was sosorbed in siandard sodium hydroxide or potassium iodide and the reauiting solution was analysed to obtain the kinetics.

All the catalysts were effective in lowering the temperature at which decomposition occured. Although the effect of changing the initial acid concentration or the llow rate was not investigated, the kinetics were apparently considered to be first order.

Chromium oxide was a good catalyst. It apparently reacted with the acid to give chromyl chloride and higher oxides of chromium. This resulted in a gradual decrease: in activity. At lower temperatures the reaction was less and an activation energy of $20.5 \mathrm{kal}$ mole $\mathrm{kas}^{-1}$ wabtained. Chromium oxide is a p-type semiconductor. Solymosi studied the effects of dopine the chromium oxide with zinc oxide, which should increase the conductivity and titanium diczice waich stonld decrease the conductivity. The incorporation of zinc oxide Increased the activity at $170^{\circ} 0$ but 
did not affect the activation energy, while the incorporation of titanium uxide, initially aecreased the activity but it sradually increased to the unduped value. The activation energy was not obtained.

Cupric oxide was found to be less effective than chromium oxide and decomposition was not observed below $200^{\circ} \mathrm{C}$. The activity did not vary and an activation energy of $28.8 \mathrm{kcal}$ mole $\mathrm{e}^{-1}$ was obtained. Both ferric oxide and zinc oxide were less effective and activation energies of 42.4 and 45 kcal mole ${ }^{-1}$ were chteined; respectively. Titaniun oxide and alumina also lowered the decomposition temperature. No data were given for alumina, but the activation energy on titanium dioxide was given as $24.5 \mathrm{kcal}$ mole $e^{-1}$ although the specific activity was low. Doping of titanium oxide with chromium oxide increased its activity but a constant value could not be obtained.

Solymosi sugeested that the activity of catalysts for the decomposition of perchloric acid is linked to the electrical properties of the catalysts, p-type semiconductors being better than n-type semiconductors. However these preliminary results were not conclusive.

Recently Solymosi and Borcs $8 \mathrm{k}^{27}$ have investigated the catalytic decomposition of perchloric acid on chromium oxide more thoroughly. They found that the decomposition was zero order and had an activation energy of $31 \mathrm{kcal}$ mole $\mathrm{k}^{-1}$. Attempts to analyze the catalyst after treatment with per- 
chloric acid, using d.t.a. and t.g.a. were not successful but clearly a mixture of bigher oxides was formed. The specific activities of the oxiaes at $160^{\circ} \mathrm{C}$ were found to De in the order, $\left.\mathrm{Cr}_{2} \mathrm{O}_{3}>\mathrm{CrO}_{2}\right) \mathrm{CrO}_{3}$ and thus the decrease in activity due to the producion of higher oxides was. explained.

Solymosi suggested that the activity of a catalyst is relatea to the stability of its perchlorate. The oxide may be: converted to the perchlorate which then decomposes: to give the final products = Ghromium oxide is a good catalyst and chromium perchlorate is thermally unstable and so this fits the hypothesis.

1.6 Perchloric: Acid Flames

The earliest reference to perchloric acid flames in the literature is in a brief note by Dietz ${ }^{28}$ in 1939. He observed the spontaneous ignition of perchloric acid vapour at 400 to $405^{\circ} \mathrm{C}$ and the subsequent decomposition flame. Hydrogen passed into the vapour also spontaneously ignited at 400 to $450^{\circ} \mathrm{C}$ but in the presence of steel turnings, the igrition temperature was reduced to $215^{\circ} \mathrm{C}$.

Cummings and Pearson 29 have stabilised the decomposition flame at one atmosphere using the vapour from $72 \%$ acid. Aralysis of the prodicts showed a ratio of chlorine to hycroger chloride of 0.7 which is much greater than the equilibrium ratio of 0.05 ? expected for a theoretical flame temperature of $1076 \mathrm{~K}$; comrection of the flame temperature 
for the observed chlorine distribution gave a value of $1160 \mathrm{~K}$, since the heat release is greater for chlorine formation. This was in good agreement with the observed uncorrected value of $1080 \mathrm{~K}$. The observed burning velocity of $19 \mathrm{~cm} \mathrm{sec}-1$ was in good agreement with a value of $20 \mathrm{~cm} \mathrm{sec}-1$ obtained using the theoretical equation of Zelajovitch and Frank-Kamenetsky and the kinetic parameters obtained by $L \in \bar{v}^{10}$. The Zeldovitch and FrankKamenetsky equation 30 is based on a purely thermal model of a Ilame and is cbtained essentially from considerations of energy and mass conservation.

Nore recently Hall and Pearson 31 have obtained a value of $12 \mathrm{~cm} \mathrm{sec}-1$ for the burning velocity, and using the van Tiggelen equation have obtained an activation energy of $25 \mathrm{kcal} \mathrm{mole} \mathrm{k}^{-1}$. The van Tiggelen equation 30 is based on a radical diffusion model of a flame involving branching reactions.

Powling 32 has studied the flat diffusion flames of 72\% perchloric acid with ammonia and propans. It appears that $\mathrm{HClO}_{4}$ decomposes in the flame zone, emitting a reddish glow before reacting with the fuel. A thermocouple trace shows an exothermic bump on the acid side. As no spectrai difference was observed between perchloric acid/ ammonia and immoria/chlorine/oxygen flames, it was conciuded that $\mathrm{HClO}_{4}$ probably decompoeed berore it reacted with the fuel。 
Premixed flames have been stabilized for such model Iuels as methane $31,33-39,44-46$, ethane $34,35,42-44,46$, ethylene $40,41,44,46$, ingdrogen ${ }^{29}$, methanol 35 , carbon monoxide 35 and formaldehyde ${ }^{5}$. The spectra of these flames $3^{34,35}$ show the same band systems as the corresponding oxygen flames, but in addition methane/perchloric acid flame shows strong "cool flame" bands sind the ethane/perchloric acid flame "hyärocarbon flame" bands. The fuel/acid flames have wuch higher burning velocity than the corresponding fuel/oxygen flames at the seme temperature. They also achieve their maximum burning velocity well on the fuel-rich side of stoichiometric and are less inhibited by halogenated hydrocarbons than oxygen flames at the same flame temperature. If both oxygen and perchloric acia are prenized with the methane fue ${ }^{45}$, two flame fronts are formed, one corresponding to the acid flame and downstream of this, one corresponding to the normal oxygen flame. Thus the perchloric acid premixed flame is quite different to the oxygen premixed flame.

Perchloric acid flames have very large flammability 2imits. In very fuel-rich flames $36-43$, the excess fuel acts simply as a diluent. Parson 44 sampled the burnt gas products of binary fuel mixtures ard was able to show that selective consumption occurred. The order of increasing ease of attack was methane, ethylene, ethane. An activetion enerey of $15 \mathrm{kcal}$ mole ${ }^{-1}$ was obtained. 
for the hydrogen flame ${ }^{29}$ using the zeldovitch and FrankKamenetsky equation for a second order reaction. Using the same Eodel, activation energies of 30,37 and 35.6 rcal mole $e^{-1}$ were obtained for the methane 37 , ethylene 40 and ethane 42 flames, respectively. A different process to thet involved in the decomposition flame is involved. An activation energy of $23 \mathrm{kcal}$ mole -1 was cbtained for the methane flame 31 using the van Tiggelen equation. This is much less than for the methane/oxygen flame.

Pearson 31 has proposed a mechanism for the methane/ perchloric acid flame in which the methane is rapidy attacked by ClO radicals from the decomposition of the acid.

$$
\begin{aligned}
\mathrm{HClO}_{4} & \longrightarrow \mathrm{OH}+\mathrm{ClO}_{3} \\
\mathrm{ClO}_{3} & \longrightarrow \mathrm{ClO}+\mathrm{O}_{2} \\
\mathrm{CH}_{4}+\mathrm{ClO} & \longrightarrow \mathrm{CH}_{3}+\mathrm{HOCI} \\
\mathrm{CH}_{3}+\mathrm{O}_{2} & \longrightarrow \mathrm{CH}_{2} \mathrm{O}+\mathrm{OH} \\
\mathrm{OH}+\mathrm{HOCl} & \longrightarrow \mathrm{H}_{2} \mathrm{O}+\mathrm{ClO} \\
\mathrm{CH}_{3}+\mathrm{ClO} & \longrightarrow \mathrm{CH}_{2} \mathrm{O}+\mathrm{HCI} \\
\mathrm{CO}+\mathrm{OH} & \longrightarrow \mathrm{CO}_{2}+\mathrm{HI}
\end{aligned}
$$

Successive radical attacks on the formaldehyde produred the carbon wonoxide used in the last step. Similar 
mechanisms were obtained for both ethane and ethylene ilames.

Combourieu and his group stuaied the decompostion flame of cilorine dioxide 47,48 and also the premixed methane/chlorine dioxide flame $49-51$. Pearson 31 has pointed out that perchloric acid flames and chlorine dioxide. rlames have a great deal in common but both differ quite considerably from oxygen flames. He suggests that tinis reflects the simiarity in the nechanisms involved. Perchloric acid provides 010 radicals bJ,

$$
\begin{gathered}
\mathrm{EClO}_{4} \longrightarrow \mathrm{OH}+\mathrm{ClO}_{3} \\
\mathrm{ClO}_{3} \longrightarrow \mathrm{ClO}+\mathrm{O}_{2}
\end{gathered}
$$

and chlorine dioxide by

$$
\begin{aligned}
\mathrm{CIO}_{2} & \longrightarrow \mathrm{ClO}+\mathrm{O} \\
\mathrm{O}+\mathrm{ClO}_{2} & \longrightarrow \mathrm{ClO}+\mathrm{O}_{2}
\end{aligned}
$$

The subsequent reaction steps are then the same. Fowever as the flame propagates, it is thought that in tise percinloric acid fleme further $\mathrm{ClO}$ radicals are produced by

$$
\begin{aligned}
\mathrm{H}+\mathrm{HClO}_{4} & \longrightarrow \mathrm{H}_{2} \mathrm{O}+\mathrm{ClO}_{3} \\
\mathrm{ClO}_{3} & \longrightarrow \mathrm{ClO}+\mathrm{O}_{2}
\end{aligned}
$$


and in chaorine oxide by,

$$
\begin{array}{ll}
\mathrm{O}+\mathrm{ClO}_{2}-\mathrm{ClO}+\mathrm{O}_{2} & (1.38 \\
\mathrm{Cl}+\mathrm{ClO}_{2}-\mathrm{ClO}+\mathrm{ClO} & (1.39
\end{array}
$$

Pearson has pointed out that the $\mathrm{OH}$ radicals, which are important in fuel/oxygen flames are probably much better hydrogen abstracting agerts than are 010 rāicais. However, as ClO radicals are readily producea in nigh concentrations in the early low temperature region of the fuel/perchioric acid flame, these fiemes are fastut than the corresponding oxygen flames.

\subsection{Beaction of Perchloric Acid with Ammonia}

Sibbett and Iobato ${ }^{17}$ studied the reaction between anhydrous percinloric acid and ammonia at 25,48 and $60^{\circ} \mathrm{C}$, using 15:1, 10.6:1 and 3.4:1 mole ratios of ammonia to perchloric acid. The reaction was initiated by rupturing a break-seal between two pyrex vessels. The pressure of ammonia was also at least a factor of ten greater than the pressure of perchloric acid and thus a jet of ammonia passed rapidly into the section of the vessel containing perchloric acia vapour to start the reaction. The reaction was faster than could be followed on the pressure measuring aevice. Equilibrium pressures were consistentiy found to excesd calculated values based on $100 \%$ amonium perchlonate formation, despite the forwation of a layer of white solid throughout the reaction yessel. The soild 
product contained substantial amounts of $\mathrm{Cl}^{-}$, the $\mathrm{CI}^{-}$: $\mathrm{ClO}_{4}{ }^{-}$mole ratios varying from 0.93 at $25^{\circ} \mathrm{C}$ to 12 at $60^{\circ} \mathrm{C}$. A satisfectory analysis of the gases was difficult to obtain. When the unreacted ammonia was removed from the sample, mass spectrometric analysis gave $68 \% \mathrm{O}_{2}, 15.5 \% \mathrm{H}_{2}$, $14.9 \% \mathrm{~N}_{2}$ and $1.1 \%$ No.

Thus the simultaneous oxidation of ammonia by perchloric acid along with the direct combination to give ammonium perchlorate occured.

Friedman and Levy 52,53 have also periorma a preliminary investigation of the reaction at $367^{\circ} \mathrm{C}$. Separate streams of nitrogen-ammonia and nitrogen-perchloric acid were mixed and passed through a reaction vessel. The products leaving the reaction vessel were then absorbed in a series of traps. Analyses were performed for $\mathrm{Cl}^{-}$and C. $\mathrm{O}_{4}^{-}$. No $\mathrm{OCI}^{-}$was found. The principal difficulty, they found, was that of mixing the reactants completely in a time short compared to the reaction time. In all four runs, the amount of perchloric acid consumed was greater than would result from just the decomposition of the acid. fussuning that the ratie equation was

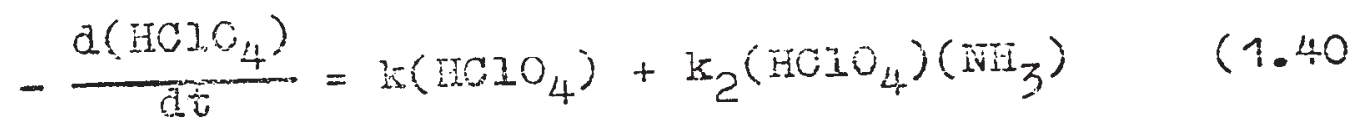

Levy and Fitaman obtained values for $k_{2}$ of $0.29,1.38$, 1.82 anc $2.20 \times 10^{5} \mathrm{~cm}^{3}$ moles $^{-1} \mathrm{sec}^{-1}$. 
As only $\mathrm{Cl}^{-}$was found in these expeximents it was assumed that ammonia reacted with perchloric acid to produce chlorine which immediately reacted with further ammonia to give ammonium chloride. It was thought that the last two values of $k_{2}$ were more reliable as they refer to experiments in which a more efficient mixer was used.

\subsection{Reactions of Chlorine Oxides}

A number of chlorine oxides have been postulated as reaction intermediates in tine decomposition of perchloric acid. Chlorine dioxide and chlorine monoxide have been observed mass spectrometrically ${ }^{22}$. Chlorine trioxide and chlorine tetroxide have not been directly observed but their presence has been suggested by Levy ${ }^{10}$.

Chlorine tetroxide appears too unstable to have an independent existence. However it is formed as a primary intermediate in the decomposition of chlorine heptoxide 54,55 .

$$
\mathrm{Cl}_{2} \mathrm{O}_{7} \longrightarrow \mathrm{ClO}_{4}+\mathrm{ClO}_{3}
$$

The reverse resction 56 ,

$$
\mathrm{ClO}_{4}+\mathrm{ClO}_{3} \longrightarrow \mathrm{Cl}_{2} \mathrm{O}_{7}
$$

is also apparently possible, for chiorine heptoxide is formed in substantial yields in the decomposition of chlorine hexoxide in the presence of fluorine. At higher temperatures, chlorine tetroxide decomposes unimolecularly 
to give chlorine dioxide añ. oxygen ${ }^{54}$.

$$
\mathrm{ClO}_{4} \longrightarrow \mathrm{ClO}_{2}+\mathrm{O}_{2}
$$

Fisher ${ }^{14}$ in his mass spectrometric study of the decomposition of chlorine heptoxide could not observe chlorine tetroxide, presumably due to its rapid unimolecular decomposition. This may have been a wall reaction.

Chlorine trioxide at low temperatures forms an orange solid which melts at $3.5^{\circ} \mathrm{C}$. to form a red oil which boils at $20.3^{\circ} \mathrm{C}$. In the liquid or solid state, it exists as a aimer, chlorine: hexoxide, but in the gaseous state this dissociates completely into chlorine trioxide $57-59$. It is reported to decompose bimolecularly in tiree possible ways 56,60

$$
\begin{aligned}
& 2 \mathrm{ClO}_{3} \longrightarrow \mathrm{ClO}_{2}+\mathrm{O}_{2} \\
& 2 \mathrm{ClO}_{3} \longrightarrow \mathrm{ClO}_{4}+\mathrm{ClO}_{2} \\
& 2 \mathrm{ClO}_{3} \longrightarrow \mathrm{Cl}_{2}+3 \mathrm{O}_{2}
\end{aligned}
$$

the activation energy for each of the reactions being about $12 \mathrm{kcal}$ mole -1 . Inder the hi.gh vacuum conditions existing in a mass spectrometer, the unimolecular decomposition of chlorine trioxide to chlorine dioxide and to chlorine monoxide has been suggested ${ }^{14}, 22$

$$
\mathrm{ClO}_{3} \longrightarrow \mathrm{ClO}_{2}+\mathrm{O}
$$




$$
\mathrm{ClO}_{3} \longrightarrow \mathrm{ClO}+\mathrm{O}_{2}
$$

Chlorine dioxide melts at $-59.5^{\circ} \mathrm{C}$ and boils at $11^{\circ} \mathrm{C}$ to give a jellowish gas. It is thermally unstable and explodes above $45^{\circ} \mathrm{C}^{61,62}$. The explosive decomposition 62 has recently been studied and was found to involve degenerate chain-branching with the formation of the stable intermeaiate, $\mathrm{Ci}_{2} \mathrm{O}_{3} \cdot$ The initial step is probably the heterogeneous reaction

$$
2 \mathrm{ClO}_{2} \longrightarrow \mathrm{ClO}+\mathrm{ClO}_{3}
$$

Clo radicals are the principal chain carriers and react first with chlorine dioxide to form $\mathrm{Cl}_{2} \mathrm{O}_{3}$

$$
\mathrm{ClO}+\mathrm{ClO}_{2} \leftrightharpoons \mathrm{Cl}_{2} \mathrm{O}_{3}
$$

and then with $\mathrm{Cl}_{2} \mathrm{O}_{3}$

$$
\begin{aligned}
& \mathrm{ClO}+\mathrm{OCl}-\mathrm{ClO}_{2} \longrightarrow \mathrm{ClOOCI}+\mathrm{ClO}_{2} \\
& \mathrm{ClOOCI} \longrightarrow \mathrm{ClOO}+\mathrm{OI} \longrightarrow 2 \mathrm{Cl}+\mathrm{O}_{2}
\end{aligned}
$$

The chlorine atoms produced tinen undergo chain branching

$$
\mathrm{CI}+\mathrm{ClO}_{2} \longrightarrow 2 \mathrm{OIO}
$$

and chain termination reactions

$$
\mathrm{Cl}+\mathrm{CI}+\mathrm{wall} \longrightarrow \mathrm{CI}_{2}+\text { wall }
$$




$$
\mathrm{Cl}+\mathrm{ClO}_{2} \longrightarrow \mathrm{Cl}_{2}+\mathrm{O}_{2}
$$

Arrhenius parameters have been obtained for the reaction of chlorine dioxide with nitroger dioxide ${ }^{63}$

$$
\mathrm{ClO}_{2}+\mathrm{NO}_{2} \longrightarrow \mathrm{NO}_{3}+\mathrm{ClO}
$$

anā กิIuorine ${ }^{64}$

$$
\mathrm{ClO}_{2}+\mathrm{F}_{2} \longrightarrow \mathrm{FClO}_{2}+\mathrm{F}
$$

Rate coustants at room temperature have also been obtainea for the fast reactions of chlorine dioxide with oxfgen atoms ${ }^{65}$, chlorine atoms ${ }^{65,66}$ and bromine atoms ${ }^{67}$. The reaction with oxygen atoms

$$
\mathrm{ClO}_{2}+\mathrm{O} \longrightarrow \mathrm{ClO}+\mathrm{O}_{2}
$$

has a rate constant of $2 \times 10^{13} \mathrm{~cm}^{3} \mathrm{~mole}^{-1} \mathrm{sec}^{-1}$ and is four times greater than the corresponding ClO radical reaction.

$$
\mathrm{ClO}+\mathrm{O} \longrightarrow \mathrm{Cl}+\mathrm{O}_{2}
$$

In the mass spectrometer 22 , the unimolecular decomposition of chlorine dioxide to ClO and to $\mathrm{Cl}$ have been postulated

$$
\begin{aligned}
& \mathrm{ClO}_{2} \longrightarrow \mathrm{OIO}+\mathrm{O} \\
& \mathrm{ClO}_{2} \longrightarrow \mathrm{Cl}+\mathrm{O}_{2}
\end{aligned}
$$


The second oi these appears to dominate.

The ClO radical is quite stable with a bond dissociation energy of $63 \mathrm{kcal}$ mole $\mathrm{e}^{-1} 68$; consequently the bimoleaular decomposition

$$
2 \mathrm{ClO} \longrightarrow \mathrm{Cl}_{2}+\mathrm{O}_{2}
$$

is iavourea $65,66,69$. The probable mechanism ${ }^{66}$ is

$$
\begin{aligned}
2 \mathrm{ClO} & \longrightarrow \mathrm{ClOO}+\mathrm{Cl} \\
\mathrm{CI}+\mathrm{CIOO} \longrightarrow 2 \mathrm{OIO} & \rightarrow \mathrm{Cl}_{2}+\mathrm{O}_{2}
\end{aligned}
$$

Iive primary step is rate controliing and has an activation enarey of $2.5 \pm 0.3 \mathrm{kcal}$ mole $\mathrm{e}^{-1}$.

An activation eneagy of $17 \mathrm{kcal}$ mole $\mathrm{k}^{-1}$ has been obtained for the reaction of $\mathrm{ClO}$ with $\mathrm{NO}_{3} \mathrm{Cl}{ }^{70}$.

$$
\mathrm{ClO}+\mathrm{HO}_{3} \mathrm{Cl} \longrightarrow \mathrm{NO}_{2}+\mathrm{Cl}_{2}+\mathrm{O}_{2}
$$

At room tempereture, the reaction with oxygen atoms ${ }^{65}$, has a rate constant greater than $6 \times 10^{12} \mathrm{~cm}^{3}$ mole $\mathrm{esec}^{-1}$ and the reaction with nitric oxide ${ }^{65}$ is very fast.

$$
\mathrm{CIO}+\mathrm{HOO} \longrightarrow \mathrm{CI}+\mathrm{NO}_{2}
$$

Although the presence of hydrogen 56 increases the rate of decchposition of $\mathrm{ClO}$, the rate constant at room temperature for tineir. airect bimolecular reaction is less 
than $3 \times 10^{8} \mathrm{~cm}^{3} \mathrm{~mole}^{-1} \mathrm{sec}^{-1}$. The enhanced rate is apparently due to

$$
\begin{aligned}
& \mathrm{Cl}+\mathrm{H}_{2} \longrightarrow \mathrm{HCl}+\mathrm{H} \\
& \mathrm{H}+\mathrm{ClO} \longrightarrow \mathrm{OH}+\mathrm{Cl}
\end{aligned}
$$




\section{CHAPTER 2}

\section{EIPERIMENTAL}

As mentioned in chapter 1, the work described in this thesis was coñüucted in an attempt to understand nore fully the thermai jecomposition and reactions of perchloric acid both in the gas phase and on solid surfaces.

i preinimary stuaj of the thermal decomposition suggested that a thorough examination of the decomposition above $280^{\circ} \mathrm{C}$ mitht reveal a more complex mechanism than that suggested by Levy ${ }^{10}$. This examination of the decomposition of perchloric acid in pyrex reaction vessels consiituted the first part of the work.

In the second part of the work, the catalytic decomposition of perchloric acid on a number of commercial cataljsts was studied. At the time of the inception of this study, there was no literature available on the catalytic decomposition apart from the report by Sibbett and isbato 17 of an isolated experiment with alumina. Howerer, it hak been suggested that additives could catalyse the acid decomposition anc that this was possibly important in the tinermal decomposition of AP-catalyst nixisis Tise sinal part of the work consisted of a preliminary inrestigation of the reaction of perchloric acid with 
the model fuels, hydrogen, methane, ethane and ethylene. while a detailed investigation of the reaction with these and other fuels present many technical difficulties a number of suggestions are given at the end of chapter 4. 2.1 Outline

The same basic experimertal system was used for the different studies. As reaction half lives of the order of seconds were encountered, it was necessary to use a flow system. This is represented schematisally in Fig. 1.

Carrier gas from a cjlinder, fitted with a reducing valve was passed through a rotameter flow meter, the flow rate being controlled by an attached needie valve. During a run, the carrier gas was diverted by means of two threeway taps through hoi $72.4 \%$ perchloric acid solution, where it became saturated with the acid vapour. The saturated carrier gas passea into a reaction vessel, where reaction took place. In the study of the catalytic decomposition, the catalyst was placed in this reaction vessel and in the study of the reaction with fuels a similarly controlled flow of fuel was introduced into the reaction vessel through a second inlet.

The effluent gas was passed through a trap containing standara soaium hydroxide solution which absorbea the unreacted acid and some of the products: The resulting solution was analysed using volumetric techniques. The flow rate was measured using a soap-biobie flow meter and 
the length of the run timed. In some runs, samples of the effluent gas which had passed through the trap were analysed using gas chromatograping.

\subsection{Materials}

\section{Carrier Gas}

Nitrogen, helium and oxpgen were used. Hitrogen was suppliea by Union Carbide, helium by Iiquid Carbonic Corp. Itả. and oxygen by Canadian Liquid Air Lta. They were all high purity graâe and were used direct from the cylinder.

Ferchloric Acid

In 211 these studies the azeotropic mixture of perchloric acid and water was used. This corresponds to a composition of $72.4 \%$ by weight of the acid and a molecular formula of $\mathrm{HClO}_{4} 2.17 \mathrm{H}_{2} \mathrm{O}$. Most of the acia used was suppi̇ea Sy Allied Chemicals Canada Itd., although samples were also used from J.T. Baker Chemicals Itd., Shamigan and Anachenia Chemicals Itd. The solution supplied corresponded to 65-70\% acid. Before use, it was therefore concentrated by passing nitrogen through the acid at $110^{\circ} \mathrm{C}$. Anbzarous acid was not used, as a fresh sample would have had to be preparad for each mun and this would have been excessively time consuming.

\section{Cataiysts}

The catalysts used were supplied by Harshaw Chemical Co. and are known by their catalogue numbers. They were. in the form of small pellets, $1 / 3$ inch long and $1 / 8$ inch 
in diameter. A brief description of the catalysts is given in Table 1 .

Euels

Hydrogen, methane, ethane and ethylene were used. Hydrogen was supplied by Canadian Iiquid Air Itd. Methane (V.H.P.) and ethylene (C.P.) were supplied by Matheson of Canada Itd. Ethane (Pure Grade) was supplied by Phillips Petroleum Co. AII Iuels were used direct,ly from the cylinder.

Anaigtical Chemicals

All chemicals used in the product analysis were of A.R. grade.

2.3 Apparatus

\section{Flow Rate Control}

For the carrier gas stream, two rotameters were used. Fither could be selected by manipulating two three-way taps. Their ranges were $30-300$ and $300-3000 \mathrm{ml} \mathrm{min}^{-1}$ air at S.T.P. These nominal readings were found useful in preselecting the required flow rate and checking constancy of the flow rate. The needle valve incorporated in the rotaweter, in conjunction with the eyiinder pressure regulator, enabled a constant flow rate to be maintained over many hours. Rather than calibrate these rotameters for different carrier gases, it was found to be more accurate tc. measurs the exit flow rate for each rü using a soap-bubble flow meter. The concentretion of perchloric acia in the 
carrier gas stream was small enough for the residence time of the acid in the reaction vessel to be calculated from the flow rate of the carriex gas alone.

In the reaction with fuels, the fuel stream also

passed through a rotameter. The flow rate was measured for fuel alone and then for fuel and perchloric acid carr ier gas.

\section{Perchloric Acia Saturator}

This is shown in Fig. 2. Both the saturator and its associated prehaat coil were made of pyrex. It was immersed in a siirrea oil bath of silicone 200 oil which was heated by a 200 watt coiled heater. The temperature of the bath was controlled to better than $\pm 0.5^{\circ} \mathrm{C}$ using a Fisher Temperature Controller. The temperature was measured $b \bar{y}$ a wercury thermometer and was usually kept at: about $115^{\circ} \mathrm{C}$

Thus at the beginning of a mun, the carrier gas could be diverted, by manipulatiug two three-way taps, througin the preheat coil and bubbled through the hot $72.4 \%$ perchloric acid. To prevent the perciloric acid which saturated the carrier gas, from condensing elsewhere in the system all tie tubing was heated to about $125^{\circ} \mathrm{C}$ with Flexicoil beating tape. The bore of the three-way tap, through which the acid passed was hoated with nichrome wire wrapped in Refrasil silica sleeving. Bll taps were lubricated with xel-I grease which was guite resistant to chemical attack 
by the hot acid.

The concentration of perchloric acid in the carrier gas could be altered by adjusting the temperature of the oil bath.

\section{Burnace}

The reaction vessel was heated by an aluminium block furrece. This consisted of a horizontal cylinder of aiuminium, 8 inchss in diameter and 16 inches long, with a 2ki inch diameter hole drilled through it in which the reaction ressel fitted. The block was wound noninductively

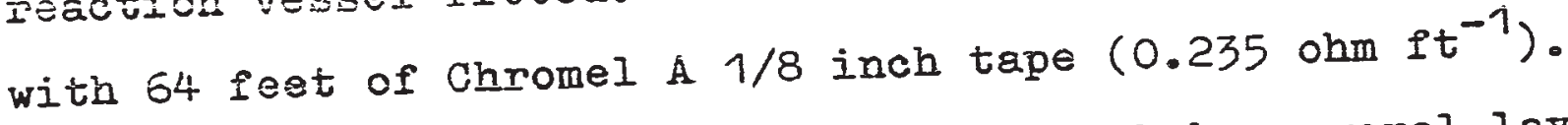
The windings were insulatea from the block by several layers of asbestos paper and the windings were: covered by A.lundum refractory cement and several more layers of asbestos paper. The block sat in a transite pipe fitted with end plates and packed with vermiculite: insulation. When in use the two ends of the furnace were packed with asbestos wool.

There were two further holes drilled in the block from one end to the middle. One of these carried a thermocouple, the other carried a temperature probe. The probe, in conjuction with a Hallakainen 2505 Thermotrol temperature controller maintained the temperature to better than $\pm 0.5^{\circ} \mathrm{C}$ over the entire working range. By probing with a second thermocouple the furnace ras found to have a region of constant temperature Ereater than $20 \mathrm{cw}$ in length, even 
in the high temperature region. When this second thermocouple was calibrated against the first, this constant temperature was found to be within $0.5^{\circ} \mathrm{C}$ of the block temperature. All temperatures quoted in Chapter 3 are block temperatures.

\section{Reaction Vessels}

Four pyrex reaction vessels of different body volumes were usea during this work. Reaction Vessel I is shown in Fig. 3 and Reaction Vessel III is shown in Fig. 4. reaction Vessel II was similar to Reaction Vessel I but had a smalier boây volume and Reaction Vessel IV consisted simply of a U-tube. The general dimensions of all four vessels are shown in Table 2 .

The decomposition of perchloric in the absence of any added cataljst ras investigated in all four reaction vessels. Reaction Vossel II was also used in the study of the catalytic decomposition and Reaction Vessel III, which had two inlets was also used in the investigation of the reaction of perchloric acid with fuels.

It was found that the condition of the pyrex surface was important and that this could change spcritaneously after remaining constant for many weeks. Apart from this ageing effect, the surface condition also depended upon its pretreatmerit. This is discussed more fully iater. The three standard pretreatments which were used were annealing, washing and coating. Annealing was achieved by 
leaving the reaction pesses in a glass blower's annealing oven overnight. Washire was with a mixture of concentratsa sulphuric acid anì potassium permanganate. After rinsing thoroughly with distiliza water, any manganese dioxide deposited yas removed with a mixture of nitiric acid and hydrofren peroxide. The rowtion tessel after further rinsing yas then driled is a current of dry air. Only one coating was usea. Tins was sorice acid. It ras applied in a $5 \%$ solution in ethanol. The evaporation of the solvent left a dill coating of tine beric acid.

\subsection{Analysis}

In order to study the kinetics of perchloric acid decomposition and its reaction with fuels, an analysis of the product gas stream from the reaction vessel must be made :

For the decomposition of perchloric acid alone, the catalysed decomposition and the reaction with hydrogen, the product gas stream can only cortain unchanged perchloric acid, water, oxyen, chlorine and hydrogen chloride. For this case, a suificient anaigsis can be achieved by passing the proauct sas strean through a trap containing standard sodium hydroxide anc analysine the resulting solution usine volumetric tesmignes. A full analysis is not achieved, but by consiaering the chlorine balance it is possible to obtain risetic results.

For a stuit of tio reaction of perchloric acid with 
other fuels, in which other prouncts are formed this anslysis is not sufficient and an analysis invoiving gas chronatography is requirea.

Yolumetric Analysis

In the former stuaies, the proauct streem yas bubblad through a trap of standard sodium hydroxide (usually 50 WI $N / 10$ NaOP). This efficiently absorbed all the unchanged perchloric acid; the chlorine and the hydrogen ciloride. When very fast flow rates were used a second ina vas sometimes necessary.

After a run, the solution was carefully transfered to a volumetric flask. It was necessary to wash into the flask any perchloric acid or hydrogen chloride which had condensed inside the inlet sinter tube. This was best acsieved by putting a trap of water in place and applying a small positive pressure to the outlet using a rubber bulb. Pisee aliquots of this solution were taken and anaIysis was made for chloride ion, hypochlorite ion and hydroxide ion.

Unchanged perchloric acid consumes sodium hydroxide according to the squation,

$$
\mathrm{HClO}_{4}+\mathrm{IaOH} \longrightarrow \mathrm{NaClO}_{4}+\mathrm{H}_{2} \mathrm{O}
$$

Chlorine consumes sodium hydroxide according to the equatioñ

$$
\mathrm{Cl}_{2}+2 \mathrm{NaOH} \longrightarrow \mathrm{NaCl}+\mathrm{NaOCI}+\mathrm{H}_{2} \mathrm{O}
$$


Hydrogen chloride consumes sodium hydroxide according to the equation,

$$
\mathrm{HCI}+\mathrm{HaOH} \longrightarrow \mathrm{NaCl}+\mathrm{H}_{2} \mathrm{O}
$$

Therefore for every atom of chlorine in the original perchloric acid (i.e. befor decomposition), one molecule of sodium hyaroxide is consuxed. Also every molecule of chlorine gives one chloride ion and one hypochlorite ion and every molecule of hydrogen chloride gives one chloride ion.

Therefore the analysis, together with a value for the flow rate and for the length of the run, allows the initial perchloric acia concentration, final perchloric acid concentration, final chlorine concentration and final hydrogen chloride concentration to be calculated.

The analysis for hypochlorite was by the iodometric 72 method. Chloride was determined by Volhard's method73 and hydroxide by an acid base titration with bromothymol blue as indicator. In the last two titrations it was necessary to raduce the hypochlorite to chloride to prevent its interference. In the acid base titration this was acnieved by excess sodium nitrite and in the Volhard titration by the stoichiometric amount of arsenious oxide solution.

This analysis was found to be reliable. Tests wero made using pure chlorine and also the chloride analysis 
was checked using a gravimetric method. While agreement was good it was clear that in the normal analysis of many of the runs only slight errors in titration could lead to a significant difference in the calculated ratios of chlorine and hydrogen chloride produced. Kinetic data were therefore always calculated in terms of amount of perchloric acid decomposed.

Gas Chromatographic Anaiysis

While a gas chromatographic analysis of the product gas stream would be much less time consuming than the volumetric techniques, it does present a number of technical difficulties. Before attempting to analyse the product gas from the reaction of perchloric acid with fuels, the simpler problem of analysing the product gas from the decomposition was iried. A Herlett-Packard 5750 Research Ghromatograph fitted with a thermal conauctivity detector was used. Helium was used as the carrier gas both for the flow system and the chromatograph. Therefore sampling of the product gas into the chromatograph should reveal only products of decomposition with no large carrier gas peak. While there is no reference to the separation of similar mixtures in the literature, it was thought that a $4 \mathrm{~m} \mathrm{col-}$ umn, packed with $30 \%$ Halocarbon oil on silica-gel 74 or a 10 foot column packed with $\mathrm{Kel-F}$ lax on Haloport $F$ support 75 would be a suitable starting point as both have been used 
in the separation of chlorine compounds. However a number of problems were encountered in sampling the gas stream and so their suitability was never really tested.

Initially a Carle micro-volume sampling valve with a capacity of $5 \mathrm{ml}$ was used. This and all the other parts of the system through which the perchloric acid passed were heated with flexicoil heating tape to prevent condensation of the acio. However the valve offered a large resistance to the effluent gas flow resulting in a dangerous back pressure in the saturator. As the possibility of catalytic decomposition of the perchloric acid on the hot metal also seemed likely, a pyrex sampling system was constructed using two four-way taps. This is shown in Fig. 5. The bores of these taps were also heated with nichrome wire, wrapped in Refrasil silica sleeving, to prevent condensation of the acid. The sampling system functioned well at room temperature and even at elevated temperatures. However, the presence of hot perchloric acid in the effluent gas attacked the Kel-F grease: sufficiently to allow the chromatograph carrier gas, which was at a high pressure, to leak. Spririg loading the taps and also pumping on the key dia not alleviate this problem. Attempts were then made to remove the perchloric acid from the gas stream before sampling the gas stream and hence to detect only the other components. Passing the gas stream through a trap at room temperacure was not effective 
due to the hygroscopic nature of perchloric acid. The perchloric acid removed the water which then dissolvea the chlorine and hydrogen chloride leaving only oxygen in the gas stream. There was no suitable chemical means of removing cnly the perciloric acio.

A number of runs were therefore carried out in which both tìe volumetric and chromatographic techniques were usea simultaneousiy. The product gas was passed through a trap containing standard sodium hydroxide and then inroupis a cola trap to remove any water vapour. The gas stream was then sampled into the gas chromato raph. A 6 foot column packea with Molecular Sieve 5A and maintained at $70^{\circ} \mathrm{C}$ was used in the chromatograph. This technique allowed the amount of oxygen as well as the amorntis of chlorine, hydrogen chloride and unchanged perchloric acid in the effluent gas stream to be obtained.

The same technique was used to study the reaction of perciloric acid with fuels. In this case the results obtained can only be semi-quantitative as unknown amounis of chlorinated organic compounds were produced which invalidate the use of the chlorine balance to interpret the volumetric titrations. This is discussed further in Chapter $\bar{j}$

\subsection{Computine}

All computing mentioned in Chapter 3 and 4 was carried out in the U. U.O. Computing Centre, using an I.B.M. 7040 Computer. 
Three basic proerammes, KASE, NLIN and FUNMIN wexe. used. KASE is a weighted least squares programme with ploiting, written at the University of Missouri. KASE was used to obtain the Arrhenius parameters from all the simple Arrhenius plots. FUNMIN is e simpler ana more versatile least squares programme, supplied by Dr. I.H. jiiiier. Tiuis was used for all the early work on investigating simple kinetic models. NIIN, a non-linear least squares programme was used for the later work. This is a more sopinisticated progremme and is available as I.B.M. Share Program iNo. 1428. 


\section{CHAPTER 3}

\section{RESULTS}

As the work described in this thesis was in three parts, this chapter is subdivided into three sections: the decomposition of perchloric acid in pyrex reaction vessels; the decomposition of perchloric acid in the presence oi akdea catalysts and the reaction of perchloric acid with iuels.

\subsection{Decomposition of Perchloric Acid in Pyrex Reaction}

\section{Vessels}

The kinetics of the decomposition of perchloric acid were investigated between 279 and $471^{\circ} \mathrm{C}$ with initial acid concentrations of $1 \times 10^{-4}$ to $1.5 \times 10^{-3}$ moles litre ${ }^{-1}$. Four different reaction vessels were used and a range of residence times from 0.9 sec to $2.8 \mathrm{~min}$ was employed. The effect of packing, ageing, washing and coating reaction vessels was investigated.

Regction Vessel I

Reaction Vessel I is shown in Fig. 3. It had a body volume of $110 \mathrm{mi}$. Other dimensions are given in Table 2. Before it was used it had been fully annealed.

The decomposition was initially investigated at nine temperatures between 286 and $386^{\circ} \mathrm{C}$, with an initial acia 
concentration of $2.5 \times 10^{-4}$ mole litre ${ }^{-1}$.

The results, obtained from volumetric analysis, sugfested that $85-95 \%$ of the perchloric acid decomposed to give chlorine while 5-15\% decomposed to give hydrogen chloriale. However the precise determination of the $\mathrm{Cl}_{2}$ ' HCl ratio is very difficult and it was clear from the very nature of these calcuiations that only small differences in the titration values woula projuce significant changes in these percentages. Therefore a number of runs were carried out at $370^{\circ} \mathrm{C}$, in which ine experimental conditions were adjusted to give optimum accuracy in the titrations. These were supplemented by gravimetxic analyses of the chloride produced in the sodium hydroxide trap. These results suggested that $95 \pm 5 \%$ of the decomposition was to chlorine. At a later date, the oxygen yield was measured for a number of runs using gas chromatography. The results were not however entirely conclusive and it was impossible to improve on the accuracy which had already been attained.

First order rate plots for the decomposition at the nine temperatures are included in Fig. 6. All the kinetic data were treated in terms of perchloric acid decomposed rarher than in terms of products formed. AIl are good straight lines but the reaction at 364 and $355^{\circ} \mathrm{C}$, which was studied to high conversions, shows a falling off in rate as corpared to a simple first order reaction. 
The first order rate constants, from these plots are included in Table 3 and also in the Arrhenius plot in Fig. 7. The Arrhenius plot is essentially linear above $340^{\circ} \mathrm{C}$ but below this temperature it forms a gentle curve. The linear portion would correspond to an activation energy of $35.2 \mathrm{kcal}$ mole $\mathrm{e}^{-1}$ and a preexponential factor of $3 \times 10^{10}$ $\sec ^{-1}$

The deviations from the first order rate plots at high conversions and the non-linearity of the Arrhenius plot over the whola temperature range, suggested that the decomposition was not entirely first order under these experimental conditions. The good reproducibility, even at low temperatures (in contrast to Levy's experience ${ }^{10}$ ) suggested, however, that a single overell mechanism might explain all the data.

In order to see if modifications of first order kinetics could explain the data, two other simple models were consicierea:

1) Parallel first and zero order reactions i.e.

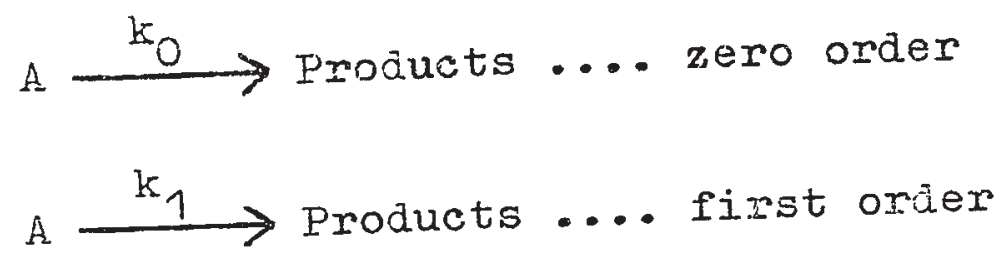

for which,

$$
a=\left(k_{0} / k_{1}+a_{0}\right) e^{-k_{1} t}-k_{0} / k
$$


2) Parallel first and second order reactions i.e.

$$
\begin{aligned}
& A \stackrel{\mathrm{k}_{1}}{\longrightarrow} \text { Products ... first order } \\
& 2 \mathrm{~A} \stackrel{\mathrm{k}_{2}}{\rightarrow} \text { Products .... second order }
\end{aligned}
$$

for which,

$$
a=\frac{a_{0} k_{1}}{\left(k_{1}+2 k_{2} a_{0}\right) e^{k_{1} t}-2 k_{2} a_{0}}
$$

Attempts were made to fit the data at each temperature to both models using mainly the least squares minimisation programme FUNMIN. It was not generally possible to fit the data to model 1 unless the zero order rate constant was negative which could have no physical meaning. A good fit could be obtained at all temperatures for model 2 ; however, the function was in fact quite insensitive to the values of the second order rate constant $k_{2}$. The iirst orcer and second order rate constants which were initially obtained obeyed the Mrrhenius equation. For the first order reaction, the activation enerey was $22 \mathrm{kcal}$ mole $\mathrm{k}^{-1}$ and the preexponential factor was $4.4 \times 10^{5} \mathrm{sec}^{-1}$. For the second orcier reaction, the activetion energy was $42 \mathrm{kcal}$ mole $\mathrm{e}^{-1}$ arc the preexponential factor was $3.6 \times 10^{15} \mathrm{sec}^{-1}$. The values of these Arrhenius parameters would require that both the rirst and 
second order reactions represent complex reactions. This analysis of the data predicted that at low temperatures the first order reaction should predominate and at high temperatures the second order reaction should predominate.

Before this was tested by extending the study to higher temperatures, the effect of varying the initial acid concentration at $364^{\circ} \mathrm{C}$ was observed. A flow technique is not really suitable for measuring initial rates at different initial concentrations, which is one method of determining the oraer of a reaction. It becomes essentially a one point method. Therefore a number of runs at different residence times were carried out for each initial acid concentration. The first order rate plots for these are shown in Fig. 8. All the data fit the same straight line except at high conversions where deviations occur. The deviation increases with increasing initial acid concentration. However, the decomposition at $364^{\circ} \mathrm{C}$ is clearly predominantly first order.

The decomposition was then investigated at three more temperatures, exiending the temperature range up to $406^{\circ} \mathrm{C}$. The first order rate plots for the decomposition at these temperatures are given in Fig. 6. The calculated first order rate constants are included in Table 3 and in the Arrhenius plot in Fig. 7. The effect of varying the initial acia concentration on the calculated first order rate constant was observed at $374^{\circ} \mathrm{C}$. The results are shown in 
Table 4. Both these sets of results show that the decoriposition is essentially first order in this temperature region. The model, involving parallel first and second order reactions was therefore not valid. Both the deviation observed in the first order plots at high conversions and the non-linearity of the Arrhenilis plot could not be explained by a simpla deviation from a single first order reaction.

The shape of the Arrhenius plot for the first order rate constants suggested that the decomposition occured by two parallel first order reactions. At the low temperatures, the reaction with the lower activation $\in$ sergy gouid predominate and at the high temperatures, the: reaction with the higher activation energy would predominate. The Arrhenius plot fould therefore consist of a curve asymptotic to the straight lines which corresponded to these individual reactions. Using the programme NLIN, it was possible to obtain the Arrhenius parameters for the two reactions. The reaction predominating at high temperatures had an activation energy of $43.3 \mathrm{kcal} \mathrm{mole}$ and a preexponential factor of $6.7 \times 10^{12} \mathrm{sec}^{-1}$ and the reaction predominating at low temperatures had an activation energy of $16 \mathrm{kcal}$ mole $\mathrm{e}^{-1}$ and a preexponential factor of $2.0 \times 10^{3} \mathrm{sec}^{-1}$. This analysis into two parallel first order reactions could not explain the observed deviations from fissi ordes kinetics. 
An attempt to obtain more date in the low temperature region revealed an ageing effect. The first ouler rate constants obtained at the three temperatures 280,312 and $349^{\circ} \mathrm{C}$, are shown in Table 5. They are considerably less than expected. The decomposition was, however, still first order as varying the initial acid concentration at $312^{\circ} \mathrm{C}$ diâ not affect the calculated fisst order rete constant. This is show in Table 6 . It thererore appeared that before this 10 temperature investigation began, there had been a change in the nature of the surface. However the reproducibility of the previous work suggested that the surface could remain unchanged for a period of weeks.

As it was now clear that at least in the low temperature region, surface effects were important, the reaction vessel was packed with glass wool. This had a surface area of about $6 \times 10^{3} \mathrm{~cm}^{2}$ and it was thought that this large increase in surface should emphasise the surface effects. The decomposition was investigated at 286 and $358^{\circ} \mathrm{C}$. The first order rate constants are shown in Table 7. At $286^{\circ} \mathrm{C}$, the rate constant was even lower than for the aged vessel and at $358^{\circ} \mathrm{C}$, it was the same as for the annealed reaction vessel. There ras no obvious simple explanation. of this. Two possibilities presented themselves. It was possible that the surface of the glass wool was practically inert in catalysing the decomposition and that these 
effects were due to the nature of the reaction vessel surface changing. An alternative explanation was that the decomposition was in fact a complex chain reaction, in which both initiation and termination were, in part at least, heterogeneous. The effect of \& surface may be to increase or decrease the rate dopending on the relative importance of the two steps.

At a later etege iI the intestigation, the decomposition was studied in Reaction Vessel I after it had been thorough? washed By using a series of two product absorption traps, faster flow rates could be used. The kineties were studied at six temperatures up to $435^{\circ} \mathrm{C}$. At the three highest temperatures, 400,416 and $435^{\circ} \mathrm{C}$, the decomposition was first order and the calculated rate constents are shown in Table 8. At the three lowest temperatures, 386,374 and $361^{\circ} \mathrm{C}$, the decomposition did not appear to be first order. The reaction was faster than the provious results suggested and there was also an induction period. Plots of the percentage decomposition of the acid against residence time for the six temperatures are shown in Fig. 9. A true induction period can result only from catalysis by products or a degenerate chain oranching mecianism involving an intermediate with a halflife of the order of seconds. An apparent induction period can result from self-heating. This is discussed later. These results showed that surface effects could 
be important at temperatures at least up to $380^{\circ} \mathrm{C}$ and that washing the surface altered its activity.

This washed reaction vessel was again packed with glass wool and the decomposition investigated at five temperatures between 290 and $417^{\circ} \mathrm{C}$. The surface area of the glass wool was roughly $5 \times 10^{3} \mathrm{~cm}^{2}$. The first order rate plots are shown in Fig. 10 and are linear. The calculated rate constants are shown in Table 9 and in the Arrhenius plot in Fig. 11. The rate of the decomposition appears to be faster than in the anrisaled ressel but lower than in the washed vessel, particularly at the lower temperatures. The Arrhenius plot was curved. An analysis into two components as was done for the decomposition in the annealed vessel was not attempted, because there were only five points.

Reaction Veasel II

In order to extend the study to higher temperatures, it was necessary to use shorter residence times. Reaction Vessel II was therefore used. This had a body volume of $80 \mathrm{ml}=$ other dimensions are given in Table 2. Before being used it was thoroughly washed.

The decomposition was studied at eight temperatures between 362 and $470^{\circ} \mathrm{C}$. The rirst order rate plots are shown in Fig. 12. The calculated first order rate constant at $362^{\circ} \mathrm{C}$ was not affected by varying the acid concentration. This is shomn in Table 10 and confirms the 
essential first order ature of the decomposition. The first order rate constants for the eight temperatures are shown in Table 11 and in the Arrhenius plot in Fig. 13. The Arrhenius plot was linear and corresponds to an activation energy of $41 \pm 0.4 \mathrm{kcal}$ mole ${ }^{-1}$ and a preerponential factor of $1.3 \times 10^{12} \mathrm{sec}^{-1}$. There was no apparent surface reaction.

The effect of changing the carrier gas from nitrogen to helium and oxpgen was negligible. This is shown in Tajie 12 .

\section{Reaction Vessel III}

Reaction Vessel III is shown in Fig. 4. It had a body volume of $80 \mathrm{ml}$. Other dimensions are given in Table 2. It was used mainly in the study of the reaction between perchloric acid and fuels. Initially it was used in an annealed state and the decomposition observed at $365^{\circ} \mathrm{C}$. The surface of the reaction vessel was then coated with boric acid and the decomposition observed at 365 and $417^{\circ} \mathrm{G}$. The first order rate plots are shown in Fig. 14. The calculated first order rate constants are shown in Table 13. Coating with boric acid increased the rate.

Reaction Vessel IV

Reaction Vessel IV bad a body volume of $25 \mathrm{ml}$. other dimensions are given in Table 2. It was initially used without annealing. The original intention was to 
extend the study of the decomposition to even higher temperatures, however the rate was found to be very fast even at $403^{\circ} \mathrm{C}$. The kinetics were studied at four tamperatures from 403 to $293^{\circ} \mathrm{C}$. At all temperatures there ras an apparent induction period. Plots of percentage decomposition against residence time are shown in Fig. 15.

After this initial stuay, the reaction vessel was removed and after a few weeks re-used. The decomposition was reinvestigated at 364 and $416^{\circ} \mathrm{C}$. The rate had decreased by a factor of about tro but the reaction still showed an induction period. The reaction vessel was removed and annealed. A further reexamination of the decomposition at 365,415 and $454^{\circ} \mathrm{C}$, showed that the rate had decreased still further and now followed first order kinetics. The first order plots are shown in Fig. 16 and the rate constants in Table 14. The results obtained in Reaction Vessel IV clearly illustrate the strong surface effects wich can be important even at high temperatures.

\section{summasy}

i) In the range 280 to $470^{\circ} \mathrm{C}$, perchloric acid decomposes according to the equation,

$$
\mathrm{HClO}_{4} \longrightarrow 1 / 2 \mathrm{Cl}_{2}+1 / 2 \mathrm{H}_{2} \mathrm{O}+7 / 4 \mathrm{O}_{2}
$$

although small amounts of hydrogen chloride may be formed.

ii) The decomposition is basically first order at all. temperatures and in all reaction vessels. However, 
deviations were observed at high conversions. Also, in the washed Reaction Vessel I below $380^{\circ} \mathrm{C}$, and in the nonanneaied Reaction Vessel IV, apparent induction periods were.

observed.

iii) An ageing effect can occur, in which the rate of the decomposition may change without there being an active external change in the experimental conditions. In Reaction Vessel I, the rate decreased suddenly after meny weeks.

iv) The rate of the decomposition may be changed by washing the reaction vessel. In the case of Reaction Vessel I, the rate increased.

v) The rate of the decomposition may be changed by coating the reaction vessel. The rate in Reaction Vessel IV was increased by costing with boric acid.

vi) Packing the reaction vessel with glass wool may alter the rate but not dramatically. In the aged Reaction Vessel I, the rate was decreased at low temperatures but was unchanged at intermediate temperatures. In the washed Reaction Vessel I, the rate was aecreased.

vii) The frrhenius plot for first order rate constants in an apparently non-ageing reaction vessel may be curved, as for the annealed Rezction Vessel I, or linear as for the washed Reaction Vessel II. The curved Arrhenius plot may be analysed in terms of the sum of two first order rate constants. 
3.2 Decomposition of Perchloric Acid in the Presence of

\section{Addea Catalysts}

The catalytic effect of five different Harshaw catalysts was studied. The catalysts are known by their catalogue numbers and Table 1 contains a brief aEscription of their properties. Reaction Vessel II was used and the catalysts were packed in this, between plugs of glass wool. The effluent gas stream was anaigsed using only volumetric techniques. In the temperature range used, there was no measurabie decomposition in the absence of catalgst. Very little, if any hydrogen chloride was produced, the decomposition occuring according to the equation,

$$
\mathrm{HClO}_{4} \longrightarrow 1 / 2 \mathrm{Cl}_{2}+1 / 2 \mathrm{H}_{2} \mathrm{O}+7 / 4 \mathrm{O}_{2}
$$

Harshaw Catalyst - Cu-0203

Two samples, each weighing $30 \mathrm{~g}$ and having surface areas of $3.45 \times 10^{2} \mathrm{~m}^{2}$ were used. Both sampies were studied at $261^{\circ} \mathrm{C}$ and the second sample was studied at five other temperatures before non-reproducible results were obtained = The initial perchloric acid concentration was varied from 3.5 to $9.9 \times 10^{-4}$ mole litre ${ }^{-1}$. A range of residence times from 0.05 to 0.26 rinutes were employeã. Preliminary work on the first sample showed that initially all the perchloric acid which was passed over the catalyst was consumed. After a few runs, the catalytic effect could be observed. The activity of the 
catalyst then increased to more than ten times the original value.

The second sample showed the same effect. After ihis initial conditioning period fairly reproducible results could be obtained for about 15 runs. After this the results were not very reproducible but the activity generally decreased.

The first order rate plots for the decomposition on the conditioned catalyst are given in Fig. 17 and the rate constants in iajie 15 . The Arrherius plot for the specific rate constants is shown in Fig. 18. The decomposition is first order under these conditions with a preexponential factor of $2.5 \times 10^{22} \mathrm{~min}^{-1} \mathrm{~m}^{-2}$ and an apparent activation energy of $54 \mathrm{kcal}$ mole $\mathrm{e}^{-1}$.

Eoth catalyst samples were visibly attacked by the perchloric acid producing a ginger coloured prodict.

Harshaw Catalyst Fe-0301

A $30 \mathrm{~g}$ sample of the catalyst, having a surface area of $1.23 \times 10^{3} \mathrm{~m}^{2}$ was studied at five temperatures from 177 to $238^{\circ} \mathrm{C}$. The initial perchloric acid concentration was varied frow $2 \times 10^{-4}$ to $1 \times 10^{-3}$ mole litre ${ }^{-1}$ and residence times from 0.05 to $0.7 \mathrm{~min}$ were used.

After an initial conditioning period in which the activity increased, reproducible results were obtained. The rirst order rate plots are shown in Fig. 19 and the rate constants in Table 16. The Arrienius plot of the 
specific rate constants is shown in Fig. 20. Under these conditions, the decomposition is first order with a preexponential factor of $2.5 \times 10^{10} \mathrm{~min}^{-1} \mathrm{~m}^{-2}$ and an apperent activation energy of $28.6 \mathrm{kcal}$ mole $\mathrm{e}^{-1}$.

The catalyst did not show any visible signs of attack by the perchloric acid.

\section{Harshaw Catalȳst - $\mathrm{Al}-0104$}

A $30 \mathrm{~g}$ sample having a surface area of $2.35 \times 10^{3} \mathrm{~m}^{2}$ was studied at rive temperatures between 176 and $251^{\circ} \mathrm{C}$. The initial acia concentration was varied from $3.2 \times 10^{-4}$ to $4.0 \times 10^{-4}$ mole litre ${ }^{-1}$ and residence times from 0.06 to $1.0 \mathrm{~min}$ were used.

No conditioning period was required and the activity of the catalyst remained constant. The first order rate plots are shown in Fig. 21 and the rate constants in rable 17. The Arrhenius plot of the specific rate constants is shown in Fig. 22. Under these conditions, the decomposition is first order with a preexponential factor of $1.3 \mathrm{x}$ $10^{10} \mathrm{~min}^{-1} \mathrm{~m}^{-2}$ and an apparent activation energy of 28.8 kcal mole $e^{-1}$.

There was no visible change in the catalyst after it had been used as a substrate for the perchloxic acid decomposition.

Harshaw Catalyst - Cu-0803

A $10 \mathrm{~g}$ sample, having a surface area of $1.37 \times 10^{3}$ $\mathrm{m}^{2}$ was studied at six temperatures between 196 and $250^{\circ} \mathrm{C}$. 
The initial acid concentration was varied from $2 \times 10^{-4}$ to $1.5 \times 10^{-3}$ mole litre. ${ }^{-1}$ and residence times Irom $0.05 \mathrm{~min}$ to $0.2 \mathrm{~min}$ were used.

The activity initially decreased to a relatively constant value. The first order rate plots are shown in Fig. 23 and the rate constants in Table 13. The Arrhenius plot of the specific rate constants is siown in Fig. 24. The aecomposition is first order under these conditions with 2 preexponential of $8 \times 10^{14} \min ^{-1} \mathrm{~m}^{-2}$ and an appaIent activation energy of $39.0 \mathrm{kcal} \mathrm{mole} \mathrm{k}^{-1}$.

The perchloric acid reacted with the catalyst changing its colour from dark green to light green.

\section{Harshaw Cataljst - Mn-0201}

A $30 \mathrm{~g}$ sample, having a surface area of $2.06 \times 10^{3}$ $\mathrm{m}^{2}$ was studied at five temperatures between 142 and $207^{\circ} \mathrm{C}$. In the injtial work an initial acid concentration of about $3 \times 10^{-4}$ moles litre ${ }^{-1}$ was used and residence times from 0.02 to 0.5 min were used. Reproducibility was very good but the kinetics were not first order. Plots of percentage decomposition against residence time are shown in Fig. 25. There is an apparent induction period. Attempts were made to fit the data to a number of Langmuir-Hinshelwood type models using the programme FUNMIN but without success.

At $177^{\circ} \mathrm{C}$, the decomposition was observed for a number of different initial acid concentrations at the same 
residence time. The percentage decomposition decreased sisghtiy rith increasing acid concentration suggesting an apparent order less than one.

Further analysis was not possible but Mn-0201 appeared to be very good catalyst. At a later date, selfheating was considered as an explanation of the observed kinetics. This is aiscussed in Chapter 4. There was no visible change in the catalyst arter it had been used as the substrate for the perchloric acid decomposition.

Summasyy

i) All the catalysts tried catalyse the decomposition positively.

ii) The decomposition follows the equation,

$$
\mathrm{HClO}_{4} \longrightarrow 1 / 2 \mathrm{Cl}_{2}+7 / 4 \mathrm{O}_{2}+1 / 2 \mathrm{H}_{2} \mathrm{O}
$$

iii) The decomposition on the catalysts, Cu-0203, $\mathrm{Fe}-0301, \mathrm{Al}-0104$ and $\mathrm{Cu}-0803$, follows first order kinetics under the experimental conditions used. The decomposition on Mn-0201, showed an apparent induction period.

iv) Arrhenius parameters were obtained for the first four catalysts. These are shown in Table 19.

v) The perchloric acid produced a visible change in the catalysts Cu-020s and Cu-0803. 
3.3 Reaction of Perchloric Acid with Fuels

Preliminary otudies have been carried out on the reacticn of perchloric acid with hydrogen, methane, ethane and ethylene; Reaction Vessel III was used. This had two inlets and is showr in Fig. 4. For the reaction with hydrogen, volumetric methods of analysis were used almost exclusively and the results are quaritititive. For the reaction of perchloric acia with the other üuls a combination of volumetric and chromatographic iechniques were used. These results can only be semi-quantitative. Owing to the experimental system used, the fuel stream was always in large excess and so it is convenient to represent the reaction in terms of the amount of perchloric acid consumed.

\section{Reaction with Hyarogen}

The reaction vessel had been annealed before use. The reaction of perchloric acid with hydrogen was observed at six temperatures between 146 and $417^{\circ} \mathrm{C}$. The initial acid concentration was approximately $3 \times 10^{-4}$ mole litre and the initial hydrogen concentration was varied from $1.4 \times 10^{-3}$ to $1.2 \times 10^{-2}$ mole litre ${ }^{-1}$. A residence time of $0.1 \mathrm{~min}$ was used. The general results are shown in Table 20.

At all temperatures the reaction was faster thar for the simple decomposition and the only chlorine-containing product was hydrogen chloride. At a later date, the 
product gas stream was analysed after passing through the sodium hydroxide trap. No oxygen was observed.

At $349^{\circ} \mathrm{C}$ and above, essentially all the perchloric acid was consumed in less than 0.1 min. Below this, reproducible results were not obtained. The results obtained at $147^{\circ} \mathrm{C}$ are shown in Table 21. The amount of perchloric acid which decomposed in 0.1 win did not appear to be related to the hydrogen concentration in the range studied. There appeared to be more of an ageing effect which showed that surface effects were important at least in this temperature region. The rate of reaction increased until after six runs, practically all the perchloric acid had decomosed in $0.1 \mathrm{~min}$. This was however a general trenà with some discrepancies.

In an attempt to improve reproducibility, the reaction vessel was coated with boric acid. The reaction was observed at 365 and $147^{\circ} \mathrm{C}$ and the general results are shown in Table 22. The rates were still fast. At $365^{\circ} \mathrm{C}$, all the perchioric acid was consumed in less than 0.1 min. The results obtained at $147^{\circ} \mathrm{C}$ are shown in $\mathrm{Table} 23$. Reprouucibility was not achieved and once more an apparent ageing effect was observed. The initial runs showed a lower rate of reaction than for the reaction in the uncoated vessel and the ageing appeared to be slower. 


\section{Reaction with Methane}

The reaction of perciloric acid with metinane was investigated at 143,350 and $417^{\circ} \mathrm{C}$. Reaction Vessel III was usea after it had been rinsed with distilled water. For most runs, the initial acid concentration was in the region $4.7 \times 10^{-4}$ to $7.6 \times 10^{-4}$ mole litre ${ }^{-1}$ and the initial methane concentration was variea from $4.5 \times 10^{-3}$ to $3.4 \times 10^{-2}$ moje litre-1.

No reaction was observed at $143^{\circ} \mathrm{C}$, although residence times up to $0.6 \mathrm{~min}$ were used. At $350^{\circ} \mathrm{C}$, no reaction was observed for a residence time of 0.1 min; however, when the residence time was increased to 0.8 min reaction occured. Only a small initial acid concentration had been used but hydrogen chloride and carbon monoxide ware observed as products. Hydrogen chloride was observed in the volumetric analysis and carbon monoxide in the chromatographic analysis.

Investigations at $417^{\circ} \mathrm{C}$, confirmed that hydrogen chloride and carbon monoxide were: principal products. No chlorine was observed in the volumetric analysis and the oxygen yiela was either very low or non-existent. No carbon dioxide was liberated when a sample of the trap contents were acidified, which sugested that carbon dioxide was not a major product. It was not possible to detect any organic products either visually or by their odour. 


\section{0}

For a residence time of 0.11 min, usine the normal method of calculation, 50\% of the perchloric atia was consumed and the carbon monoxide to bydrogen chloride ratio was approximately two. For a residence time of $0.40 \mathrm{~min}$, 80\% of the pexchloric acid was consumed and the ratio was nearer three.

These percentage decomposition can only be approximate as a complete product analysis was not achieved. The production of non-ionizable chlorine products would result in a value of the percentage aecomposition which was too low, while the production of compounas other than hydrogen chloride which will consume sodium hydroxide, would result in too high a value.

Reaction with Ethane

The reaction of perchloric acia with ethane was investigated at 147 and $417^{\circ} \mathrm{C}$. The initial acid concentration was in the range $3.5 \times 10^{-4}$ mole 1 itre $e^{-1}$ and the initial ethane concentration was varied from $6.8 \times 10^{-3}$ to $1.4 \times 10^{-2}$ mole litre ${ }^{-1}$.

There was no reaction at $147^{\circ} \mathrm{C}$. The major products at $417^{\circ} \mathrm{C}$ were hyarogen chlcride and carbon monoxide. No chlorine was observed but appreciable amounts of oxygen were formed. Droplets of organic iiquias were produced in the sodium hydroxide trap and there was a persistent odour. For residence time of 0.10 min, the calculated consumption of perchioric acia was $26 \%$. The carbon 
monoxide to hydrogen chloride ratio was approximately 0.8 and the oxygen to hydrogen chloride ratio was approximately 0.4. For a residence time of $0.21 \mathrm{~min}$, 51\% of the acid was consumed and the ratios were 3 and 0.8 , respectively. The run, with a residence time of $0.10 \mathrm{~min}$ had an ethane to perchloric acid ratio of 15 which was about a third of the value for the man, with a residence time of $0.21 \mathrm{~min}$.

Reaction with Ethylene

The reaction of perchloric acid with ethylene was investigated at 14 ? and $417^{\circ} \mathrm{C}$. An initial perchloric acid concentration of $7.2 \times 10^{-4}$ mole litre ${ }^{-1}$ and an initial ethylene concentration of $6.4 \times 10^{-3}$ mole litre ${ }^{-1}$ were used.

There was no reaction at $147^{\circ} \mathrm{C}$. Only one run was carried out at $417^{\circ} \mathrm{C}$; a residence time of 0.10 min wo.s used. Hydrogen chloride and carbon monoxide were the main products. An appreciable amount of oxygen was formed and there was a large soot formation. Organic oils collected in the sodium hydroxide trap and there were persistent odours. The calculation basea on the volumetric analysis suggested that $63 \%$ of the perchloric acid had been consumed. The ratio of carbon monoxide to hydrogen chloride was approximately four and the oxygen to hydrogen chloride ratio was 0.3 . 
CHAPTER is

\section{DISCUSSION}

The results contained in the previous chapter have, With a few exceptions, been presented in chronological order. Particularly in section 3.1, it was necessary at various stages to discuss briefly the results and to draw Iimited conclusions, in order to reveal the motivations behind the subsequent work. In the first section of this chapter, the decomposition of perchloric acid in pyrex reaction vessels will be discussed and the kinetic models which were mentioned previously, will be fully developed. The ability of each of these. models to explain the large body of results, presented in section 3.1, will be considered. The second section will be devoted to the meaning and significance of the results obtained on the catalytic decomposition and in the third section, the preliminary work on the reaction of perchloric acid with the ruels will be discussed and the relevance of these results to the decomposition will be considered. In the inal section, the conclusions of the entire work will be sumarised and the relevance of these conclusions to the aecomposition of AP will be briefly touched upon alorif with suggestions for further work. 
4.1 Decomposition of Peronloric Acid in Pyrex Reaction

\section{Vessels}

A large body of results on this seaction were presented in the previous chapter. Before suggesting any rcaction mechanisms to explain these results, a number of qualitative features of the decomposition will be discussed.

Perchloric acid decomposes to give mainly chlorine, oxygen and water,

$$
\mathrm{HClO}_{4} \longrightarrow 1 / 2 \mathrm{Cl}_{2}+1 / 2 \mathrm{H}_{2} \mathrm{O}+7 / 4 \mathrm{O}_{2} \text { (4.1 }
$$

although small amounts of hydrogen chloride are probably produced. The calculated hydrogen chloride gield was always small. The largest yields were observed in the decomposition in Reaction Vessel I and these were consistently higher than the values observed for the decomposition in the other reaction vessels. It is not possible to explain these small amounts of hydrogen chloride in terms of the Deacon equilibrium

$$
2 \mathrm{CI}_{2}+2 \mathrm{H}_{2} \mathrm{O} \rightleftharpoons 4 \mathrm{HCl}+\mathrm{O}_{2}
$$

for the equilibrium constant is very small at these temperatures.

The hydrogen chloride is probably produced in a side reaction. As this is always small and probably variable it was not possible to observe anj clear dependence of 
the hydrogen chloride yield on temperature.

In observing the decomposition of perchloric acid in Reaction Vessel I, it was found that washine the reaction vessel not only increased the rate of decomposition but also apparently changed the reaction mechanism. In the annealed reaction vessel the decomposition was basically first order, however in the washed reaction vessel the decomposition below $380^{\circ} \mathrm{C}$, was apparently much more complex. Plots of the extent of decomposition against time were sigmoid in shape, exhibiting an induction period. These curves were never mathematicaliy analysed.

A similar observation was made in the decomposition in Reaction Vessel IV. Sigmoid shaped decomposition curves were observed at all temperatures, even after ageing which resulted in a decrease in rate. It was not until the reaction vessel was annealed that the decomposition became first order and this also was accompanied by a decrease in rate.

Such complex kinetics can result from a number of causes. Auto-catalytic reactions in which the rate is catalysed by a product, have sigmoid decomposition time curves. There is no evidence to suggest that the decomposition of perchloric acid, under the experimental conditions used, is autocatalytic. The decomposition is certainly not catalysed oy oxgen or water and it would be difficult to propose a mechanism for the autocatalysis 
by chlorine. Mest autocatalytic reactions in fact occur in condensed phases.

Kinetic schemes involving induction periods are common in combustion studies in which complex chain reactions occur. Sometimes these are a consequence of inhibition by impurities, which break the chains in the early part of the reaction, being themselves consumed in the process. Semenov however postulated the existence of degenerate or delayed branching mechanisms which seem to be more generally applicable. The basic assumption is that chain branching is due to a relatively stable intermediate which has a half-life of the order of seconds. This intermediate is icrmed in a non-branching process and is then able to react to give either inert products or radicals which can initiate the primary chain leading to the formation of more intermediate. Neither of these explanations seem applicable to the decomposition of perchloric acid. There are no obvious impurities which would consume radicals and no intermediate was found. The analysis of the product gas stream during the induction period was not any different to the normal analysis. In fact, none of the possible intermediates have half-lives as long as a few seconds, at these temperatures.

Sigmoid decomposition curves may also result from seli-heating. If a reaction is exothermis, self-heating occurs if the rate of heat production exceeds the rete of 
heat 1oss. As rate constants increase rapidiy with increasing temperature, accoraing to the Arrhenius equation. thermal explosion can result. The sigmoid decomposition curves obtainea for the decomposition of perchloric acid are a conseguence of self-heating. Thermal explosion doas not occur because most of the perchloric acid is consumed. before the seif-heating effect is large. The decomposition is therefore always Iirst order but if the rate is much larger than normal due presumably to strong surface effects, self-heating can mask the finst order nature.

The reason seli-heating effects are not always important is due to the high dilution of the perchloric acid. Without such dilution, perchloric acid spontaneously ignites at $400^{\circ} \mathrm{C} 28$ and in the presence of catalysts at even lower temperatures.

The rate of the perchloric acid decomposition is ofter irreproducible, especially at the low temperatures. Thia clearly demonstrates the importance of surface effects, which may even be significant at quite high temperatures. The g.geing effect observed in Reaction Vessel I illusirates bow the magnitude of this effect may change sudienly. The difficulty of reproducing a surface is illustrated by the efiect of washing Reaction Vessels I and II. Washing Reaction Vessel II presumably reduced the surface effect while washing Reaction Vessel I increased is. kny reaction nechanism, which is proposed 
must clearly include surface reactions.

Three possible mechanisms will be considered, two of which are chain mechanisms. One difriculty involved. in proposing a mechanism is the lack of kinetic information on all but a very few of the possible intermediate reactions.

\section{SimpIe rioảeI}

This is essentialiy the mechanism sugsested by Levy ${ }^{10}$. Perchloric acid decomposes both in the gas phase and heterogeneously on the pyrex surface. The gas phase. decomposition is unimolecular and the heterogeneous decomposition is first order.

The unimolecular decomposition probably corresponds to the breaking of the $\mathrm{HO}-\mathrm{CIO}_{3}$ bond,

$$
\mathrm{HClO}_{4} \stackrel{\mathrm{k}_{1}}{\longrightarrow} \mathrm{ClO}_{3}+\mathrm{O}
$$

for which the enthaipy change $\Delta H=48.3 \mathrm{kcal}$ mole $\mathrm{e}^{-1}$.

If the chlorine trioxide radical is too unstable to have a separate existence, two other alternatives are possible

$$
\begin{aligned}
& \mathrm{HClO}_{4} \longrightarrow \mathrm{ClO}+\mathrm{O}_{2}+\mathrm{OE} \\
& \mathrm{ISIO}_{4} \longrightarrow \mathrm{CIO}_{2}+\mathrm{C}+\mathrm{CI}
\end{aligned}
$$

These involve enthalpy changes of +35.9 and +96.3 kcal mole , respectively. The second reaction, 4.5 would seem very unikely due to this high positive 
entinalpy change =

A third alternative 22 ,

$$
\mathrm{HClO}_{4} \longrightarrow \mathrm{HO}_{2}+\mathrm{ClO}_{2} \quad(4.6
$$

involves only an enthalpy change of $+31.1 \mathrm{kcal} \mathrm{mole}{ }^{-1}$; however, a high activation energy would be expected due to the large internal rearrangement involved.

As only final products were ubserved, it is not possible to distinguish between these alternatives. However, equation 4.3 probably represents the initiai step although equation 4.4 is possible.

If perchloric acid is not consumed by any other reaction, the rate equation is given by,

$$
-\frac{a\left(\mathrm{HClO}_{4}\right)}{d t}=k_{1}\left(\mathrm{HClO}_{4}\right)
$$

Levy ${ }^{10}$ suggested that the hydroxyl radical produced in equation 4.3 , abstracts a hydrogen atom from a second perchloric aciá molecule,

$$
\mathrm{HClO}_{4}+\mathrm{OH} \stackrel{\mathrm{k}_{2}}{\longrightarrow} \mathrm{ClO}_{4}+\mathrm{H}_{2} \mathrm{O} \quad(4.8
$$

The enthalpy charge for this reaction is $\Delta H=-8.3 \mathrm{kcal}-$ mole $e^{-1}$. If the hydroxyl radical is in its steady state concentration, then the rate of perchloric acid decomposition is given by 


$$
-\frac{a\left(\mathrm{HClO}_{4}\right)}{d t}=2 \mathrm{k}_{1}\left(\mathrm{HClO}_{4}\right)
$$

Levy used equation 4.7 .

The heterogeneous decomposition corresponds to the first order decomposition of perchloric acid adsorbed on the pyrex surface. On a Langmuir-Hinshelwood model, the perchloric acid is only sparsely adsorbed on the suriace. In practice, the perchloric acid is probably adsorbed 0.2 many different types of sites some of which may even be saturated; however, those sites on which mosti or tue perchloric acia decomposes are sparsely populated. These sites correspond to a low activation energy for the decomposition. Once more it is not possible to decide wiach is the initial step. Reaction 4.6 is now also possible because adsorption of the activated complex will lower the activation energy.

The heterogeneous rate equation will correspond to either 4.7 or 4.9 depending on the fate of the hydroxyl radical which sis produced. The heterogeneous rate constant, $k_{1}^{\prime}$ contains the equilibrium constant for the adsorption of perchioric acia on pyrex, $K$; and the surface area of the pyrex, $S$, as well as the specific rate constant, $x_{S}$,

$$
k_{1}^{\prime}=\mathrm{KSK}_{5}
$$

The overali rate of decomposition is therefore, 


$$
-\frac{a\left(\mathrm{HCIO}_{4}\right)}{a t}=\left(\mathrm{k}_{1}+\mathrm{k}_{1}\right)\left(\mathrm{HC}_{4} \mathrm{O}_{4}\right) \quad(4=11
$$

This simple model therefore has a mumber of consequences:

i) The decomposition should be first order under al1 conditions.

ii) The Arrhenius plot of the first order rate constants should normally be a smooth curve. The asymptote with the higher slope should correspond to the unimolecular decomposition and the asymptote with the lower slope should correspond to the heterogeneous decomposition.

iii) If there is no surface reaction, the Arrhenius plot should be linear and correspond to the unimolecular decomposition.

iv) If the number but not the type of decomposition sites is changed, then the position of the lower asymptote in the Arrhenius plot should clange: but the slope should remain the same.

v) If either the number or type of the sites is constanty changing irreproducible rate constants should be obrained.

The observed results agree quite well with the above general features. Inis model cannot, however, explain the deviations from first order kinetics obtained at high conversions.

The Iinear Arrhenius plot for the decomposition in 
Reaction Vessel II suggests that washing the reaction vessel has poisoned all the sites. The activation energy for the unimolecular decomposition is $41.2 \mathrm{kcal}$ mole $\mathrm{e}^{-1}$ and the preexponential factor is $1.3 \times 10^{12} \mathrm{sec}^{-1}$. If the hydroxyl radical does react with a further perchloric acid molecule the preexponential factor is then $6.5 \times 10^{11}$ $\sec ^{-1}$

A curvea Àrrhenius plot was obtained for the decomposition in the annealed Reaction Vessel I. This could be anaiysed to obtain the Arrhenius panameters for the two separate reactions as was mentioned in section 3.1 ; however, the errors in these values could be significant. Owing to a technical problem in the computer analysis it was not possible to calculate these exrors. If the Arrhenius parameters obtained for the unimolecular decomposition in Reaction Vessel II were used an activation energy of $15.1 \mathrm{kcal}$ mole $\mathrm{e}^{-1}$ and a preexponential factor of $5.6 \times 10^{4} \mathrm{sec}^{-1}$ yere obtained for the heterogeneous reaction.

Only three rate constants were obtained for the aged reaction vessel and so it is difficult to decide whether both the Arrhenius parameters for the heterogeneous decomposition had changed on just one. It is also possible that the parameters were not constant for the three rate constants. Is the activation energy hed remained constant a about $15 \mathrm{kcal} \mathrm{nole-1}$, this woula 
correspond to a preexponential factor of $2.0 \times 10^{4} \mathrm{sec}^{-1}$ which would suggest that about $65 \%$ of the sites had become poisoned.

The results obtained when this reaction vessel was then packed, suggest that the glass wool packing was essentially inert and possessed few if any suitable decomposition sites. The variations in the rate constant are presumably due to a further ageing of the pyrex surface which initially decreased the heterogeneous reaction at $286^{\circ} \mathrm{C}$ but then increased it at $366^{\circ} \mathrm{C}$.

Washing Reaction VesseJ. I increased the heterogeneous reaction. Due to the effect of self-heaing it is not possible to make any quantitative conclusions; however, at the higher temperatures the rate constants agree quite closely with those obtained in Reaction Vessel II demonstrating that the uninolecular decomposition predominates at high temperatures.

When this Reaction Vessel was then packed with glass wool, a curved Arrhenius plot was obtained. Again it seems probable that the glass wool is inert and that the decrease in rate is dus to an ageing of the washed surface. This can be analysed in a similar way to the annealed vessel and an activation energy of $15.4 \mathrm{kcal}$ mole $\mathrm{k}^{-1}$ and a preexponential factor of $1.4 \times 10^{5} \mathrm{sec}^{-1}$ were obtained. The washed reaction vessi therefore had two and a half times as many sibes as the annealed vegsel. As the sur- 
face area was the same, this means that the concentration of sur:ace sites had increased by a factor of two and a hal.

Tinree rate constants were obtained using Reaction Vessel III, but only one of these was in the annealed reaction vessel. The rate constant obtained at $366^{\circ} \mathrm{C}$ for the decomposition in the annealed vessel was the same as that obtained in the anneaied Reaction Vessel $I$. The surface area of Reaction Vessel III is about 90\% of the area of Reaction Viessei I, and so provided the activation energy is still the same this corresponds to approximately the same concentration of sites.

Coating the reaction vessel at $366^{\circ} \mathrm{C}$ increased the rate by a factor of two. This suggests that the decomposition on boric acid has a lower activation energy than on pyrex and that the concentration of sites is probably increased. At $416^{\circ} \mathrm{C}$, the rate constant agrees with the value obtained in Reaction Vessel II and so the heterogeneous contribution to the decomposition is small, as expected.

It is not possible to draw any quantitative conclusions on the decomposition of perchloric acid in Reaction Vessei IV, where sigmoid shaped decomposition curves were observed. It is clear that the heterogeneous reaction was very important in these cases. This is presumabiy associated with the contamination of the surface. 
Three rate constants were obtained for the decomposition in the annealed vessel. The two values obtained in the high temperature region demonstrate that at these temperatures only the unimolecular decomposition is inportant. The rate constant obtained at $366^{\circ} \mathrm{C}$ is onj a little higher than the value obtained in the annealed Raction Vessel $I$. The surface area is about $70 \%$ of the suriace area c: Eeaction Vessel I. This means that provided the activation is unchanged, the concentration of sites is only slightIy higher than on the annealed Reaction Vessel I.

\section{Simple Chain Model}

In practice, it is often very difficult to distinguish between a unimolecular decomposition and a chain reaction. Chain reactions are involved in perchloric acia. flames and there is a strong possibility that the normal aecomposition involves a chain mechaisism. This may explain the deviations from first order kinetics observed at high conversions, which cannot be expiained cn the first model. The simple model also requirea a number of rather special and perhaps arbitrary assumptions to explain the surface effects; however, a chain model may offer a more realistio explanation.

Unfortunately there is 1 thie infomation on the possom ible reactions involved and this makes it diffjoult to be sure about a mechanism. Chain reactions in general cosist of an initiation reaction, propagation reaction and a 
termination reaction. The most likely chain carrier would appear to be the clo radical since it has the necessary stability (in contrast to chlorine dioxide, chlorine trioxide and chlorine tetroxide) and might be expected to be an efficient hydrogen abstraction agent. It has been suggested 31 as the probable chain carrier in perchloric acid flames. The following mechanism was therefore proposed,

$$
\begin{gathered}
\mathrm{FClO}_{4} \stackrel{\mathrm{k}_{1}}{\longrightarrow} \mathrm{ClO}+\mathrm{O}_{2}+\mathrm{OH} \\
\mathrm{HClO}_{4} \stackrel{\mathrm{k}_{1}}{\longrightarrow} \mathrm{ClO}+\mathrm{O}_{2}+\mathrm{OH} \\
\mathrm{ClO}+\mathrm{HClO}_{4} \stackrel{\mathrm{k}_{2}}{\longrightarrow} \mathrm{ClOH}+\mathrm{O}_{2}+\mathrm{ClO}_{2} \\
\mathrm{CHClO}
\end{gathered}
$$

The significance of two very recent reports? ${ }^{7677}$ on the reactivities of both perchloric acid and the CiO radical will be considered later.

Whe above reactions are not necessarily simple reaction steps, anci tif they are not then the rate constant may contain the rate constants for the several steps which are involved. As surface effects are obviously importent, a gas phase and a heterogeneous initiation 
reaction, 4.12 and 4:13; are included. The enthalpy change for these reactions is $\Delta \mathrm{H}=+48.3 \mathrm{kcal} \mathrm{mole}{ }^{-1}$. As the $\mathrm{CIO}$ radical is the proposed chain carrier, equations 4.14 and 4.15 represent the propagation reactions. The enthalpy changes for these: reactions are $\Delta H=-18.9 \mathrm{kcal}$ mole $\mathrm{k}^{-1}$ and $\Delta \mathrm{H}=+12.9 \mathrm{kcal}$ mole $\mathrm{e}^{-1}$, respectively. The termination reaction, 4.15 , is the recombination of the $\mathrm{ClO}$ radicals and involves an enthalpy change of $\Delta H=-48.4 \mathrm{kcal} \mathrm{mole^{-i }}$. The mode in which any of the other intermediates are removed will not affect the kinetics unless they consume perchloric acid.

On this model the rate of perchloric acid decomposition is given by

$$
\begin{gathered}
-\frac{a\left(\mathrm{HClO}_{4}\right)}{a t}=\mathrm{k}^{\prime}\left(\mathrm{HClO}_{4}\right)-\mathrm{k}_{2}(\mathrm{CIO})\left(\mathrm{HClO}_{4}\right)+ \\
2 \mathrm{k}_{3}(\mathrm{HOCl})\left(\mathrm{HClO}_{4}\right)
\end{gathered}
$$

where $\mathrm{k}^{\prime}=\mathrm{k}_{1}+\mathrm{k}_{1}^{\prime}$. If the $\mathrm{ClO}$ radicals and the hypochlorous acid molecules are in their steady state concentrations, the rate becomes

$$
\begin{aligned}
-\frac{a\left(\mathrm{HClO}_{4}\right)}{a t}= & \left.k^{\prime}\left(\mathrm{HClO}_{4}\right)+\frac{\mathrm{k}_{2}^{2}}{2 \mathrm{k}_{4}}(\mathrm{HC}] \mathrm{O}_{4}\right)^{2}[1+ \\
& \left.\left(1+\frac{8 \mathrm{k}_{1} \mathrm{k}_{4}}{\mathrm{k}_{2}^{2}\left(\mathrm{HClO}_{4}\right)}\right)^{1 / 2}\right]
\end{aligned}
$$

If the hydrongl radical attacks a second perchloric acia 
molecule by reaction 4.8 , then $\mathrm{k}^{\prime}$ must be replaced by $2 \mathrm{k}^{\prime}$ in the above equation.

If the first term in equation 4.19 is dominant, then the overall rate of decomposition will be basically first oraer but modified by the second term. This might explain the deviations observed at high conversions.

The Arrhenius parameters for reaction 4.14 have not been determined; however it is useful to see the efiect of usins estimated values. In the annealed Reaction Vessel $I$ at $350^{\circ} \mathrm{C}, \mathrm{k}^{\prime}$ is approximately $10^{-?} \mathrm{sec}^{-1}$; the value of $k_{4}$ has been Eiven by clyne 77 as $10^{11.89} \exp ($ $-2,300 / \mathrm{RT}) \mathrm{cm}^{3}$ mole $\mathrm{sec}^{-1}$ so that at $350^{\circ} \mathrm{C}, \mathrm{k}_{4}$ is approximately $10^{11} \mathrm{~cm}^{3}$ mole $\mathrm{sec}^{-1}$. The initial perchloric acid concentration was $2 \times 10^{-4}$ mole litre ${ }^{-1}$. Bimolecular reactions usually have preexponential factors of about $10^{12}$ $\mathrm{cm}^{3}$ mole $\mathrm{sec}^{-1}$ and so if reaction 4.14 does not require an activation energy then $k_{2}$ will be approximately $10^{12}$ $\mathrm{cm}^{3} \mathrm{~mole}^{-1} \mathrm{sec}^{-1}$.

For these values, the rate equation reduces to

$$
-\frac{a\left(\mathrm{iCIO}_{4}\right)}{d t}=\mathrm{k}\left(\mathrm{NOIO}_{4}\right)+\frac{\mathrm{k}_{2}^{2}}{\mathrm{k}_{4}}\left(\mathrm{NCIO}_{4}\right)^{2} \quad(4.20
$$

and the sccond term is muci larger than the first. This means that the decomposition would be basically second order which is not the case. If reaction 4.14 has an activation enerey of approx- 
imatcly 15 kcal mole $e^{-1}$ or more, the rate equation becomes

$$
-\frac{\mathrm{a}\left(\mathrm{IIClO} \mathrm{O}_{4}\right)}{\mathrm{dt}}=\mathrm{k}^{\prime}\left(\mathrm{HCIO} \mathrm{O}_{4}\right)+\left(\frac{2 \mathrm{k}^{\prime}}{\mathrm{k}_{4}}\right)^{1 / 2} \mathrm{k}_{2}\left(\mathrm{HClO}_{4}\right)^{3 / 2}(4.21
$$

where the second term is less than 1; of the first term at $t=0$ for the above choice of the activation energy. As the concentration of perchioric acid decreases, the approximation to first oraer kinetics improves so that departures from first order beiaviour cannot be explained if the above conaition on $k_{2}$ is satisfied.

Also as the only heterogeneous rate constant in equation 4.19 is $k_{1}^{\prime}$, which is contained in $k^{\prime}$, this simple chain model offers no alternative explanation for the variation of the observed first order rate constants under different surface conditions. It thus suffers from the same disadvantages as the first model at the cost of added complexity.

Complex Chain Hodel

The simple chain mechanism which was considered, could not provide an alternative explanation of the surface effccts because only one heterogeneous reaction was involved. In this complex chain model, as vell as the steps proposer in the simple chain model, that is reactions 4.12 to 4.17 , the folloring heteroceneous termination reaction will be consiaered,

$$
\text { cic } \stackrel{n_{5}}{-} \rightarrow 1 / 2 \mathrm{Cl}_{2}+1 / 2 \mathrm{O}_{2} \quad \text { (4.22 }
$$


The overall enthalpy change for this reaction is $\Delta H=-24.2 \mathrm{kcal}$ mole $\mathrm{e}^{-1}$.

The rate or perchloric acia deccmposition is given by equation 4.18 but the expressions for the steady state concentrations of the intermediates are changed.

If reaction 4.22 was the only termination reaction, the rate equation is

$$
-\frac{d\left(\mathrm{HClO}_{4}\right)}{d t}=\mathrm{k}^{\prime}\left(\mathrm{HClO}_{4}\right)+\frac{2 \mathrm{k}^{\prime} \mathrm{k}_{2}\left(\mathrm{HClO}_{4}\right)^{2}}{k_{5}-\mathrm{k}_{2}\left(\mathrm{HClO}_{4}\right)}
$$

For probable values of the unknown rate constants, this becomes,

$$
-\frac{\mathrm{d}\left(\mathrm{BClO}_{4}\right)}{d t}=\mathrm{k}^{\prime}\left(\mathrm{HClO}_{4}\right)+\frac{2 \mathrm{k}^{\mathrm{i}} \mathrm{k}_{2}}{\mathrm{k}_{5}}\left(\mathrm{HClO}_{4}\right)^{2} \quad(4.24
$$

This model cannot therefore explain the deviations from first order kinetics at high conversions nor provide an alternative explanation of the surface effects.

If both termination reactions ara considered, the following rate equation results,

$$
\begin{aligned}
-\frac{a\left(\mathrm{HCIO}_{4}\right)}{d t}= & k^{\prime}\left(\mathrm{HClO}_{4}\right)+\frac{\mathrm{k}_{2}\left(\mathrm{HClO}_{4}\right)\left[\mathrm{k}_{2}\left(\mathrm{HCIO}_{4}\right)-\mathrm{k}_{5}\right]}{2 \mathrm{k}_{4}} \\
& {\left[1+\left(1+\frac{8 \mathrm{k}^{\prime} \mathrm{k}_{4}\left(\mathrm{HClO}_{4}\right)}{\left(\mathrm{k}_{2}\left(\mathrm{HCIO}_{4}\right)-\mathrm{k}_{5}\right)^{2}}\right)^{\not / 2}\right](4.25}
\end{aligned}
$$


Tibis rate equation is complex and as the Axrhenius parameters for both $k_{2}$ and $k_{5}$ are unknown, it is difficult to apply. However, using the values for the known rate constants at $350^{\circ} \mathrm{C}$ in the annealed Reaction Vessel $I$ and roughly estimating the unknown values, the rate equation reduces to,

$$
\begin{aligned}
-\frac{a\left(\mathrm{HCIO}_{4}\right)}{\mathrm{dt}}= & \left(\mathrm{k}^{\prime}-\frac{\mathrm{k}_{2} \mathrm{k}_{5}}{\mathrm{k}_{4}}\right)\left(\mathrm{HClO}_{4}\right)+ \\
& \frac{\mathrm{k}_{2}^{2}}{\mathrm{k}_{4}}\left(\mathrm{HClO}_{4}\right)^{2}
\end{aligned}
$$

This rate equation also cannot explain the deviations observed at high conversions and the second order term must be negligible. However, an alternative explanation of the surface effects is suggested. The observed first order rate constant now contains two heterogeneous rate constants, $k_{5}$ and $k_{1}^{\prime}$, which is included in $k^{\prime}$. Increasing the surface, increases not only $k_{1}^{\prime}$ but $k_{5}$. It is therefore the difference in these effects which controls the change in rate. The rate may either increase or decrease depending on the relative magnitudes of these two effects. As nearly all experiments on packing reaction vessels resulted in a decrease in rate it would suggest that the heterogeneous termination is the most sensitive to area. However it is clear that ageing effects do occur and so perhaps both effects are involved. 
No ettempt was made to analyse the Arrhenius plots in terms of this model in view of the large number of unknown parameters involved. If $k_{5}$ and $k_{1}^{\prime}$ were zero at all temperatures, then the Arrhenius plot for the first order rate constants would be linear and if $k_{5}$ was zero at all temperatures the Arrhenius plot would be gently curvea as in the simple model. If $k_{5}$ was finite this would result in a decrease in the rate constant but it is difficult to estimate whether this would be clearly observable in the Arrhenius plot.

The anaiysis into two first order reactions which was possible for the decomposition in the annealed Reaction Yessel I might suggest that

$$
\begin{aligned}
& E_{1}^{\prime}=E_{5}+E_{2}-E_{4}=15 \mathrm{kcal} \mathrm{mole} \mathrm{ka}^{-1} \\
& A_{1}^{\prime}-\left(A_{5} A_{2}\right) / A_{4}=5.6 \times 10^{4} \mathrm{~min}^{-1} .
\end{aligned}
$$

However as both $A_{1}^{\prime}$ and $A_{5}$ should be proportional to the surface area, it would mean that the overall preexponential factor should be proportional to the surface area. This was not observed experimentally. This may mean that the two exponentials are not the same end that the analysis into two first order reactions is cnly an approximation to the true analysis into the equivalent of three first order reactions. Unfortunately it was not possible to extend the temperature range to ever lower temperatures which might havo revealed this effect. An alternative 
explanation maj be that the surface ageing effects mask this effect.

The possibility therefore exists that the decomposition of perchloric acid involves a chain mechanism, which has both heterogeneous and homogeneous initiation and termination reactions. However, the absence of Arrhenius parsmeters for reactions 4.14 and 4.22 makes it difficuit to draw more definite conclusions regarding the mechanism. 4.2 Decomposition of Perchloric Acid in the Presence or Added Catalysts

The five Harshaw catalysts, which were used, all catalysed the decomposition of perchloric acid, These included Cu-0203, whose effectiveness as an AP catalJst is utilised in certain rocket propellants, and Al-0104 which is known to have no effect on the decomposition of AP. While there has been no previous investigation of the catalytic effect of Cu-0803, Fe-0301 and Mn-0201 on the decomposition of AP, a number of preiiminary experiments using a Perkin-Elmer Differential Scanning Calorimeter DSC-1B demonstrated that all three were positive cataljsts. The trensition metal oxides which are contained in these catalysts, namely cupric oxide, ferric oxide and manganese dioxide are also known to be AP catalysts 1 .

The stoichiometry of the decomposition corresponded to equation 4.1. The calculated hydrogen chloride vields 
were sionfificently less than in the uncatalysed decompo-. sition and were generally either very sinall or zero. Under the experimental conditions used, the decomposition of perchloric acid was clearly first order on all the catalysts, except Mn-0201. It is probable that the sigmoid shaped decomposition curves, obtained on Mn-0201 do not reflect a complex mechanism, but are a consequence of self-heating. Min-0201 was a very effective catalyst and as such the heat evolution could exceed the heat loss. The decomposition of perchloric acid on Mn-0201 may also therefore be first order. At the temperatures used, the homogeneous decomposition and the heterogeneous decomposition on pyrex were negligible in comparison to the observed decomposition. The simplest explanation of the first order kinetica is in terms of a Langmuir-Hinshelwood model, in which the perchloric acid is decomposing on active sites, which are sparsely populated. If it had been technically possible to increase the perchloric acid concentration sufficiently, the decomposition would presumably have become zero order.

The apparent activation enerso obtained from the first order rate constants in a Langmuir-Hinshelwood system, is the sum of the activation energy for the susiace reaction and the heat of adsorption of the reactant on the surface. Therefore, the apparent ectivation energies which are given in Table 19, represent the smallest 
values possible for the true surface reaction. The heats of adsorption may be expected to be at least 10 to 15 keal mole $e^{-1}$.

At $170^{\circ} \mathrm{C}, \mathrm{Fe}-0301$ is the most effective catalyst in the decomposition of perchloric acid; the order of decreasing specific rate being $\mathrm{Fe}-0301>\mathrm{Al}-0104>\mathrm{Cu}-0803 \sim \mathrm{Cu}-0203$. At $250^{\circ} \mathrm{C}$, the order is practically reversed with $\mathrm{Cu}-0203$ ) $\mathrm{Cu}-0803>\mathrm{Fe}-0301>\mathrm{Al}-0104$.

While it is clear that there is no simple correlation between the activity of a catalyst for the decomposition of perchloric acid and its activity for the decomposition of $\mathrm{AP}$, it is worth noting that $\mathrm{Cu}-0203$ has very little effect on the low temperature AP decomposition but considerably accelerates the high temperature decomposition ${ }^{\text {. }}$ The reversal in the order of activity between 170 and $250^{\circ} \mathrm{C}$ is caused by the different activation energies which are observed on the different catalysts. These range from 28 to $54 \mathrm{kcal}$ mole -1 and in order of decreasing activation energy correspond to $\mathrm{Cu}-0203>\mathrm{Cu}-0803>\mathrm{Al}-0104 \sim \mathrm{Fe}-0301$. Such a wide range of activation energies would nomally lead to very large differences in the specific rates observed on different catalysts, however this is compensated for by a similar variation in the values of the preexponential factors. A plot of apparent activation energy against logarithm of the specific preexponential factor is shown in Fig. 26. This is a straight line and 
the apparent activation energy in kcal mole $e^{-1}$ and the specific preexponential factor in $\min ^{-1} \mathrm{~m}^{-2}$ are related by the equation,

$$
E=2.1 \log _{10} \dot{A}+7.7
$$

Compensation effects have been observed in many invesigations of heterogeneous catalysis, however as yet there does not appear to be a universally applicable explanation of its occurrence. As the specific preexponential factor contains terms involving the entropy of activation and also the concentration of active sites, it would appear that one or both of these terms is related to the activation energy.

In view of the large activation energy observed for the ascomposition of perchloric acid on $\mathrm{Cu}-0203$, it is probable that this contains an energy of formation of the active sites. This would occur if the concentration of sites increased exponentially with temperature. This may also be the case with the other catalysts.

Chemical reaction between the perchloric acid and catalyst was observed for $\mathrm{Cu}-0203$ and $\mathrm{Cu}-0803$, and this may in part be responsible for the observed conditioning periods before a constant activity tas observed. Mhe colour change observed in $\mathrm{Cu}-0203$ corresponds to the oxidation of $C x^{I I I}$ to $C r^{V I}$ and $C r^{V I I}$ while the coloux change in cu-0803 is probably due to the formation of the 
chloride, although only a weak positive chloride test was observed. There was no visible change in the case of Min-0201, Fe-0301 and Al-0104 although a conditioning period was observed for Fe-0301.

4.3 Reaction of Perchloric Acid with Fuels

While it was possible to make only a preliminary study of the reaction of perchioric acid with rarious fuels, a number of interesting observations were made. Perchloric acid appears to react in a similar manner with the different hydrocarbon fuels, but the reaction with hgdrogen appears to be quite different.

The stoichiometry of the reaction of perchloric acid with hyarogen is,

$$
4 \mathrm{H}_{2}+\mathrm{HCIO}_{4} \longrightarrow \mathrm{HCl}+4 \mathrm{H}_{2} \mathrm{O}
$$

and the enthalpy change is $\Delta H=-250.9 \mathrm{kcal} \mathrm{mole}-1$. The reaction was observed at temperatures well below the decomposition temperature of the perchloric acid alone and it is clear therefore, that direct reaction between hydrogen and perchloric acid occurs. The ageing effect observea at $146^{\circ} \mathrm{C}$ illustrates that, at least at low temperatures, this direct reaction is heterogeneous. The subsequent fast reactions of the primary products may also be heterogeneous but in viev of their reactive nature they probably react mainly in the gas phase. The following mechanism is sugeested, 


$$
\begin{aligned}
& \mathrm{HClO}_{4}+\mathrm{H}_{2} \longrightarrow \mathrm{H}_{2} \mathrm{O}+\mathrm{ClO}_{2}+\mathrm{OH} \\
& \mathrm{OH}+\mathrm{H}_{2} \longrightarrow \mathrm{H}_{2} \mathrm{O}+\mathrm{H} \\
& \mathrm{H}+\mathrm{ClO}_{2} \longrightarrow \mathrm{OH}+\mathrm{ClO} \\
& \mathrm{H}+\mathrm{ClO} \longrightarrow \mathrm{OH}+\mathrm{Cl}(4.28 \\
& \mathrm{Cl}+\mathrm{H}_{2} \longrightarrow \mathrm{HCl}+\mathrm{H}
\end{aligned}
$$

All the above equations refer to reactions which are thermodynamically feasible.

By analogy with the reaction of hydrogen and oxygen, an alternative mechanism may be proposed,

$$
\begin{gathered}
\mathrm{H}_{2}+\mathrm{S} \longrightarrow \mathrm{SH}+\mathrm{H} \\
\mathrm{H}+\mathrm{HClO}_{4} \longrightarrow \mathrm{H}_{2} \mathrm{O}+\mathrm{ClO}_{2}+\mathrm{O}_{2}
\end{gathered}
$$

where $S$ represents the surface. However, this mechanism seems unlikely as oxygen was not observed as a major product. Also, Clyne ${ }^{76}$ has very recently reported that in a discharge-ilow system, no reaction between hydrogen atoms and perchloric acid could be observed at $500 \mathrm{~K}$. It would appear that in this study the walls of the reaction vessel were covered by recombining hydrogen atoms, preventing the adsorption of perchloric acid, necessary for reaction 4.28 .

The reaction of perchloric acid with the hydrocarbon fuels was only observed under conaitions in which the 
perchloric acid decomposes alone. It therefore appears that no direct reaction between the perchloric acid and the fuel occurs, but that the fuel reacts with the decomposition intermediates of perchloric acid. At $417^{\circ} \mathrm{C}$, the decomposition of perchloric is basically unimolecular aud about 50 to 55\% decomposition would be expected after $0.1 \mathrm{~min}$. In the presence of methane, the percentage aecomposition calculated in the normal way from the rolumetric analysis results, was 50\%. The values, when ethane and ethylene were usec, were 26 and $63 \%$, IEspectively = It might appear that ethane reduces the anount of decomposition and that einylene increases it, but it is more likely that the discrepancy reflects the failure of the volumetric analysis to give the true extent of decomposition. A low value of the calculated percentage decomposition would result from the formation of chlorine compounds in which the chlorine was not ionizable and high values would result from the formation of other products, besides hydrogen chloride, which consume sodium hydroxide. While the experimental errors in this series of experiments were larger than in the other work, owing to the difficulty of maintaining a constant residence time, it is clear that chlorinated organic compounds are formed when perchloric acid decomposes in the presence of ethane. This would explain the formation of os droplets in the sodium hydroxide trag. The oils formed in the presence of ethylere 
probably include addition compounds, rather than chlorine compounds. If it is assumed that the hyarocarbon fuel does not aifect the extent of decomposition, it would appear that at $417^{\circ} \mathrm{C}$, approximataly 1.5 moles of carbon monoxide are produced for every mole of perchloric acid decomposed, for residence times of 0.11 and $0.4 \mathrm{~min}$. For ethane, the amount of carbon monoxide is 0.3 moles at $0.1 \mathrm{~min}$ and 1.3 moles at 0.2 min and for ethylene, it is 5 moles at 0.1 min. The number of moles of oxygen which is apparently produced for every mole of acid decomposed is probably an artifact, in view of the fuel-rich systems studied. The apparent oxyger yields probably arose from an incomplete flushing of the flow system with helium, after the sodium hydroxide trap was replaced.

4.4 Conclusions

Three reaction mechanisms were considered for the decomposition of perchloric acid in pyrex reaction vessels. It was seen that the results could be explained in terms of a parallel unimolecular gas phase reaction and a first order heterogeneous reaction, and also in terms of a chain reaction involving both heterogeneous and homogeneous initiation and termination reactions. The rirst model required ruther special assumpticns about the activities of the different surfaces while the chain mechanism offered a more realistic explanetion of the surface effects. IIowever, the chain mechanism contained too many unknown 
parameters, which make a quantitative treatment impossible. clyno 76,77 has very recently reported that the clo radical is apparently quite unreactive. No reaction could be observed with nitrous oxide or carbon monoxide and only a very slow reaction with hydrogen and methane was observed even at $587 \mathrm{~K}$. He also found that perchloric acid had a low kinetic reactivity at temperatures near $500 \mathrm{~K}$ in respect to its reaction with free atoms. It would therefore appear that reaction 4.14 would be very slow. The simple model, not involving a chain reaction therefore appears to be the most probable.

However, it is clear that, whether chain steps are important or not, above approximately $400^{\circ} \mathrm{C}$ the decomposition is essentially unimolecular. The activation energy for this is $41.2 \mathrm{kcal} \mathrm{mol} \mathrm{e}^{-1}$ and the preexponential factor is $1.3 \times 10^{12} \mathrm{sec}^{-1}$. The preexponential factor lies within the accepted range for a unimolecular reaction. The activation energy is $7.1 \mathrm{kcal}$ mol. $\mathrm{e}^{-1}$ below the calculated $\mathrm{HO}_{-} \mathrm{ClO}_{3}$ bond energy of $48.3 \mathrm{kcal}$ mole $\mathrm{e}^{-1}$. In vien of the preliminary nature of the previous studies ${ }^{10,20}$. this value is to be preferred, however it is not clear why it is $7 \mathrm{kcal}$ mole $\mathrm{e}^{-1}$ below the bond energy.

If the unimolecular decomposition yas occurring at its low pressure limit, then the activation energy should be 48.3 - SRT kcal mole-1 where $s$ is the effective number of degrees of fretam. On Slater's theory this is half 
the total number of degrees of freedom and this theory would thus predict a value for the activation energy of approximately $4 \uparrow \mathrm{hcal}$ mole $\mathrm{i}^{-1}$ at a mean temperature of $600 \mathrm{~K}$. However, while the perchloric acid pressure is only a few torr, the total pressure of the system is atmospheric and the high pressure limit should be the one concerned. In that case it is difficult to understand an activation energy substantially less than the bond energy. In the decomposition of perchloric acid in the presence of methane and ethylene, there did not appear to be dramatic change in rate. This suggests that either the reaction

$$
\mathrm{OH}+\mathrm{HClO}_{4} \longrightarrow \mathrm{H}_{2} \mathrm{O}+\mathrm{ClO}_{4}
$$

is very fast and so the hydroxyl radical concentration is not affected by reactions with organic radicals or that this reaction does not occur in the normal decomposition. The hydroxyl radical may react with chlorine oxide intermediates.

If the low temperature reaction represents simply a heterogeneous reaction of the Langeuir-Hinshelwood type, then the reaction on pyrex has an activation energy of $15 \mathrm{kcal}$ mole $\mathrm{e}^{-1}$ and probably a value even less on boric acia. The concentration of the active sites is very sensitive to pre-treating and ageing the surface. The decomposition of perchloric acid can be cata- 
$17 s e d$ by a number of Harshaw catalysts, however it is clear that there is no simple relationship between the activities of a catalyst in the perchloric acid decomposition and the AP decomposition, as alumina is a positive catalyst for the decomposition of perchloric acid but has no effect on the decomposition of AP. However, the strong catalytic effect of $\mathrm{Cu}-0203$ on the high temperature decomposition of AP is probably due to the enhanced decomposition of the primary product perchloric acid on the catalyst surface. Both decompositions, have high activation energies in the region of $50 \mathrm{kcal}$ mole $\mathrm{k}^{-1}$. It would be interesting to extend this study, by concentrating on the two catalysts $\mathrm{Cu}-0203$ and Al-0104. The former, while of more technical interest, has the inconvenience of nonconstant activity; the latter appears to remain constant indefinitely. By selecting a smaller sample it may be possible to observe the change in kinetics from first order to zero order, and this would enable the heat of adsorption and the activation energy of the true surface reaction to be found. In practice, this may prove difficult, for a smaller sample size requires a higher temperature to give observable decomposition and the gas phase decomposition mag become significant.

Perchloric a:id reacts with hydrogen heterogeneously on pyrex and an inability to produce reproducible surfaces may make a systenatic study of this reaction difficult. 
The reaction of perchloric acid with hydrocarbon fuels appears to involve only the reactisil of decomposition intermediates with the fuel. Probably a systematic study of these reactions would throw more light on the decomposition. Proviajed a constant surface could be used, a study of the reaction at low temperatures may prove whether a chain mechanism is involved in the decomposition. Such a study presents many analytical probiems, however by using smaller concentrations of fuel, it should be possible to measure the amount of fuel consumed which rould be a useful parameter. This also allows the fuel concentration to be varied without affecting the perchloric acid concentration. As there is no direct reaction between the fuel and perchloric acia, the problem of ensuring complete mixing in the reaction vessel can be overcome by pre-mixing at temperatures below the reaction temperature.

Until such a systematic study has been made, it would appear difficult to rule out the possibility of a chain mechanism being important in the thermal decomposition of perchloric acid. 


\section{TABIE 1}

CATAIYST PARAMETERS

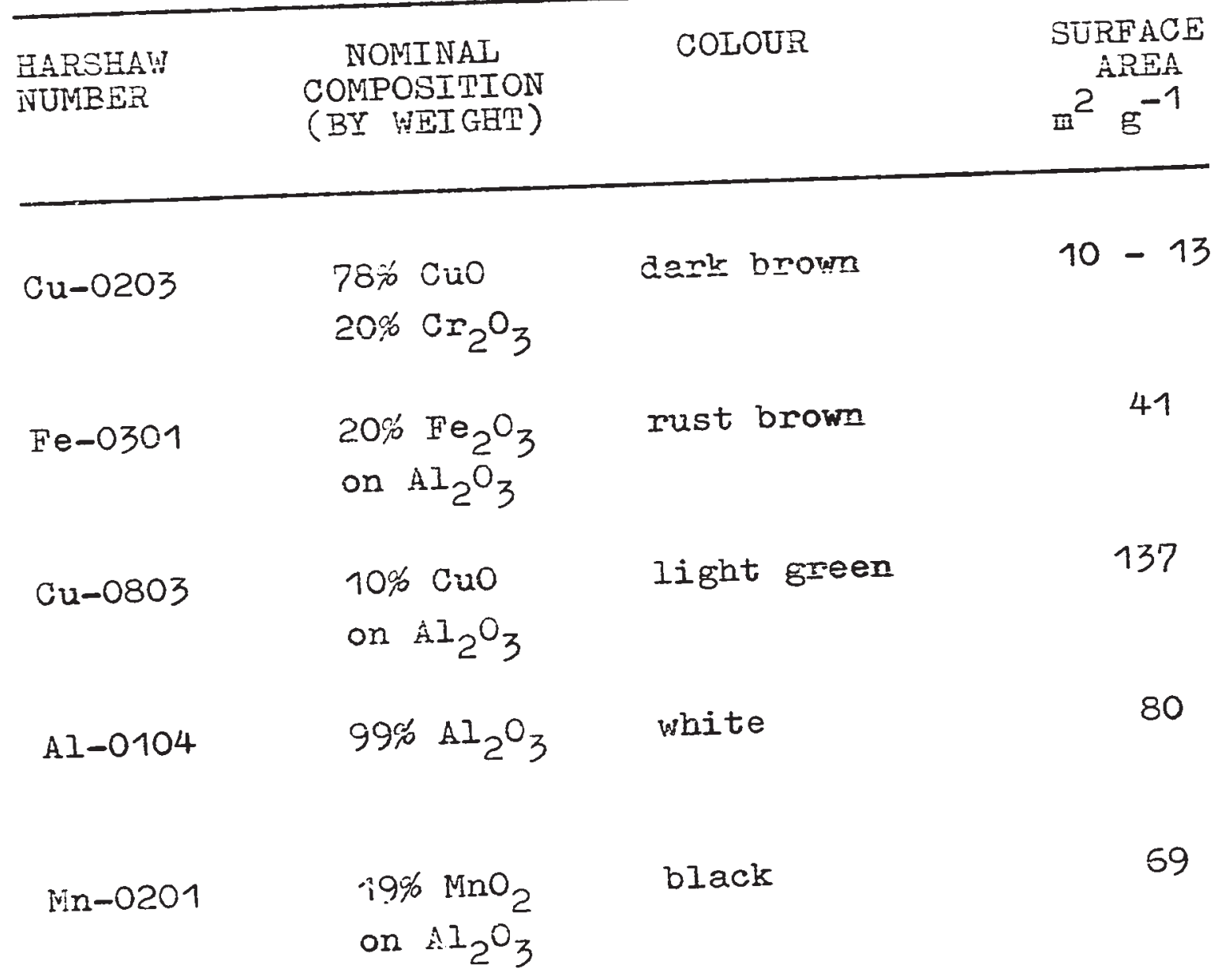


TABIE 2

REACTION VESSEL PARAFETERS

\begin{tabular}{|c|c|c|c|c|}
\hline $\begin{array}{l}\text { REACTION } \\
\text { VESSEI }\end{array}$ & $\begin{array}{c}\text { BODY } \\
\text { VOLUIIE } \\
\text { ml }\end{array}$ & $\begin{array}{c}\text { PREHEAT } \\
\text { VOLUME } \\
\mathrm{ml}\end{array}$ & $\begin{array}{c}\text { BODY } \\
\text { SURFACE } \\
\mathrm{cm}^{2}\end{array}$ & $\begin{array}{c}\text { PREHEAT } \\
\text { SURFACE } \\
\text { cMI }^{2}\end{array}$ \\
\hline$I$ & 110 & 25 & 160 & 167 \\
\hline II & 56 & 14.5 & 115 & 97 \\
\hline III & 80 & 13 & 140 & 87 \\
\hline IV & 25 & - & 110 & - \\
\hline
\end{tabular}




\section{TABLE 3}

FIRST ORDER RATE CONSTANTS FOR DECOMPOSITION ANNEALED REACTION VESSEL I

\begin{tabular}{|c|c|c|c|c|}
\hline RUN & $\begin{array}{c}\text { TEMP. } \\
{ }^{\circ} \mathrm{C}\end{array}$ & $\begin{array}{c}10^{3} / \mathrm{T} \\
\mathrm{K}^{-1}\end{array}$ & $\min ^{-1}$ & $\mathrm{IOG}_{10} \mathrm{~K}$ \\
\hline 1 & 335.8 & 1.642 & 0.334 & 7.524 \\
\hline 2 & 354.9 & 1.592 & 0.633 & 7.802 \\
\hline 3 & 369.9 & 1.555 & 1.21 & 0.0835 \\
\hline 4 & 386.1 & 1.517 & 2.42 & 0.384 \\
\hline 5 & 331.3 & 1.654 & 0.276 & 7.462 \\
\hline 6 & 311.6 & 1.710 & 0.155 & 7.192 \\
\hline 7 & 286.0 & 1.788 & 0.0749 & 2.874 \\
\hline 8 & 346.2 & 1.614 & 0.472 & 1.674 \\
\hline 9 & 364.4 & 1.568 & 0.942 & T.974 \\
\hline 10 & 406.0 & 1.472 & 5.53 & 0.743 \\
\hline 11 & 394.6 & 1.497 & 3.32 & 0.521 \\
\hline 12 & 378.6 & 1.534 & 1.75 & 0.243 \\
\hline
\end{tabular}


TABLE 4

PFFECT OF INITIAL ACID CONCENTRATION

ON THE FIRST ORDER RATE COINSTANT

AT $374.4^{\circ} \mathrm{G}$ ANNEALED REACTION VESSEL I

\begin{tabular}{|c|c|c|c|}
\hline $\begin{array}{l}10^{4}{ }^{2} 0 \\
\text { mole }{ }^{1 i t r e}\end{array}$ & $t_{\min }$ & \% DECOMP & $\min ^{-1}$ \\
\hline 4.8 & 0.185 & 25.8 & 1.6 \\
\hline 3.8 & 0.183 & $25 \cdot 1$ & 1.6 \\
\hline 8.6 & 0.173 & 22.0 & 1.4 \\
\hline 14.8 & 0.181 & 24.9 & 1.6 \\
\hline
\end{tabular}




\section{TABIE 5}

FIRST ORDER RATE CONSTANTS FOR DECOMPOSITIONN AGED REACTION VESSEI I

\begin{tabular}{llccc}
\hline RUN & $\begin{array}{c}\text { TEMP. } \\
{ }^{C} \mathrm{C}\end{array}$ & $\begin{array}{c}10^{3} / \mathrm{T} \\
\mathrm{K}^{-1}\end{array}$ & $\begin{array}{c}\mathrm{k} \\
\mathrm{min}^{-1}\end{array}$ & LOG $_{10^{k}}$ \\
\hline 1 & 311.9 & 1.709 & 0.064 & $\overline{2.81}$ \\
2 & 279.3 & 1.810 & 0.037 & $\overline{2} .57$ \\
3 & 348.8 & 1.607 & 0.34 & 7.53
\end{tabular}


TABLE 6

EFFECT OF INITIAI ACID CONCENTRATION

ON THA FIRST ORDER RATE CONSTANT

AT $311.9^{\circ} \mathrm{C}$ AGED REACTION VESSEL I

\begin{tabular}{cccc}
\hline $\begin{array}{l}10^{4} \varepsilon_{0} \\
\text { mole litre }\end{array}$ & $\begin{array}{l}\mathrm{t}_{\mathrm{r}} \\
\mathrm{min}\end{array}$ & \% DECOMP & $\begin{array}{c}\mathrm{k} \\
\mathrm{min}^{-1}\end{array}$ \\
\hline $\begin{array}{l}1.62 \\
6.4\end{array}$ & 9.5 & 0.062 \\
9.5 & 1.74 & 9.9 & 0.060 \\
10.2 & 1.72 & 11.7 & 0.072 \\
4.7 & 1.73 & 10.5 & 0.064 \\
& 1.67 & 10.0 & 0.063
\end{tabular}


TABLE 7

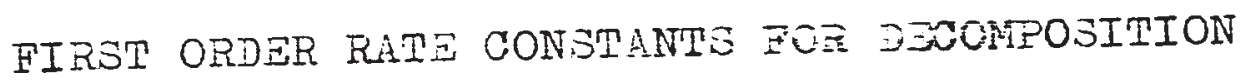

AGED REACTION TESIE⿱一𫝀口 I

PACKED WITH GLESS TCOL

\begin{tabular}{lcccc}
\hline RUN & $\begin{array}{c}\text { TEMP. } \\
{ }^{\circ} \mathrm{C}\end{array}$ & $\begin{array}{c}10^{3} / \mathrm{T} \\
\mathrm{K}^{-1}\end{array}$ & $\begin{array}{c}\mathrm{k} \\
\min ^{-1}\end{array}$ & IOG $_{10} \mathrm{k}$ \\
\hline 1 & 285.7 & 1.789 & 0.025 & 2.40 \\
2 & 358.5 & 1.583 & 0.76 & 7.88
\end{tabular}




\section{TABLE 8}

FIRST ORDER RATE CONSTANTS FOR DECOIPOSITION

WASHED REACTION VESSEL I

\begin{tabular}{lllrl}
\hline RUN & $\begin{array}{c}\text { TEMP. } \\
{ }^{\circ} \mathrm{C}\end{array}$ & $\begin{array}{c}10^{3} / \mathrm{T} \\
\mathrm{K}^{-1}\end{array}$ & $\begin{array}{c}\mathrm{k} \\
\mathrm{min}^{-1}\end{array}$ & $\mathrm{IOG}_{10} \mathrm{k}$ \\
1 & 434.6 & 1.413 & 16.1 & 1.21 \\
2 & 416.3 & 1.450 & 8.41 & 0.93 \\
3 & 400.1 & 1.485 & 4.95 & 0.70
\end{tabular}


TABLE 9

FIRST ORDIR RATE CONSTANTS FOR DECOMPOSITION WASHED REACTION VESGEL I PACKED WITH GLASS WOOL

\begin{tabular}{lllll}
\hline RUN & $\begin{array}{c}\text { TEMP. } \\
{ }^{\circ} \mathrm{C}\end{array}$ & $\begin{array}{c}10^{3} / \mathrm{T} \\
\mathrm{K}^{-1}\end{array}$ & $\begin{array}{c}\mathrm{k} \\
\mathrm{min}^{-1}\end{array}$ & IOG $_{10^{\mathrm{k}}}$ \\
\hline 1 & 364.2 & 1.569 & 1.36 & 0.13 \\
2 & 416.8 & 1.449 & 9.8 & 0.99 \\
3 & 291.1 & 1.772 & 0.17 & 1.24 \\
5 & 322.5 & 1.679 & 0.31 & 1.49 \\
5 & 388.1 & 1.512 & 3.1 & 0.49
\end{tabular}




\section{TABLE 10}

EFFECT OF INITIAI ACID CONCENTRATION

ON THE FIRST ORDER RATE CONSTANT

AT $362^{\circ} \mathrm{C}$ HASHED REACTION VESSEL II

\begin{tabular}{cccc}
\hline $\begin{array}{l}10^{4} a_{0} \\
\text { mole litre }\end{array}$ & $\begin{array}{l}t_{\mathrm{r}} \\
\min \end{array}$ & \% DECOMP & $\begin{array}{c}\mathrm{k} \\
\min ^{-1}\end{array}$ \\
\hline .7 & 0.440 & 20.1 & 0.51 \\
6.5 & 1.15 & 45.3 & 0.53 \\
8.9 & 1.45 & 53.8 & 0.54
\end{tabular}




\section{TABLE 11}

FIRST ORDER RATE CONSTANTS FOR DECOMPOSITION REACTION VESSEL II

\begin{tabular}{|c|c|c|c|c|}
\hline RUUi & $\begin{array}{c}\text { TISMP } \\
{ }^{\circ} \mathrm{C}\end{array}$ & $\begin{array}{c}10^{3} / \mathrm{T} \\
\mathrm{K}^{-1}\end{array}$ & $\min ^{-1}$ & $\mathrm{IOG}_{10^{\mathrm{K}}}$ \\
\hline 1 & 450.2 & 1.382 & 27.6 & 1.44 \\
\hline 2 & 470.9 & 1.344 & 64.5 & 1.81 \\
\hline 3 & 434.1 & 1.414 & 13.4 & 1.13 \\
\hline 4 & 416.0 & 1.451 & 7.25 & 0.361 \\
\hline 5 & 399.5 & 1.487 & 3.13 & 0.496 \\
\hline 6 & 443.9 & 1.395 & 20.7 & 1.32 \\
\hline$?$ & 362.0 & 1.574 & 0.53 & 1.72 \\
\hline 8 & 375.2 & 1.540 & 1.06 & 0.025 \\
\hline
\end{tabular}


TABLE 12

WTFECT OF CARRTER GAS ON THE FIRST ORDER RATE CONSTANT AT THREE TIMPERATURES WASHED REACTION VESSEL II

\begin{tabular}{lllll}
\hline RUN & $\begin{array}{c}\text { TEMP } \\
{ }^{\circ} \mathrm{C}\end{array}$ & $\begin{array}{c}\text { is }\left(\mathrm{iN}_{2}\right) \\
\min ^{-1}\end{array}$ & $\begin{array}{c}\mathrm{k}(\mathrm{ie}) \\
\min ^{-1}\end{array}$ & $\begin{array}{c}k\left(\mathrm{O}_{2}\right) \\
\min ^{-1}\end{array}$ \\
\hline 5 & 399.5 & 3.13 & 3.04 & - \\
6 & 443.9 & 20.7 & 23.1 & - \\
7 & 362.0 & 0.53 & 0.45 & 0.43
\end{tabular}


TABIE 13

FIRST ORDER RATE CONSTANTS FOR DECOMPOSITION REACTION VISSEL III

\begin{tabular}{lcccc}
\hline RUN & $\begin{array}{c}\text { TIMP. } \\
{ }^{\circ} \mathrm{C}\end{array}$ & $\begin{array}{c}10^{3} / \mathrm{T} \\
\mathrm{K}^{-1}\end{array}$ & $\begin{array}{c}\mathrm{k} \\
\mathrm{min}^{-1}\end{array}$ & LOG $_{10} \mathrm{k}$ \\
\hline $\begin{array}{c}\text { UNCOATED } \\
1\end{array}$ & 365.2 & 1.566 & 0.90 & 1.95 \\
$\begin{array}{l}\text { BCRIC ACID } \\
\text { COATED } \\
2\end{array}$ & 365.2 & 1.566 & 1.89 & 0.28 \\
3 & 416.9 & 1.449 & 7.90 & 0.90
\end{tabular}


TABIE 14

FIRST ORDER BATE CONSTANTS FOR DECOHPOSITION ANIEALED REACTION VESSES IV

\begin{tabular}{lcccc}
\hline RUN & $\begin{array}{c}\text { TEMP. } \\
{ }_{\mathrm{C}}\end{array}$ & $\begin{array}{c}10^{3} / \mathrm{T} \\
\mathrm{K}^{-1}\end{array}$ & $\begin{array}{c}\mathrm{k} \\
\mathrm{min}^{-1}\end{array}$ & LOG $_{10^{\mathrm{k}}}$ \\
\hline 1 & 364.7 & 1.568 & 1.06 & 0.025 \\
3 & 416.2 & 1.451 & 8.75 & 0.94 \\
3 & 453.6 & 1.376 & 37.5 & 1.57
\end{tabular}


TABLE 15

FIRGT ORDAR RATE CONGTANTS

CATAIYTIC DECOMPOSIIION ON Cu-0203

\begin{tabular}{|c|c|c|c|c|}
\hline RTIST & $\begin{array}{c}\text { TPMP } \\
{ }^{\circ} \mathrm{C}\end{array}$ & $\begin{array}{c}10^{3} / \mathrm{I} \\
\mathrm{K}^{-1}\end{array}$ & $\min ^{-1} m^{-2}$ & $I^{\prime O G} 10^{k} \mathrm{~s}$ \\
\hline 1 & 206.4 & 2.085 & $1.01 \times 10^{-3}$ & 3.06 \\
\hline 2 & 186.2 & 2.177 & $3.34 \times 10^{-4}$ & 4.52 \\
\hline 3 & $227 \cdot 9$ & 1.996 & $5.9 \times 10^{-2}$ & 2.77 \\
\hline 4 & 238.5 & 1.954 & $2.05 \times 10^{-1}$ & $\pi .32$ \\
\hline 5 & 250.3 & 1.910 & $3.34 \times 10^{-1}$ & $\overline{1} .52$ \\
\hline
\end{tabular}


TABLE 16

FIRST ORDER RATE CONSTANTS

CATAIYTIC DECOMPOSITION ON Fe-0301

\begin{tabular}{|c|c|c|c|c|}
\hline RUN & 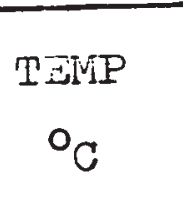 & $\begin{array}{c}10^{3} / \mathrm{T} \\
\mathrm{K}^{-1}\end{array}$ & $\min ^{-1} m^{-2}$ & $\operatorname{IOG}_{10} \mathrm{k}$ \\
\hline 1 & 196.1 & 2.131 & $1.12 \times 10^{-3}$ & 3.05 \\
\hline 2 & 216.7 & 2.041 & $4.46 \times 10^{-3}$ & 3.65 \\
\hline 3 & 238.5 & 1.954 & $1.68 \times 10^{-2}$ & $\overline{2} .23$ \\
\hline 4 & 176.7 & 2.223 & $3.56 \times 10^{-4}$ & 4.55 \\
\hline 5 & 206.5 & 2.085 & $2.17 \times 10^{-3}$ & 3.34 \\
\hline
\end{tabular}


TAETE 17

FIRST ORA RATE CONSTAINS

CAPAIITIC DECCUPOSITION ON AI-0104

\begin{tabular}{|c|c|c|c|c|}
\hline RUIN & $\begin{array}{c}{ }^{\circ} \mathrm{C} \\
\mathrm{Pap}\end{array}$ & $\begin{array}{c}10^{3} \\
\mathrm{~K}^{-1}\end{array}$ & $\min ^{-1} \mathrm{k}_{\mathrm{s}}-2$ & $\mathrm{I} O \mathrm{G}_{10} \mathrm{k}_{\mathrm{s}}$ \\
\hline 1 & 202.0 & 2.104 & $6.99 \times 10^{-4}$ & 4.845 \\
\hline 2 & 222.4 & 2.018 & $2.54 \times 10^{-3}$ & 3.405 \\
\hline 3 & 234.1 & 1.971 & $6.06 \times 10^{-3}$ & 3.783 \\
\hline 4 & 251.3 & 1.907 & $1.20 \times 10^{-2}$ & 2.079 \\
\hline 5 & 176.2 & 2.225 & $1.32 \times 10^{-4}$ & 4.121 \\
\hline
\end{tabular}


TABLE 18

FIRST CRDER RATE CONSTANTS

CATEIYTIC DECOMPOSITION ON Cu-0803

\begin{tabular}{lllll}
\hline RUN & $\begin{array}{c}\text { TEMP } \\
{ }^{\circ} \mathrm{C}\end{array}$ & $\begin{array}{c}10^{3 / \mathrm{T}} \\
\mathrm{K}^{-1}\end{array}$ & $\begin{array}{c}\mathrm{k}_{\mathrm{S}} \\
\mathrm{min}^{-1} \mathrm{~m}^{-2}\end{array}$ & LOG $_{10^{k} \mathrm{~s}}$ \\
\hline 1 & 216.7 & 2.041 & $3.04 \times 10^{-3}$ & $\overline{3} .481$ \\
2 & 238.5 & 1.954 & $2.35 \times 10^{-2}$ & $\overline{2} .372$ \\
3 & 250.0 & 1.911 & $3.70 \times 10^{-2}$ & $\overline{2} .568$ \\
4 & 227.5 & 1.997 & $7.74 \times 10^{-3}$ & 3.888 \\
5 & 206.3 & 2.086 & $1.34 \times 10^{-3}$ & 3.129 \\
6 & 196.0 & 2.131 & $5.88 \times 10^{-4}$ & 4.770
\end{tabular}




\section{跬正 19 \\ ARREFGIUS PARAMIPTERS \\ CATAEYAE DECOMPOSITION}

\begin{tabular}{|c|c|c|}
\hline $\begin{array}{l}\text { HARSHAW } \\
\text { NUMBER }\end{array}$ & 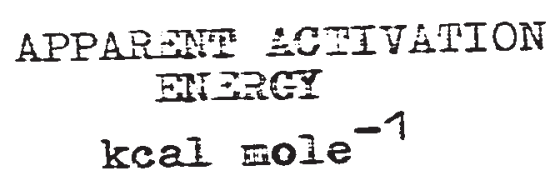 & $\begin{array}{c}\text { SPECIFIC } \\
\text { PREEXPONENII } \\
\min ^{-1} \mathrm{~m}^{-2}\end{array}$ \\
\hline $\mathrm{Cu}-0203$ & 54.0 & $2.5 \times 10^{22}$ \\
\hline $\mathrm{Fe}-0301$ & 28.5 & $2.5 \times 10^{10}$ \\
\hline$A I-0104$ & 28.8 & $1.3 \times 10$ \\
\hline $\mathrm{Cu}-0803$ & 39.0 & $8.0 \times 10$ \\
\hline
\end{tabular}


TABLE 20

GEN ERAI REDULTS FOR HYDROGEN REACTION

IN UNCOATAD REACTION VESSEL III

\begin{tabular}{|c|c|c|c|}
\hline $\begin{array}{c}{ }^{\circ}=M_{\mathrm{C}} \\
{ }^{\circ} \mathrm{C}\end{array}$ & $\begin{array}{c}\text { INITIAL } \mathrm{H}_{2} \\
\text { CONC RANGE } \\
10^{-3} \mathrm{NI}\end{array}$ & $\begin{array}{c}\text { DICONP } \\
\text { RANGE WITH } \\
\mathrm{H}_{2}\end{array}$ & $\begin{array}{c}\text { DECOMP } \\
\text { WITHOUT } \\
\mathrm{H}_{2}\end{array}$ \\
\hline 250.6 & $1.8-11.2$ & $50-90$ & 0 \\
\hline 349.1 & $4.5-11.2$ & $87-90$ & 3.7 \\
\hline 416.9 & $2.2-4.5$ & $94-97$ & 4.3 \\
\hline 453.8 & 4.9 & 99 & 76 \\
\hline 145.5 & $1.4-11.6$ & $30-90$ & 0 \\
\hline 351.9 & 4.5 & 90 & 7.7 \\
\hline
\end{tabular}


TABLE 21

PERCENTAGE DECOMPOSITION FOR A RESIDENCE TIME OF 0.10 MIN AT $146.5^{\circ} \mathrm{C}$

IN UNCOATED REACTION VESSEU III

\begin{tabular}{|c|c|c|}
\hline $\begin{array}{l}\text { INITIAI HCIO } \\
\text { CONCEMTRATION } \\
10^{-4} \mathrm{M}\end{array}$ & $\begin{array}{c}\text { INITIAI } \mathrm{E}_{2} \\
\text { CONCENTRATION } \\
10^{-3} \mathrm{M} /\end{array}$ & \% DECOMP \\
\hline 3.4 & 4.5 & 33.6 \\
\hline 3.3 & 0 & 0 \\
\hline 2.8 & 11.6 & 30.4 \\
\hline 3.6 & 3.4 & 87.9 \\
\hline 3.7 & 1.4 & 62.6 \\
\hline $3=5$ & 4.4 & 92.5 \\
\hline
\end{tabular}




\section{TABLE 22}

GENERAI RESULTS FOR HYDROGEN REACTION

IN BORIC ACID COATED

REACTION VESSEL III

\begin{tabular}{cccr}
\hline $\begin{array}{c}\text { TEISP } \\
{ }^{\circ} \mathrm{C}\end{array}$ & $\begin{array}{c}\text { INITIAI } \mathrm{H}_{2} \\
\text { CONC RANGE } \\
10^{-3}\end{array}$ & $\begin{array}{c}\% \text { DECOMP } \\
\text { RANGE WITH } \\
\mathrm{H}_{2}\end{array}$ & $\begin{array}{c}\% \text { DECO } \\
\text { WITHON } \\
\mathrm{E}_{2}\end{array}$ \\
\hline 365.2 & 4.5 & 94 & 14 \\
147.2 & $2.4-9.3$ & $4-83$ & 0
\end{tabular}


PABLE 23

PERCENTAGE DECOMPOSITION FOR A RESIDENCE TIME

OF $0.10 \mathrm{MIN}$ AT $147.2^{\circ} \mathrm{C}$ IN BORIC

ACID COATED REACTION VESSEI III

\begin{tabular}{lcc}
\hline $\begin{array}{c}\text { INITIAI HCIO } \\
\text { CONCENTRATION } \\
10^{-4} \mathrm{M}\end{array}$ & $\begin{array}{c}\text { INITIAI H } \\
\text { CONCENTRATION } \\
10^{-3} \mathrm{M}\end{array}$ & $\%$ DECOMP \\
3.8 & 0 & 0 \\
3.5 & 4.5 & 4.6 \\
3.0 & 9.3 & 3.8 \\
3.7 & 2.4 & 68.3 \\
3.4 & 5.9 & 33.9 \\
3.7 & 4.4 & 78.2 \\
3.8 & 2.4 & 83.2
\end{tabular}


FIG. 1

SCHCPATIC DIAGRAM OF FIOH SYSTEM

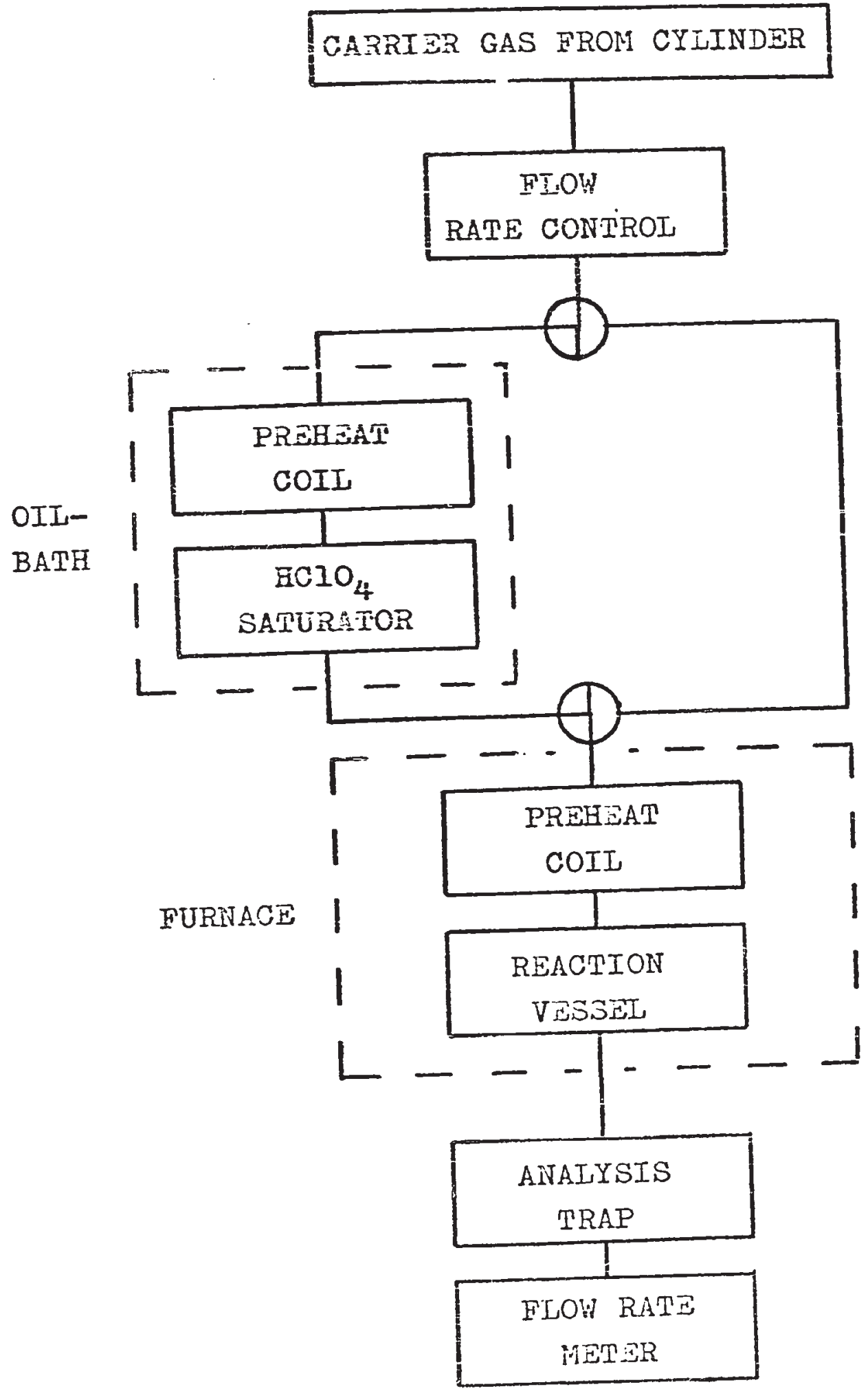



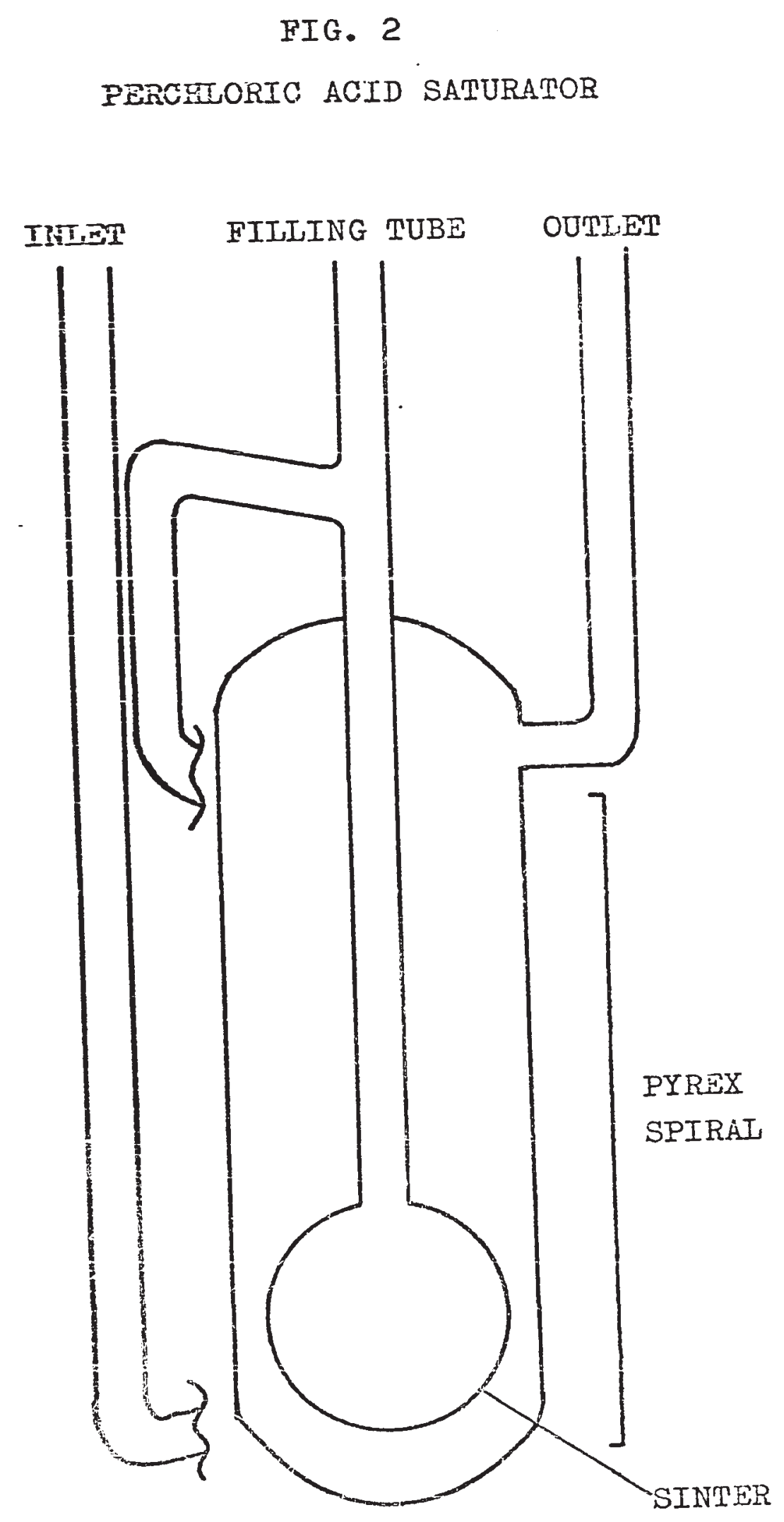
FIG. 3

REACTION VESSEU I

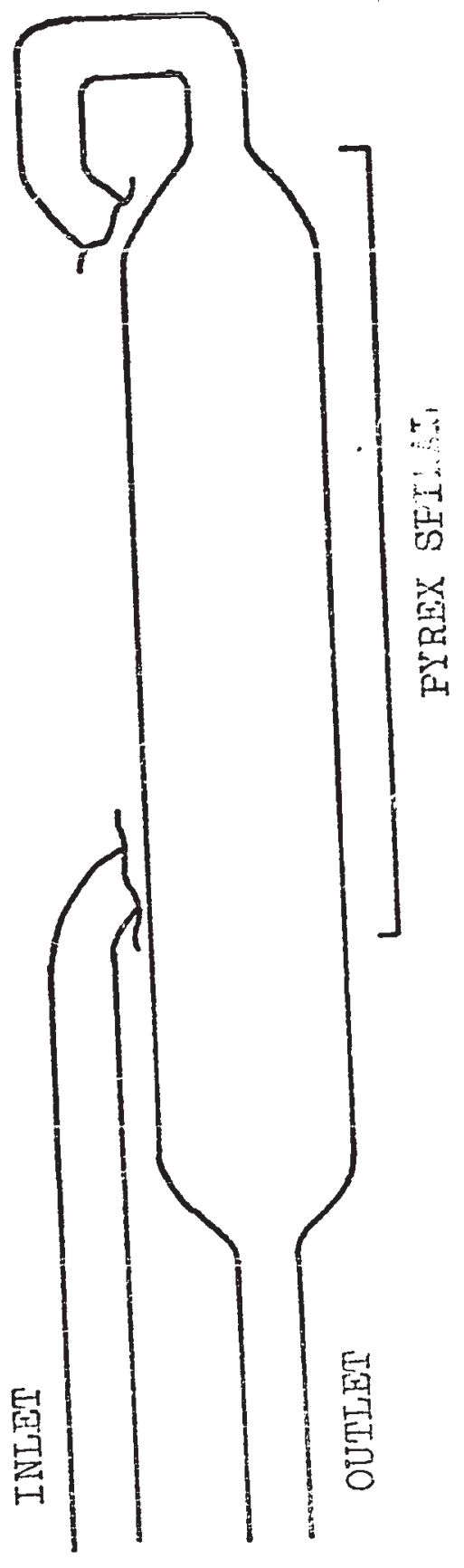


FIG. 4

REACTION VESSEL III

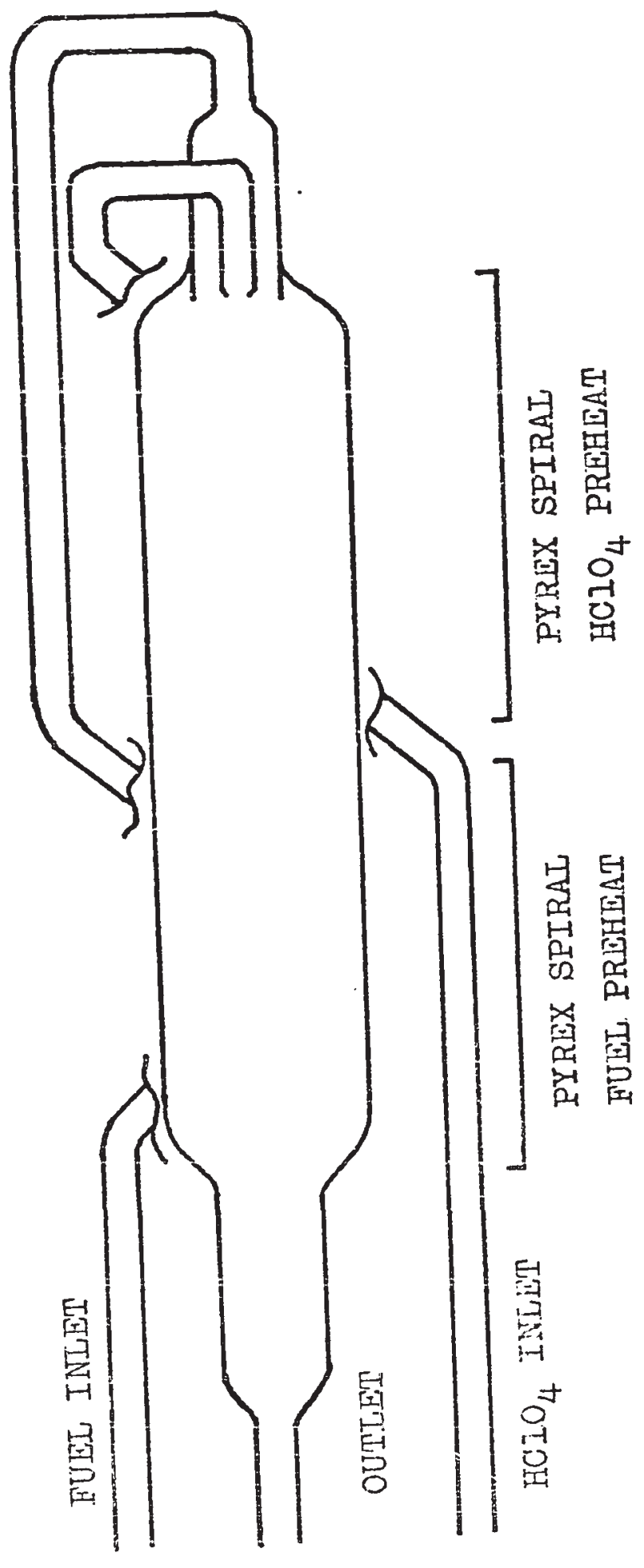


FIG. 5

SAMPLING SYSTEM

NORMAL POSITION

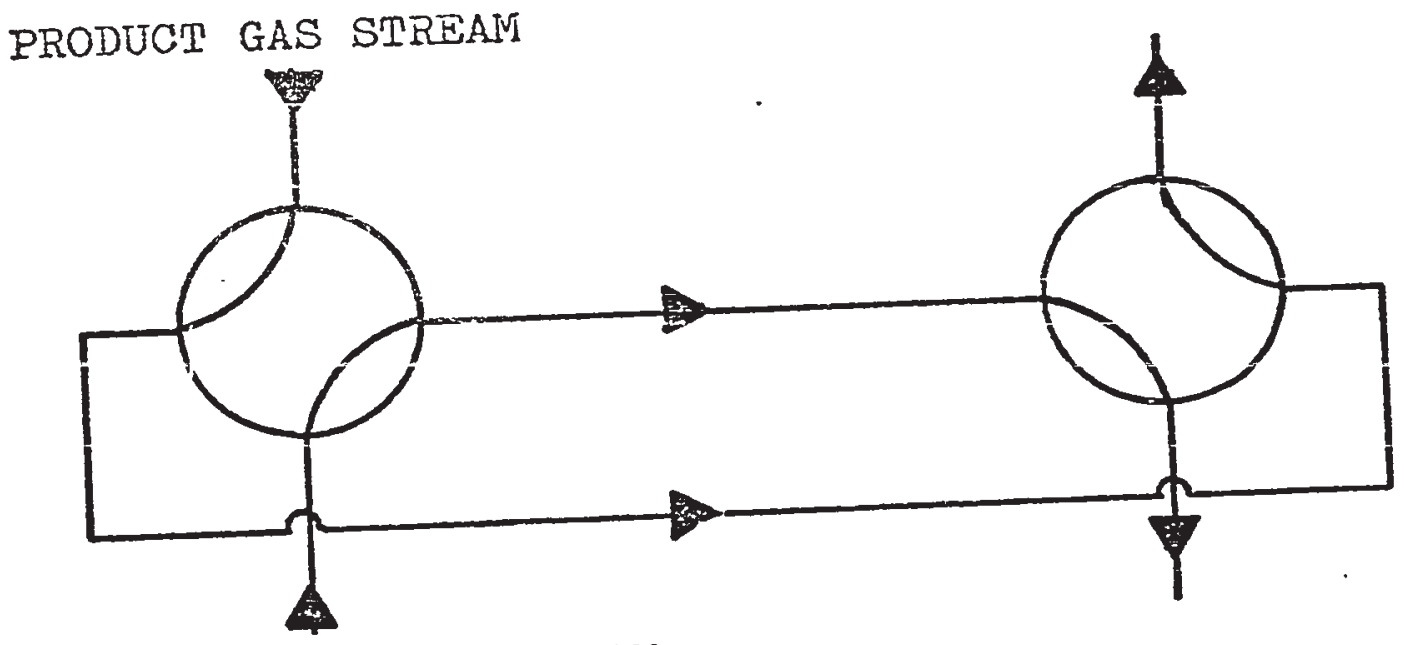

G.I.C. CARRIER GAS STREAM

SAMPIING POSITION

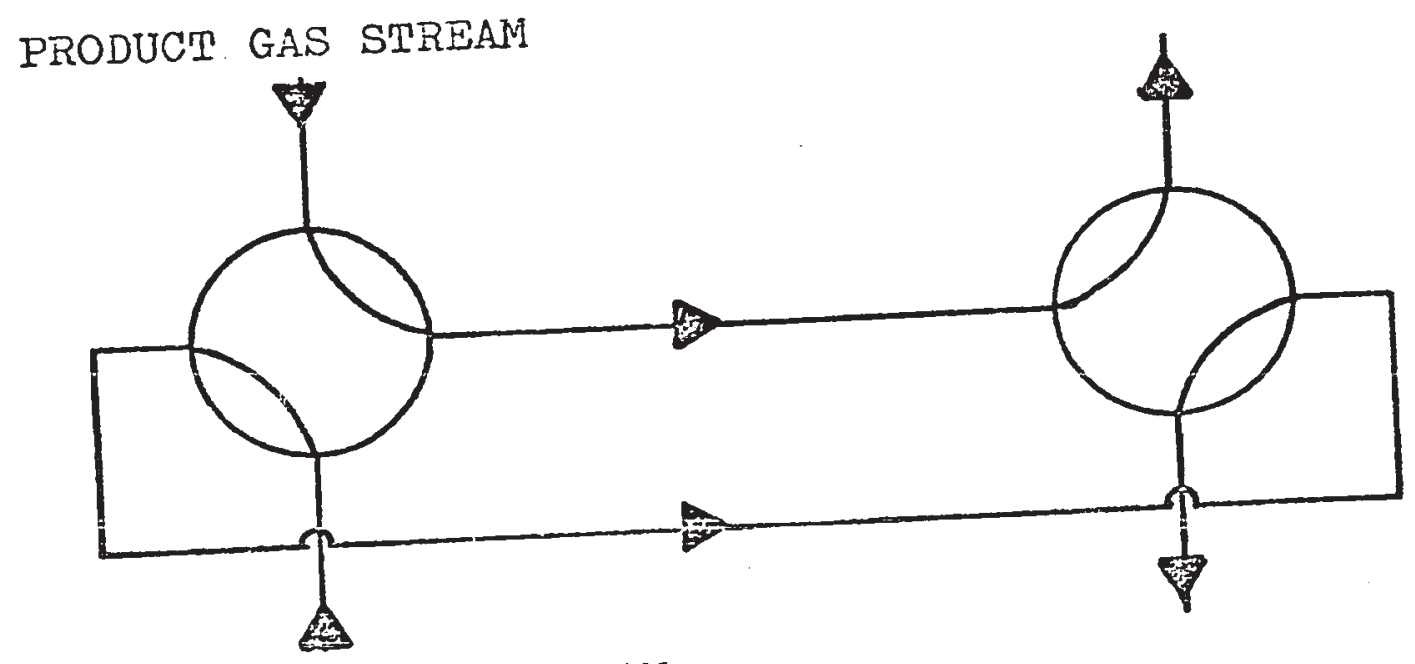

G.I.C. CARRIIR GAS STREAM 
HIG. 6

FIRST ORDER RAIIS PIOTS

ANNEALED REACTION VESSEL I

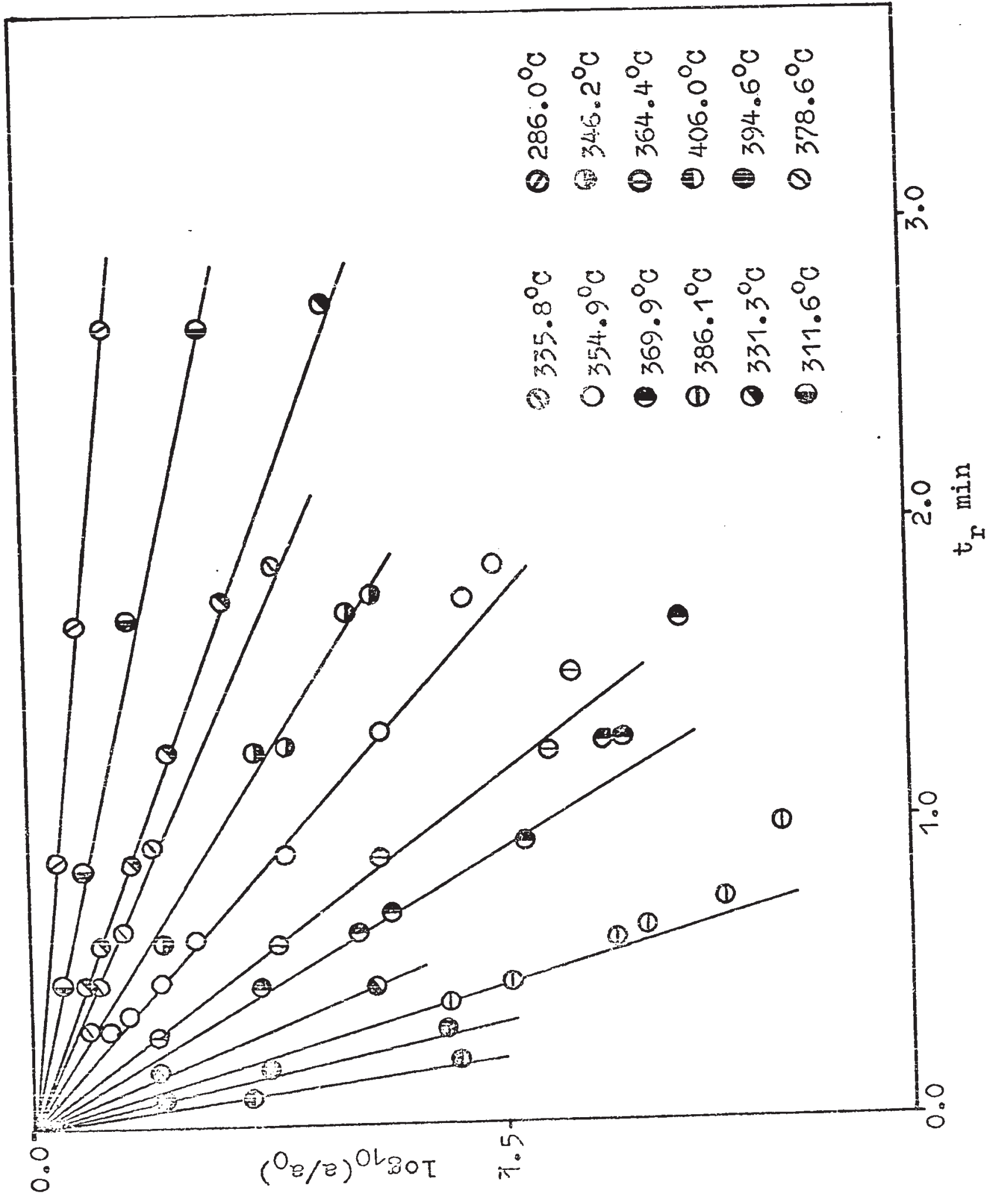


FIG. 7

ARRHENIUS PIOT FOR FIRST ORDER RATE CONSTANTS ANNEALED REACTION VESSEJ I

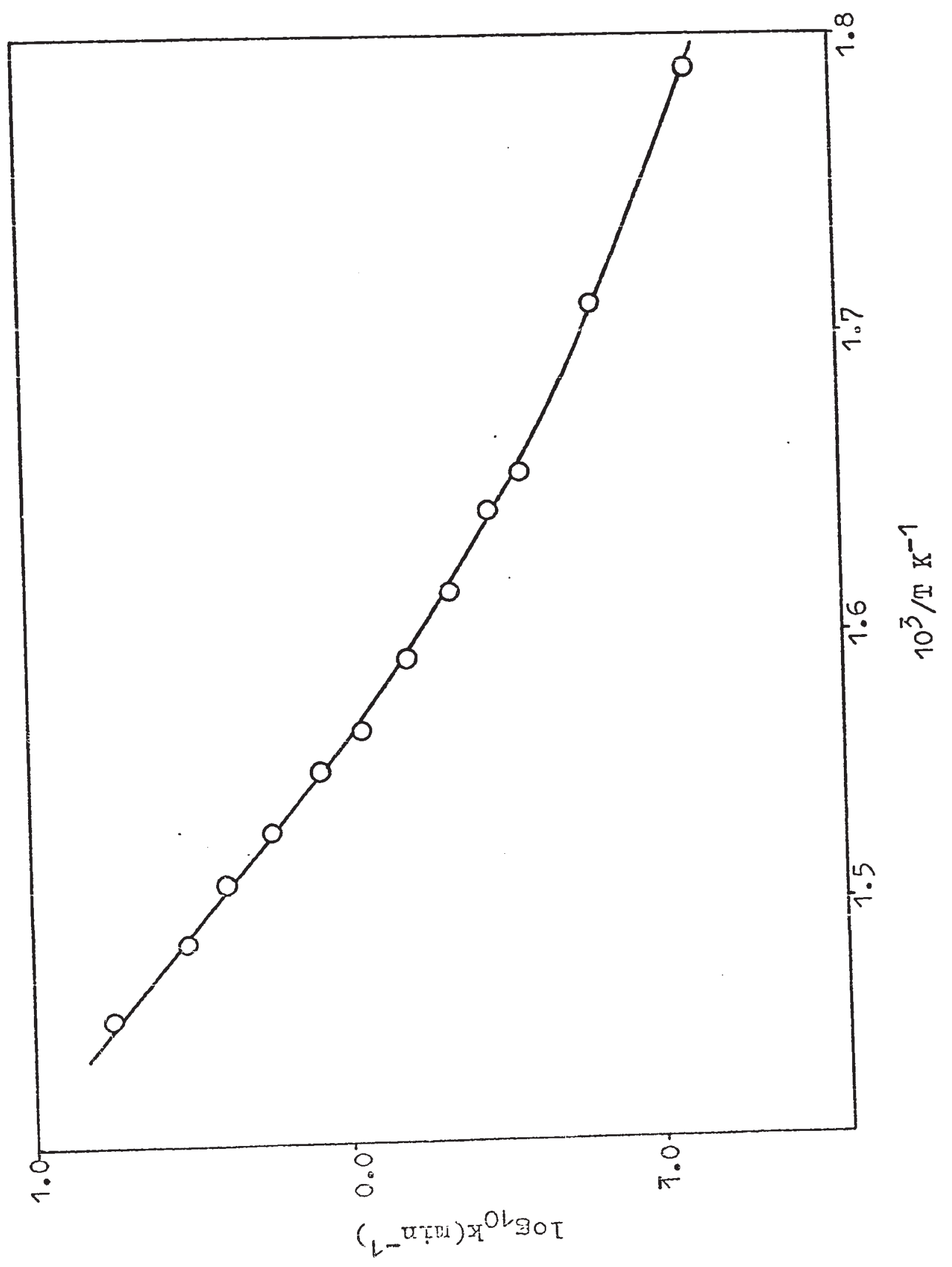


FIG. 8

FIRST ORDER RATE. PIOTS AT $364.4^{\circ} \mathrm{C}$ FOR THREE

INITIAL AGID CONGEMTRATIONS - ANNEALED REACTION VESSEL I

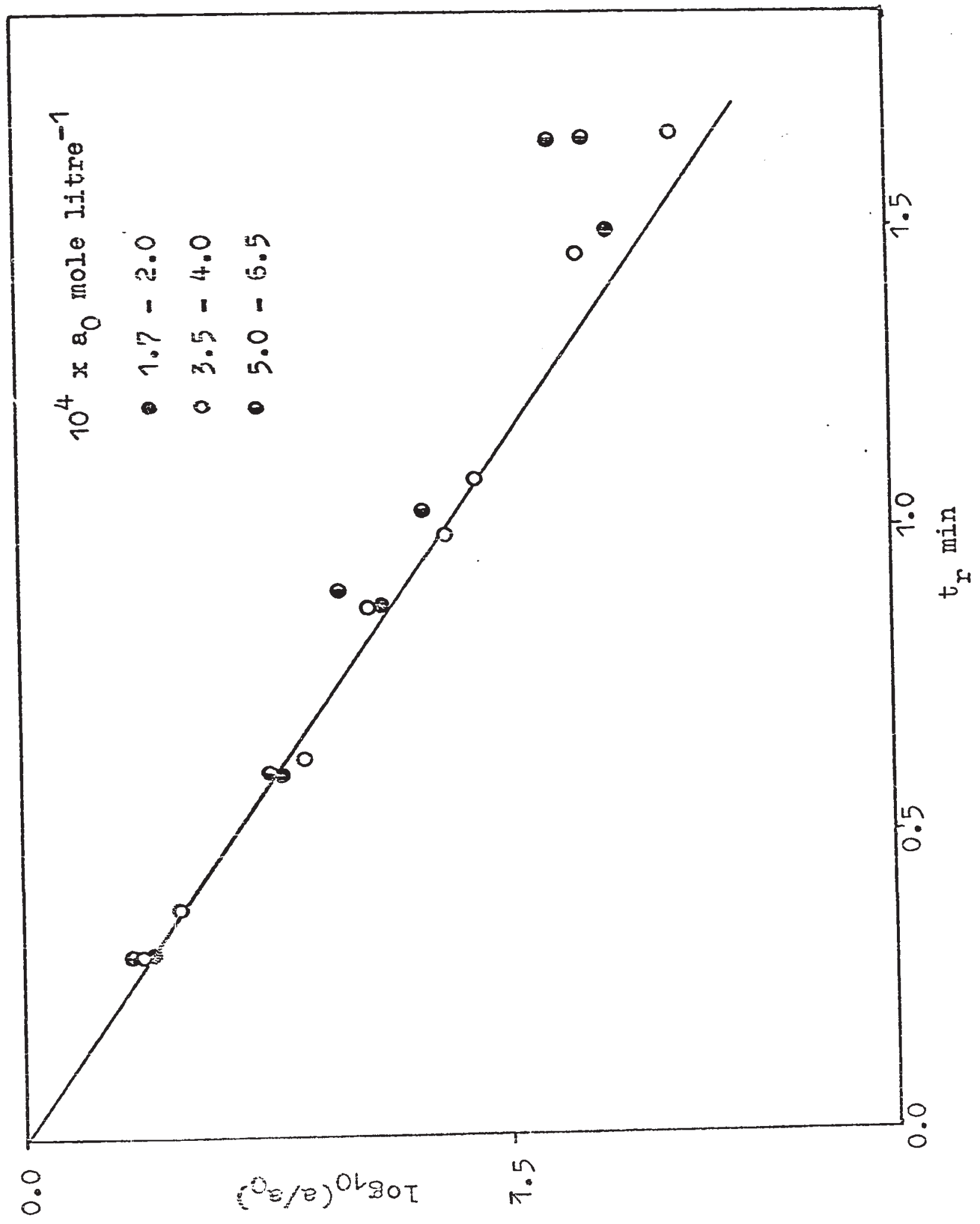


FIG. 9

PERCENTAGE DECOMPOSITION PLOTS

WASHED REACTION VESSEL I

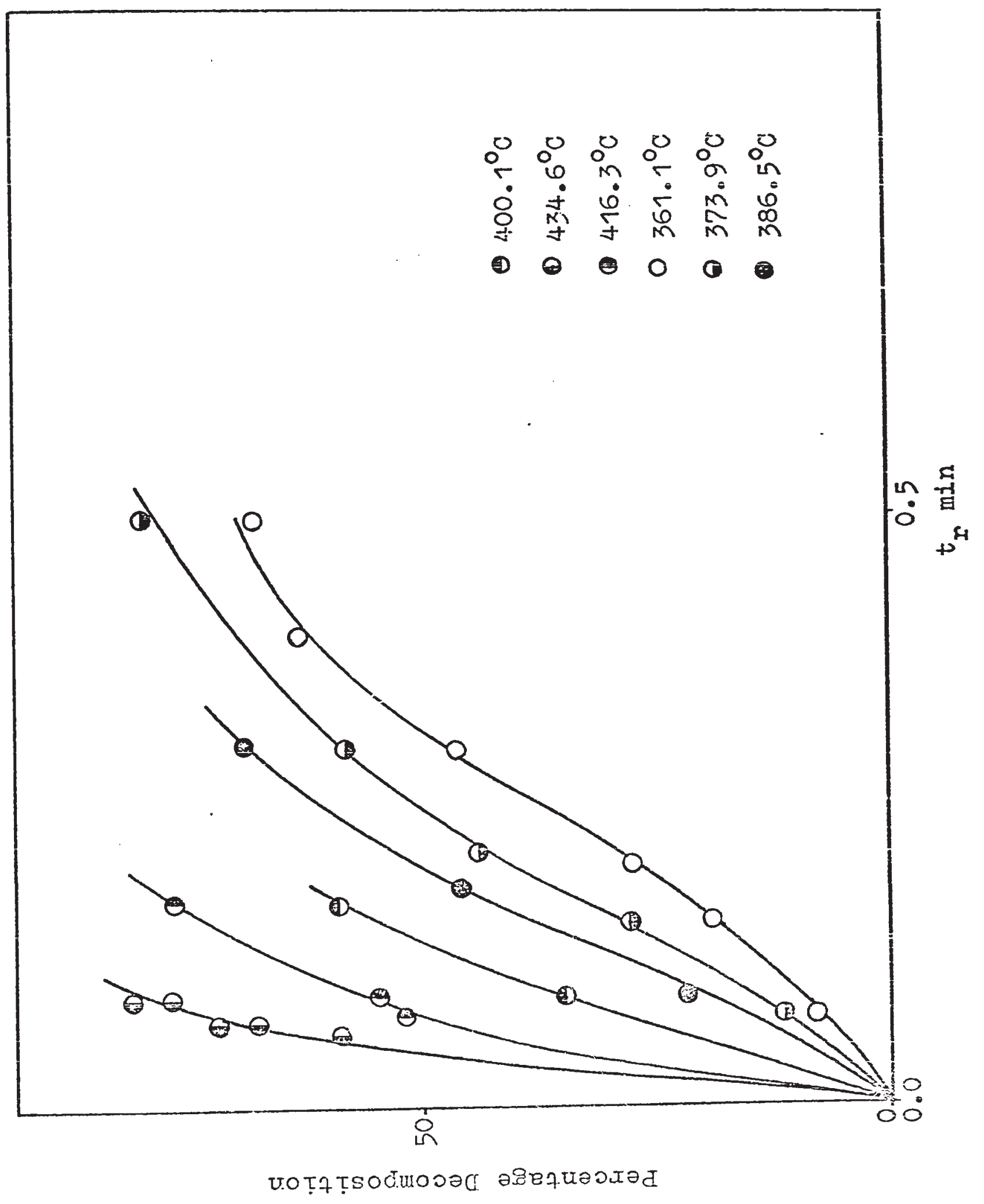


FIG. 10

FIRST ORDER RATE PIOTS

WASHED REACTION VESSEL I PACKED WITH GLASS WOOL

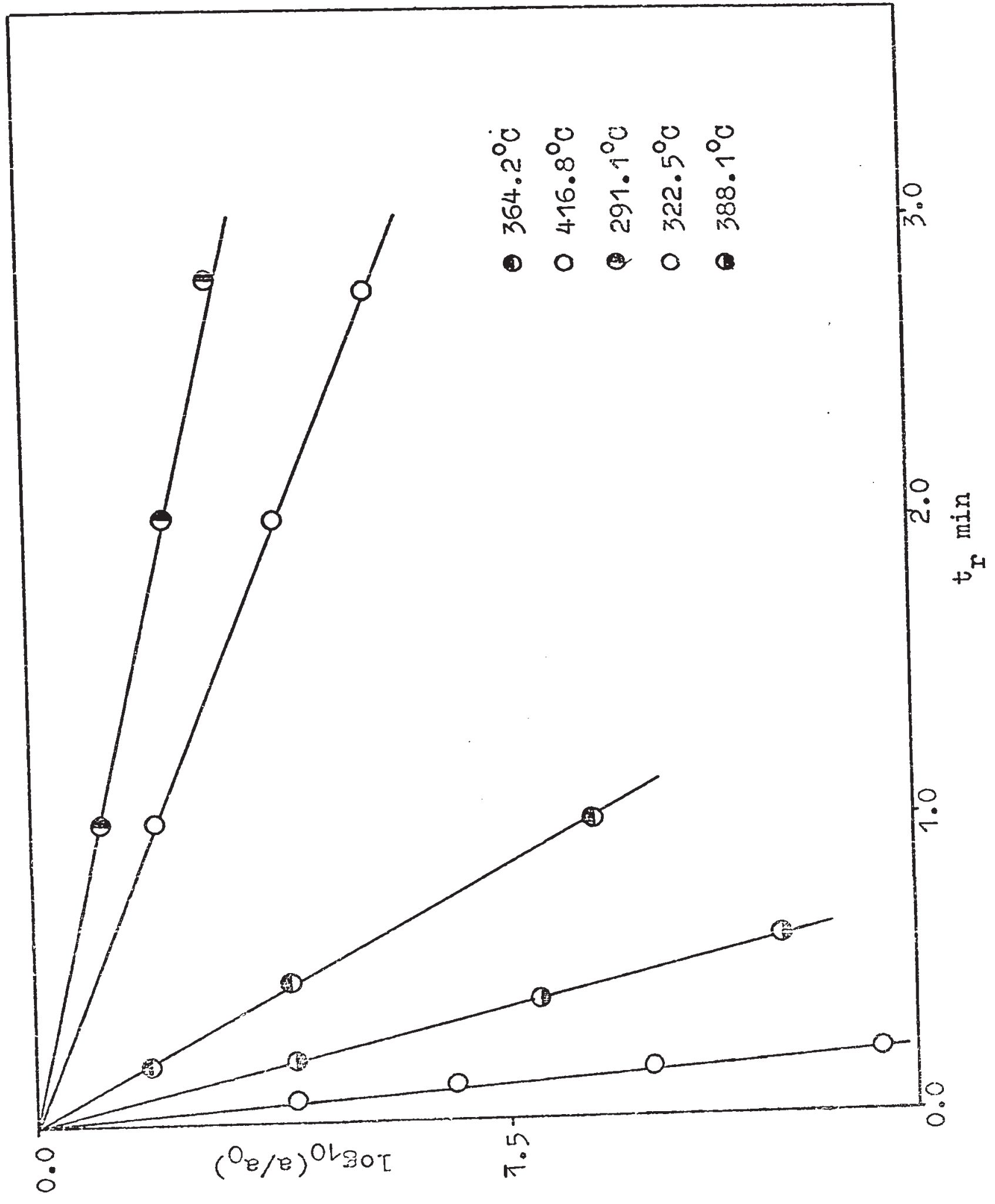


FIG. 11

ARRHENIUS PLOT FOR FIRST ORDER RATE CONSTANTS

WASHED REACTION VESSET I PACKED WITH GLASS WOOL

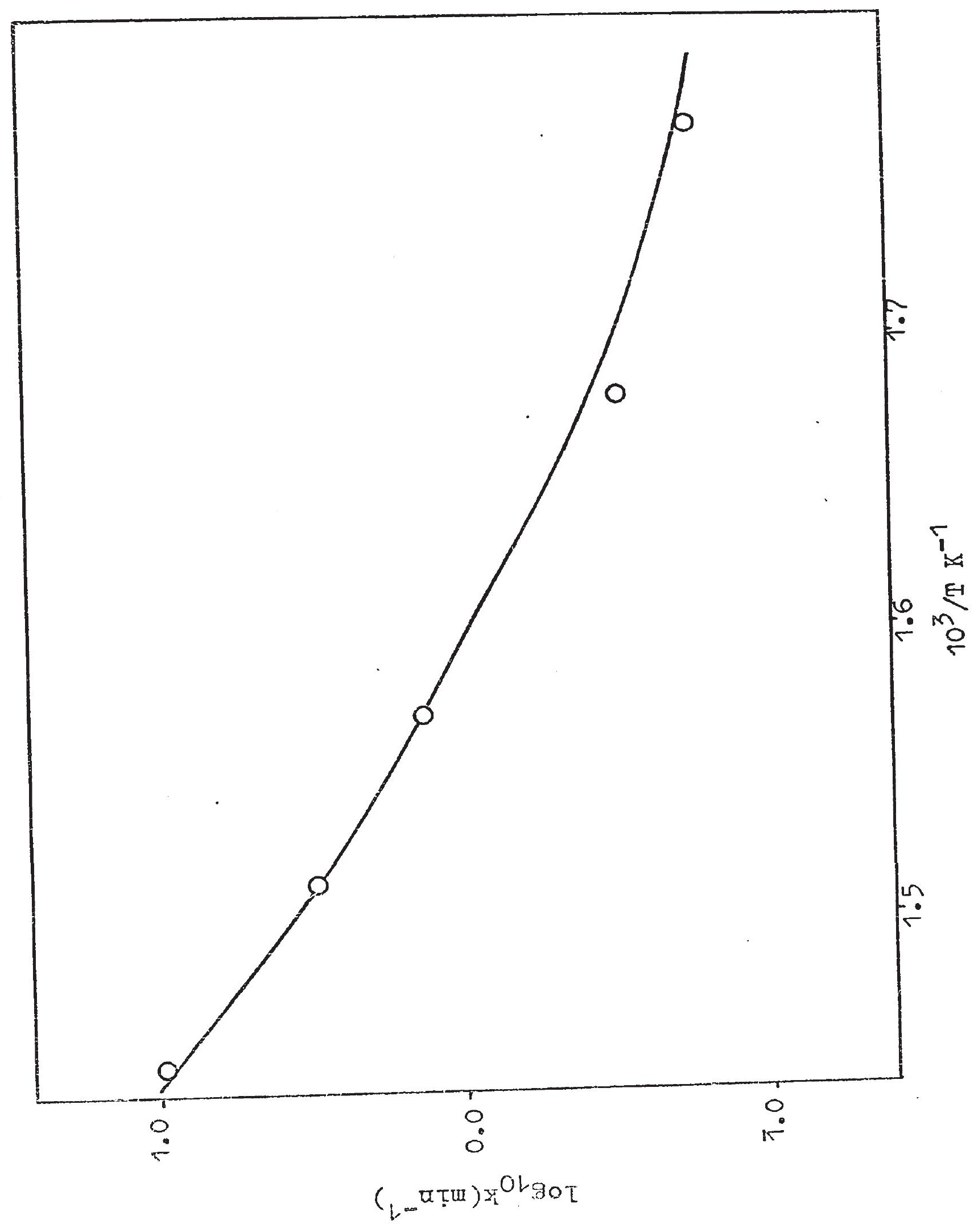


FIG. 12

FIRST ORDER RATE PLOTS

WASHED REACTION VESSEL II

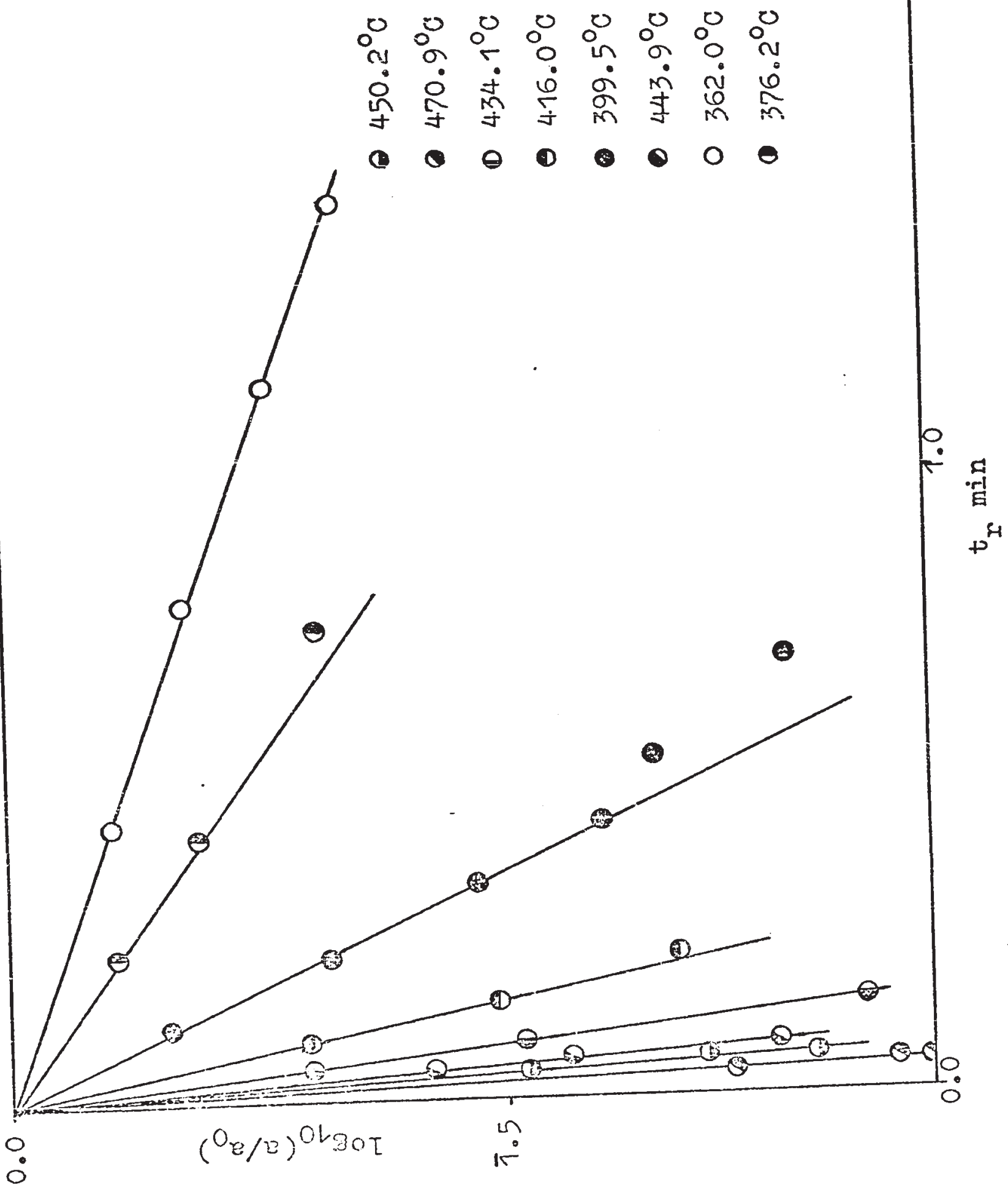


FIG. 13:

ARRHENIUS PLOT FOR FIRST ORDER RATE CONSTANTS WASHED REACTION VESSEI II

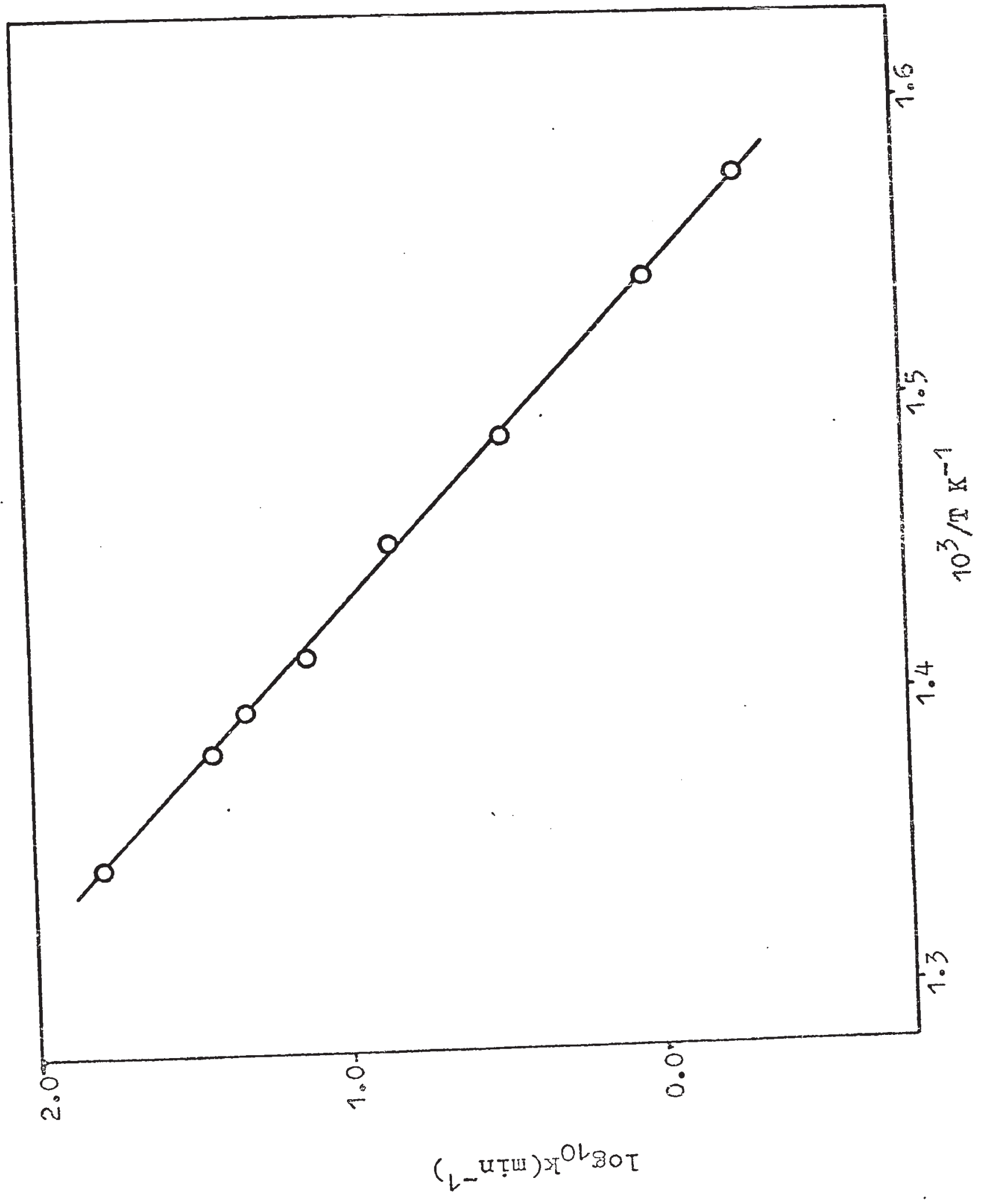


RIG. 14

FIRST ORDER PIOTS

COATED AND UNCOATED REACTION VESSEL III

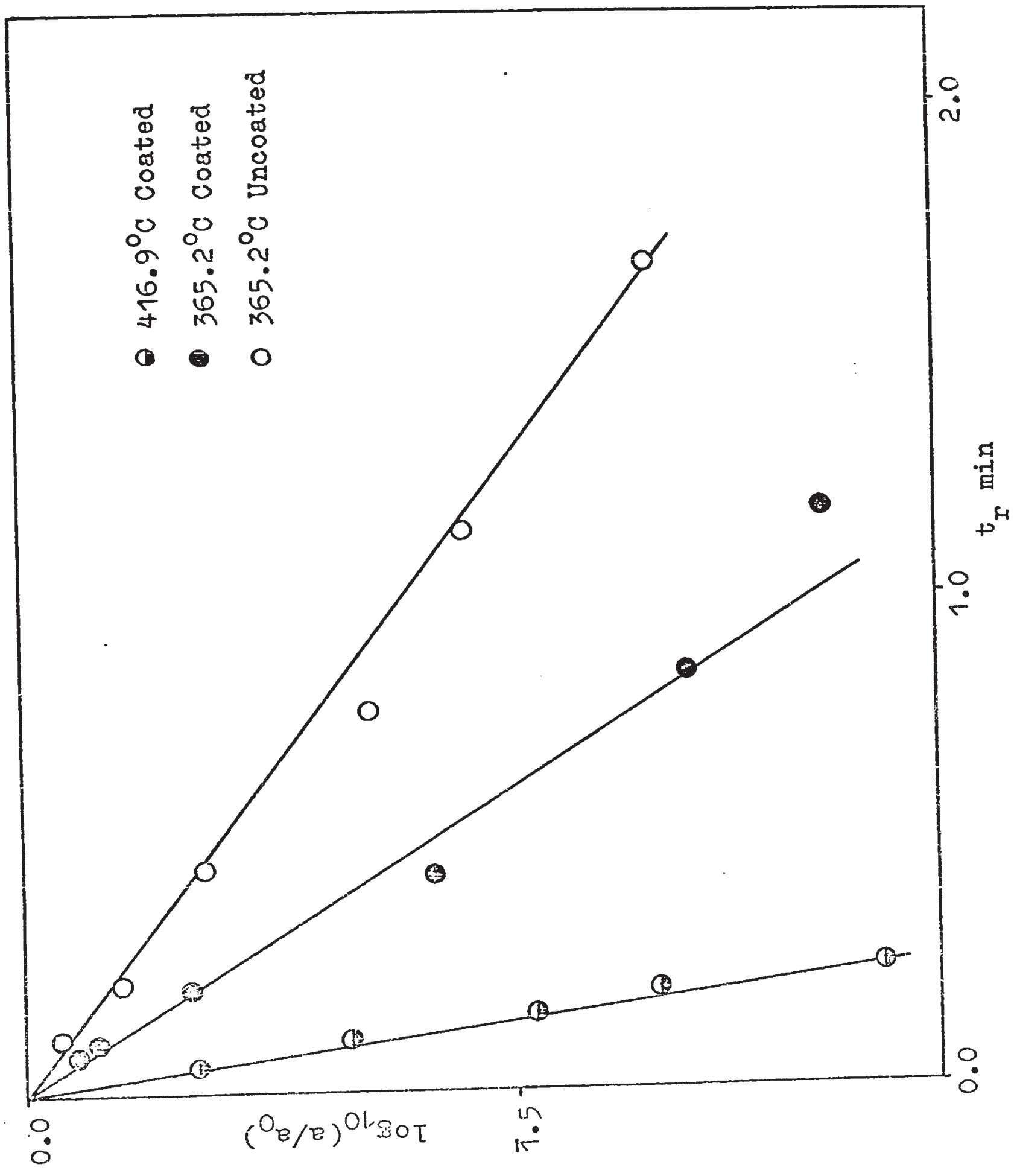


FIG. 15

PERCENTAGE DECOIPOSITION PLOTS

UNTREATED REACTION VESSEL IV

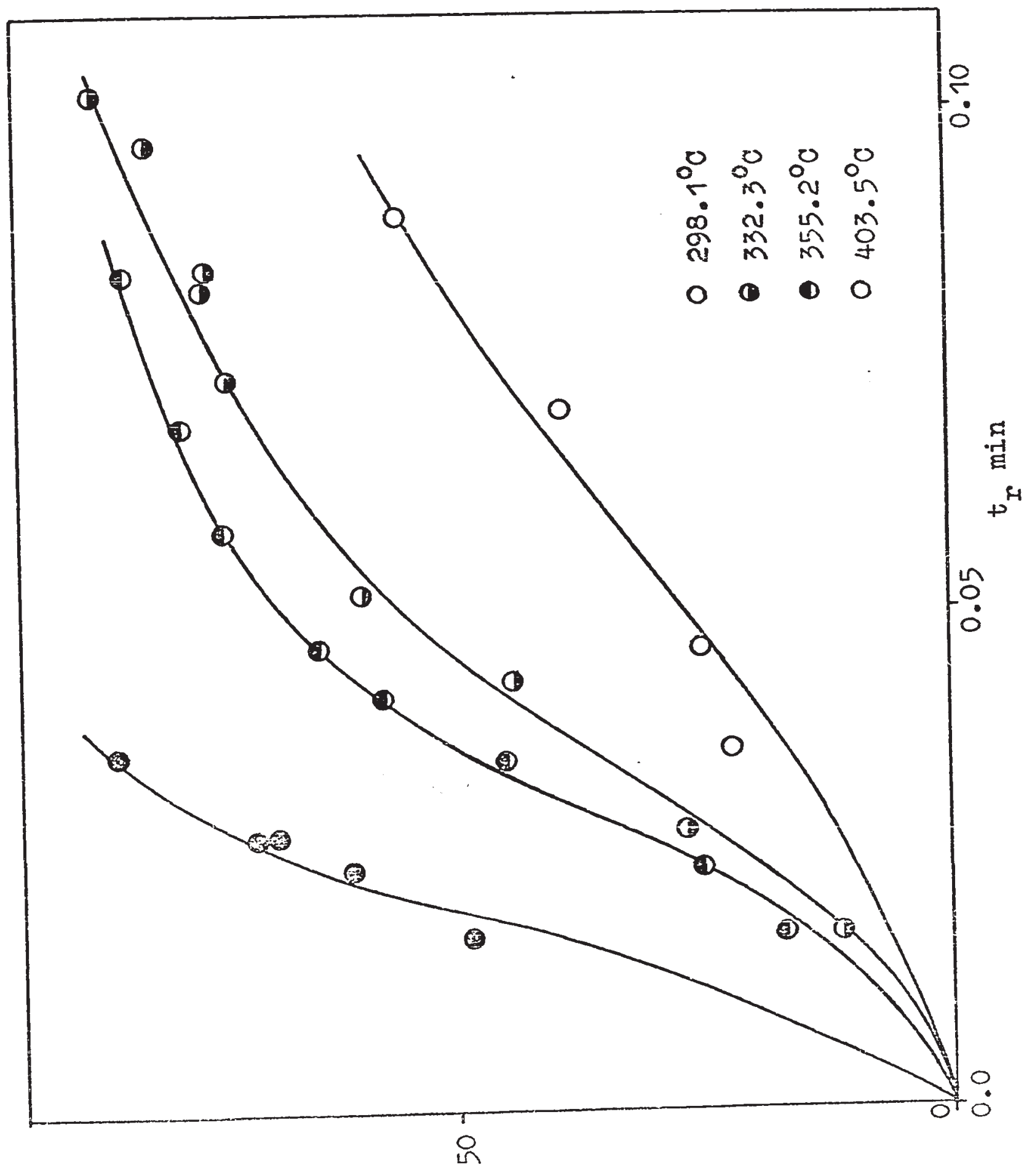

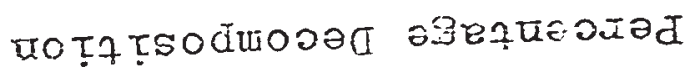


FIE. 16

FIRST ORDER RATE PLOTS

ANNERIED REACTION VESSEU IV

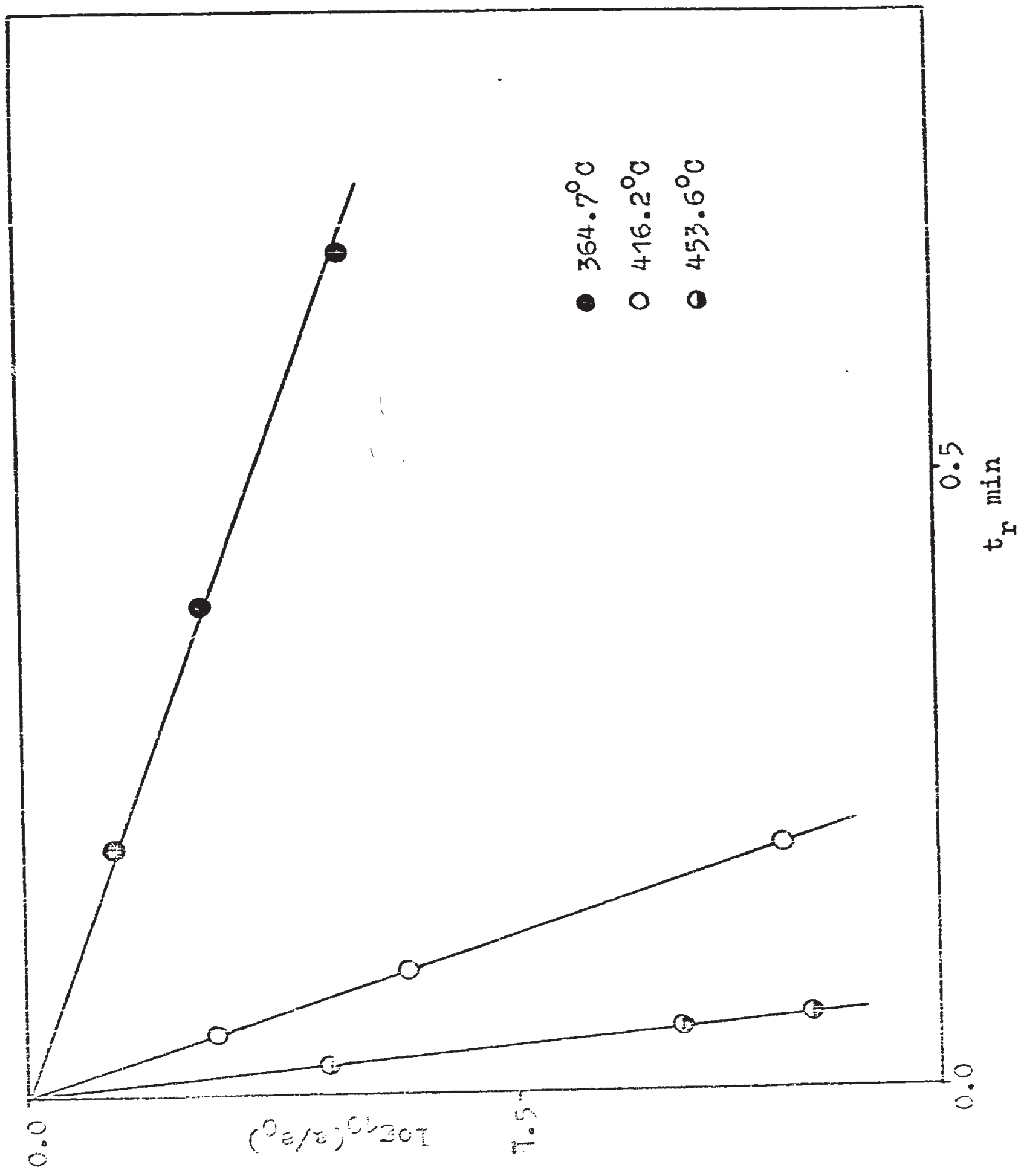


FIG. 16

FIRST ORDER RATE FEOTS

ANNEALED REACTION VESSEL IV

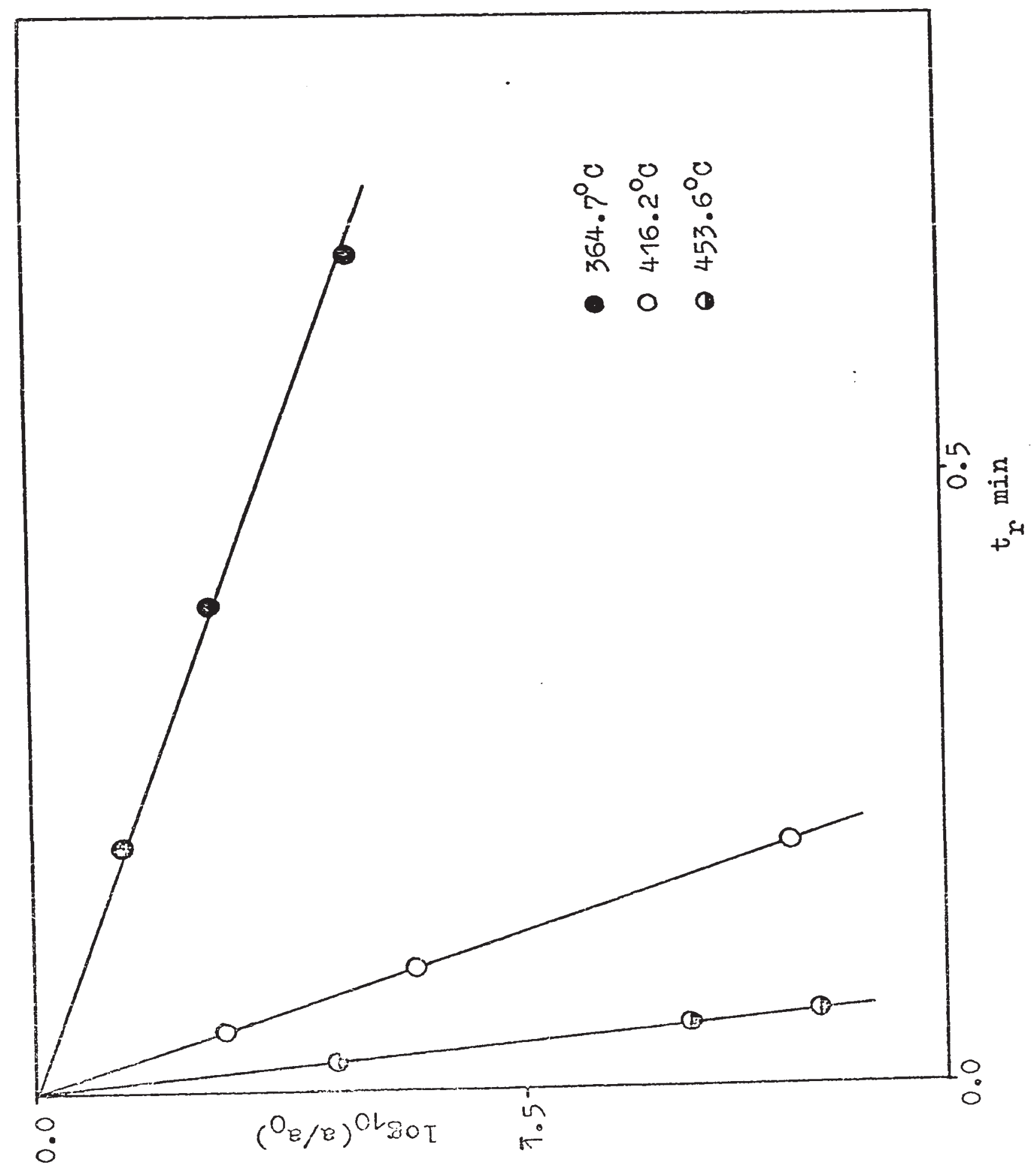


FIG. 17

FIRST ORDER RATE PLOTS

$\mathrm{Cu}-0203$

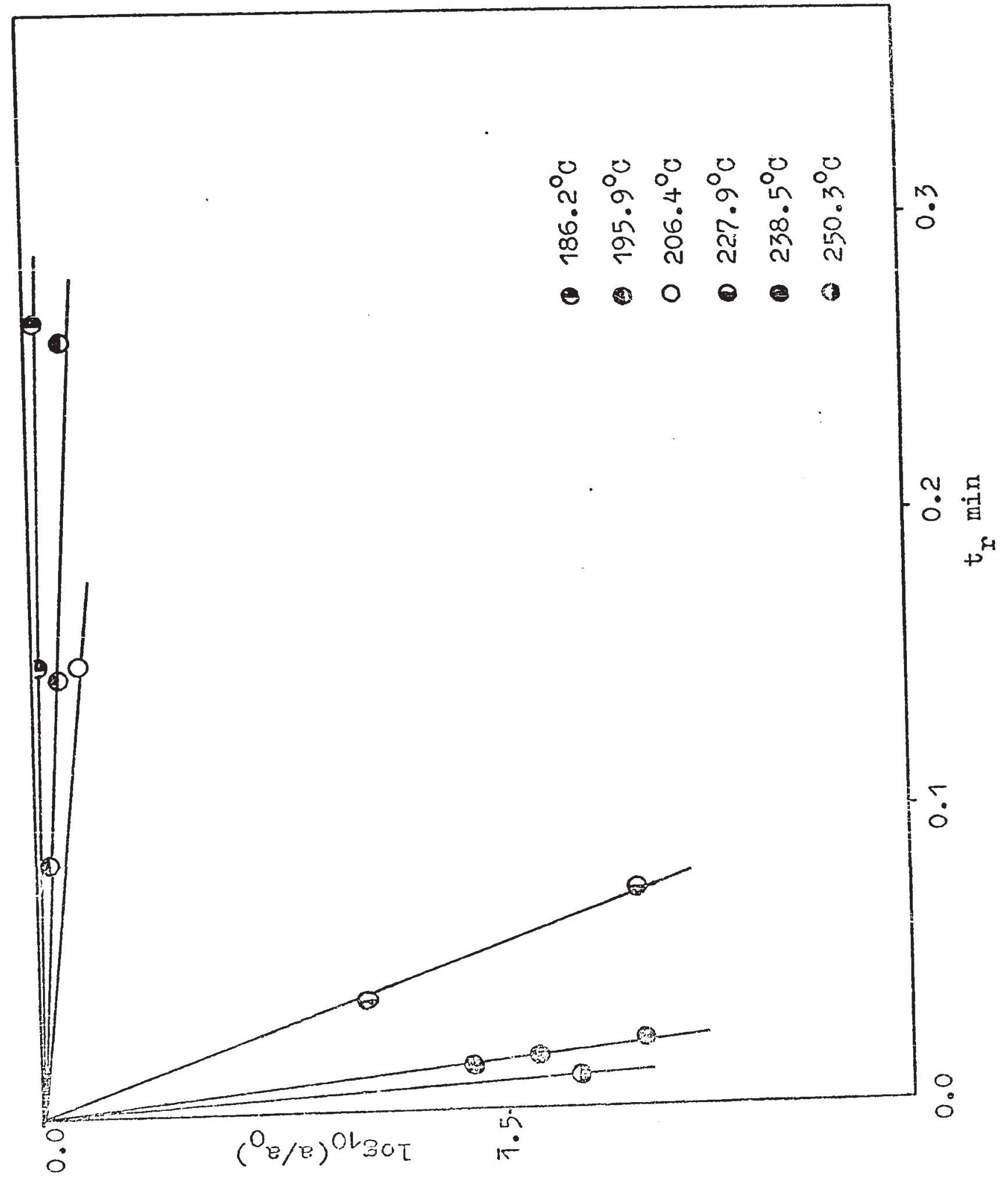


FIG. 18

ARRHENIUS PLOT OF FIRST ORDER RATE CONSTANTS

$\mathrm{Cu}-0203$

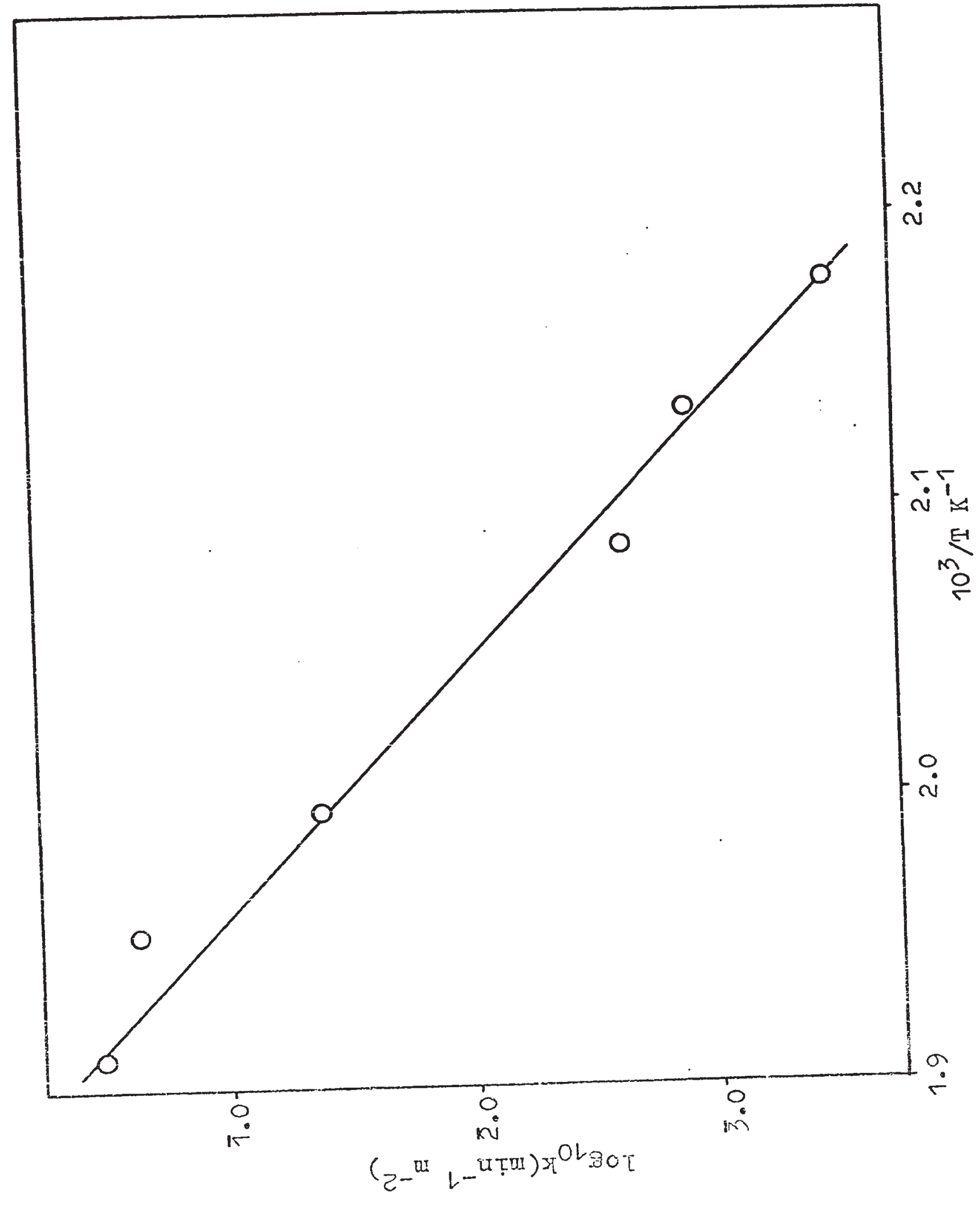


FIG. 19

FIRST ORDER RATE PLOTS

Fe-0301

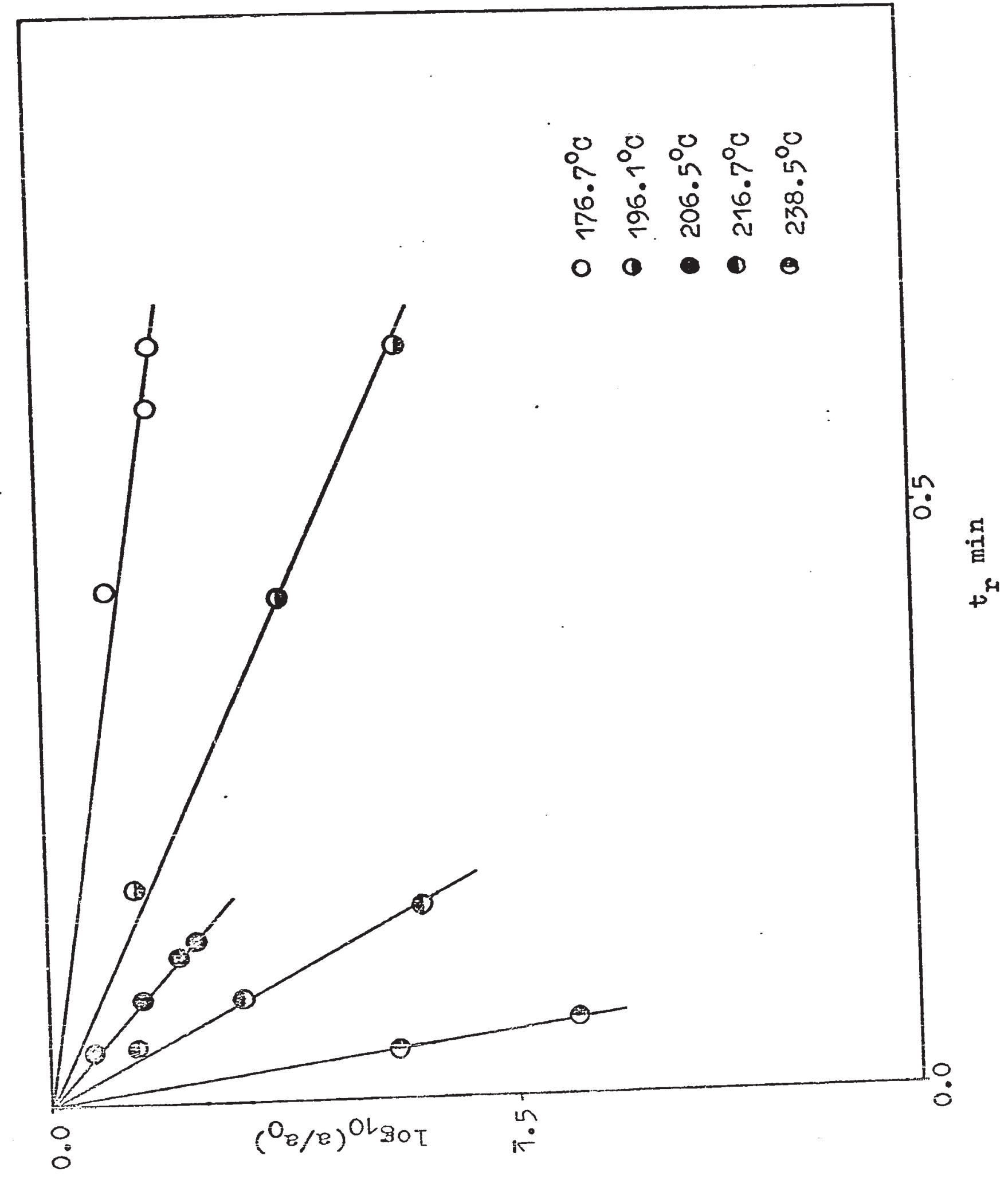


FIG. 20

ARRHENIUS PLOT OF FIRST ORDER RATE CONSTANTS

Fe-0301

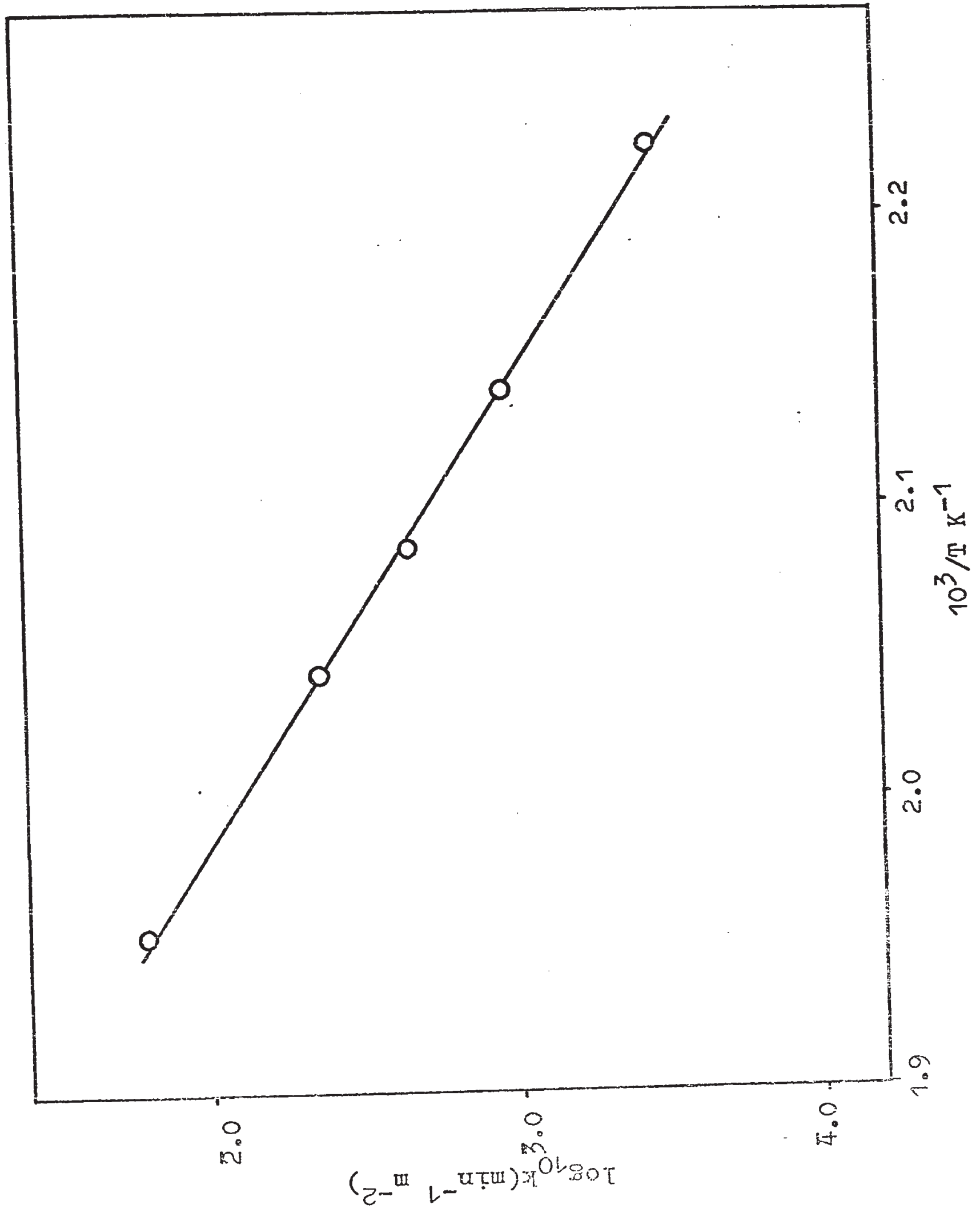


FIG. 21

FIRST ORDER RAIS PLOTS

Al-0104

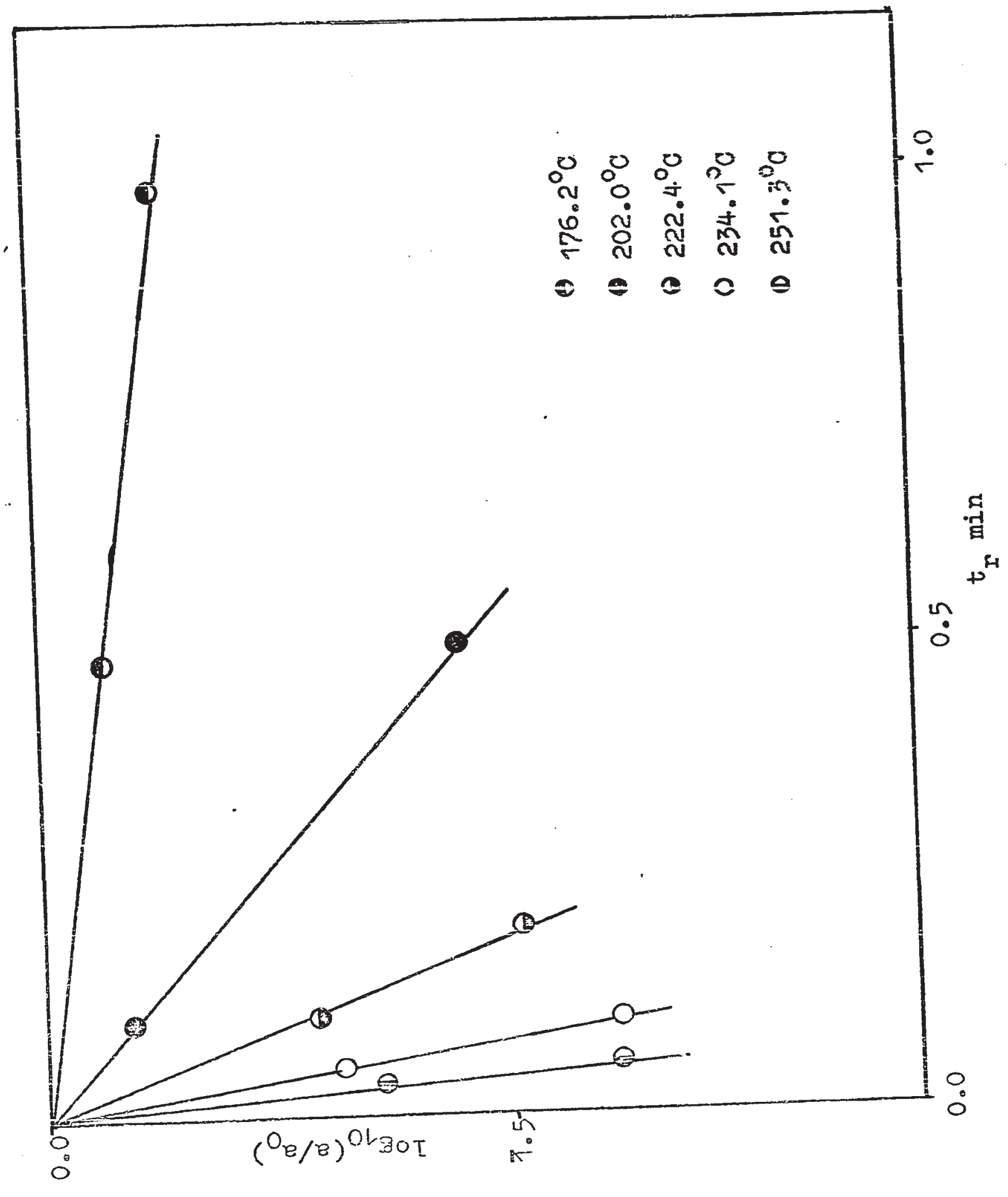


FIC, 22

ARRHENIUS PLOT OF FIRST ORDER RATE CONSTANTS

Al-0104

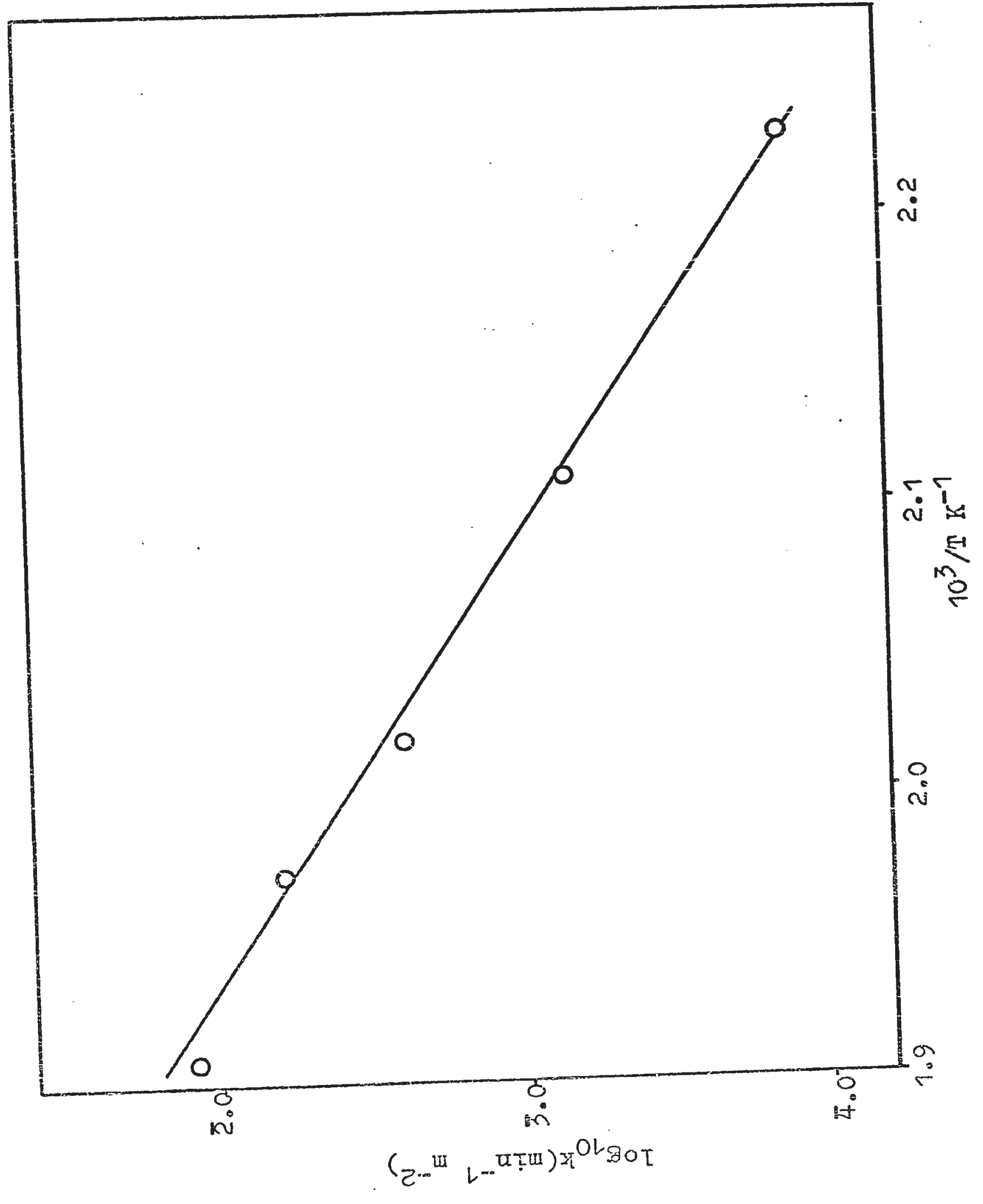


FIG. 24

ARRHENIUS PLOT OF FIRST ORDER RATE CONSTANTS

$\mathrm{Cu}-08303$

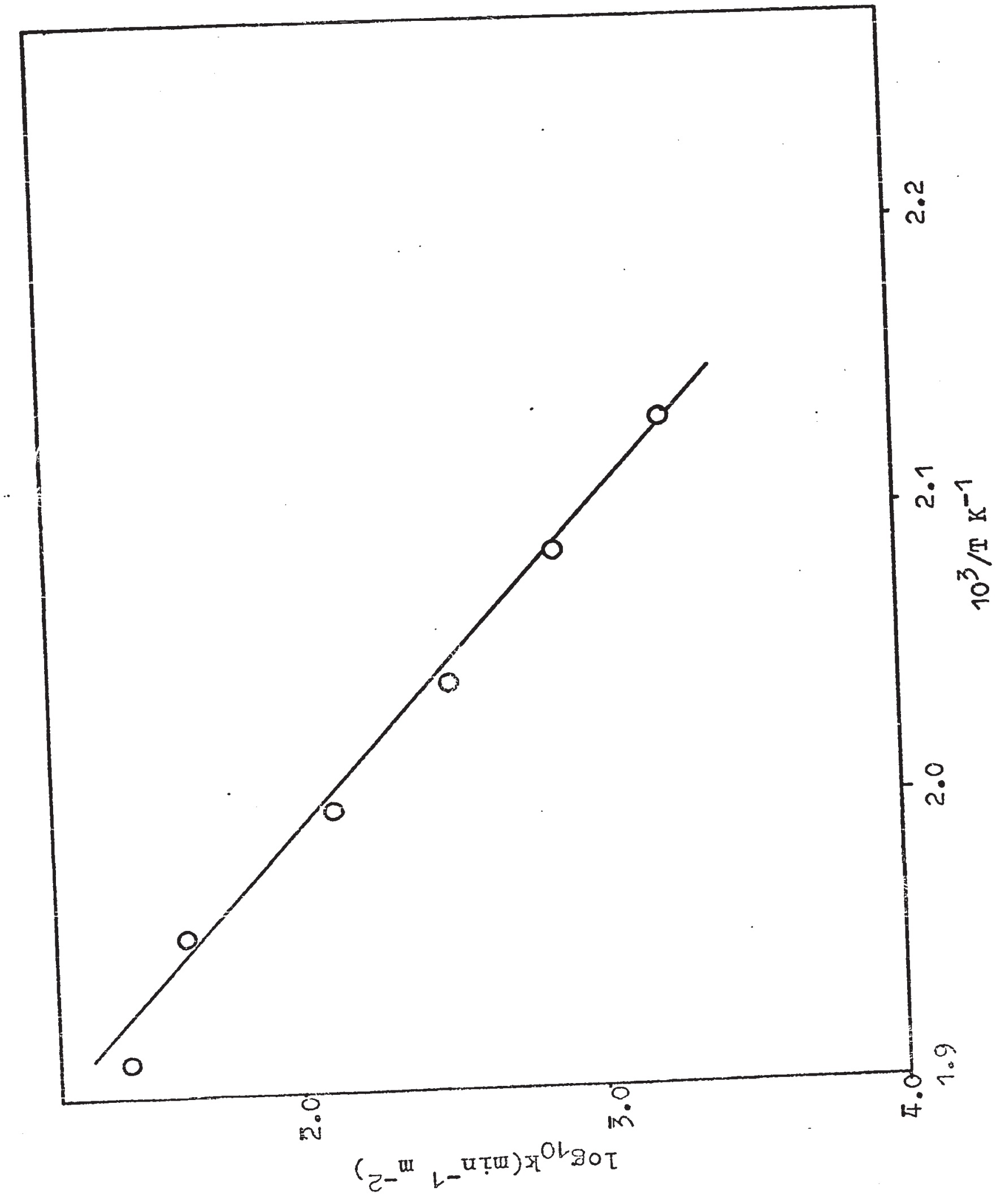


FIG。 25

PERCENTAGE DECOMPOSITION PLOTS

Mn-0201

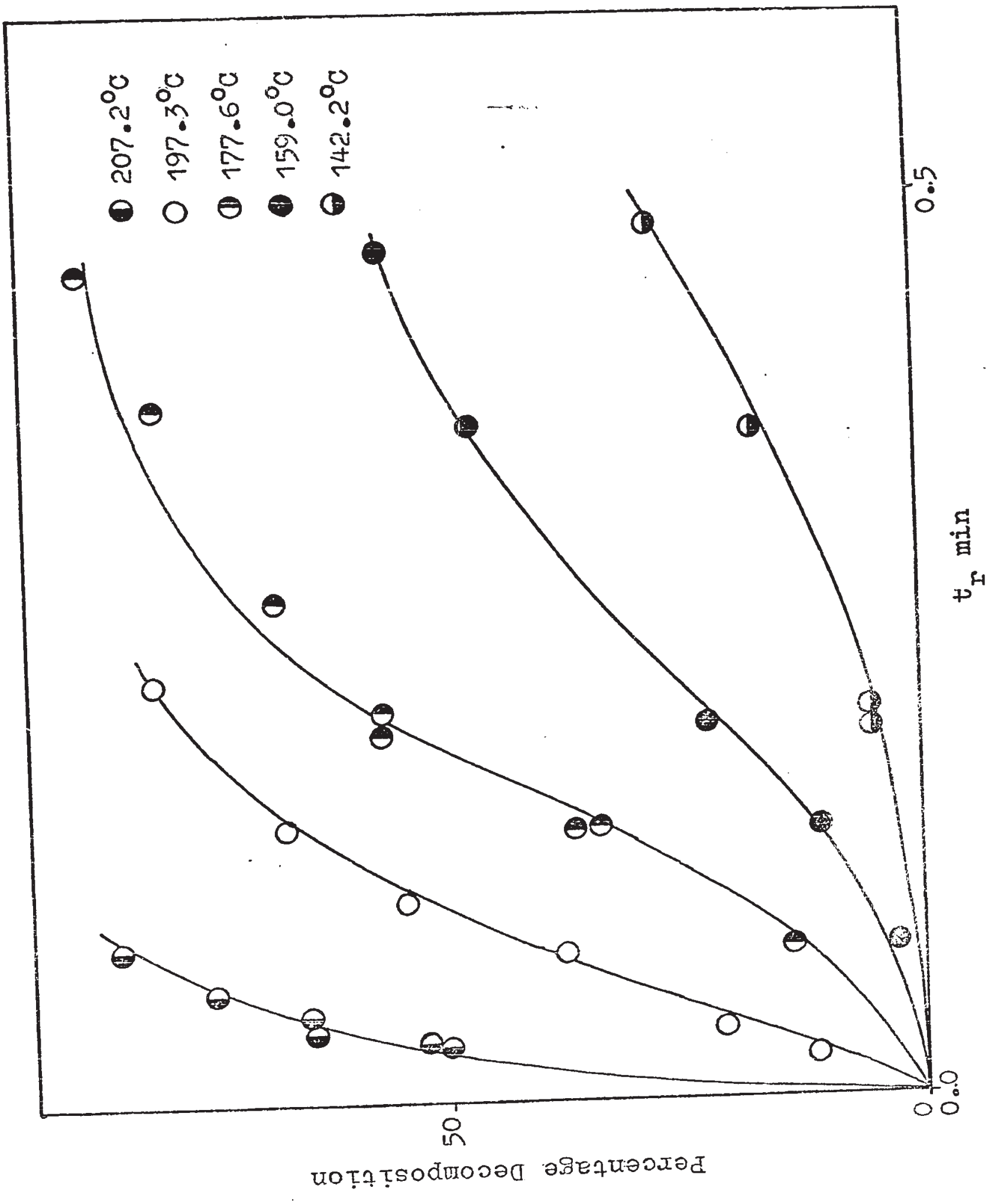


FIG. 26

COMPEINSATION EFFECT PLOT

HARSHAW CATALYSTS

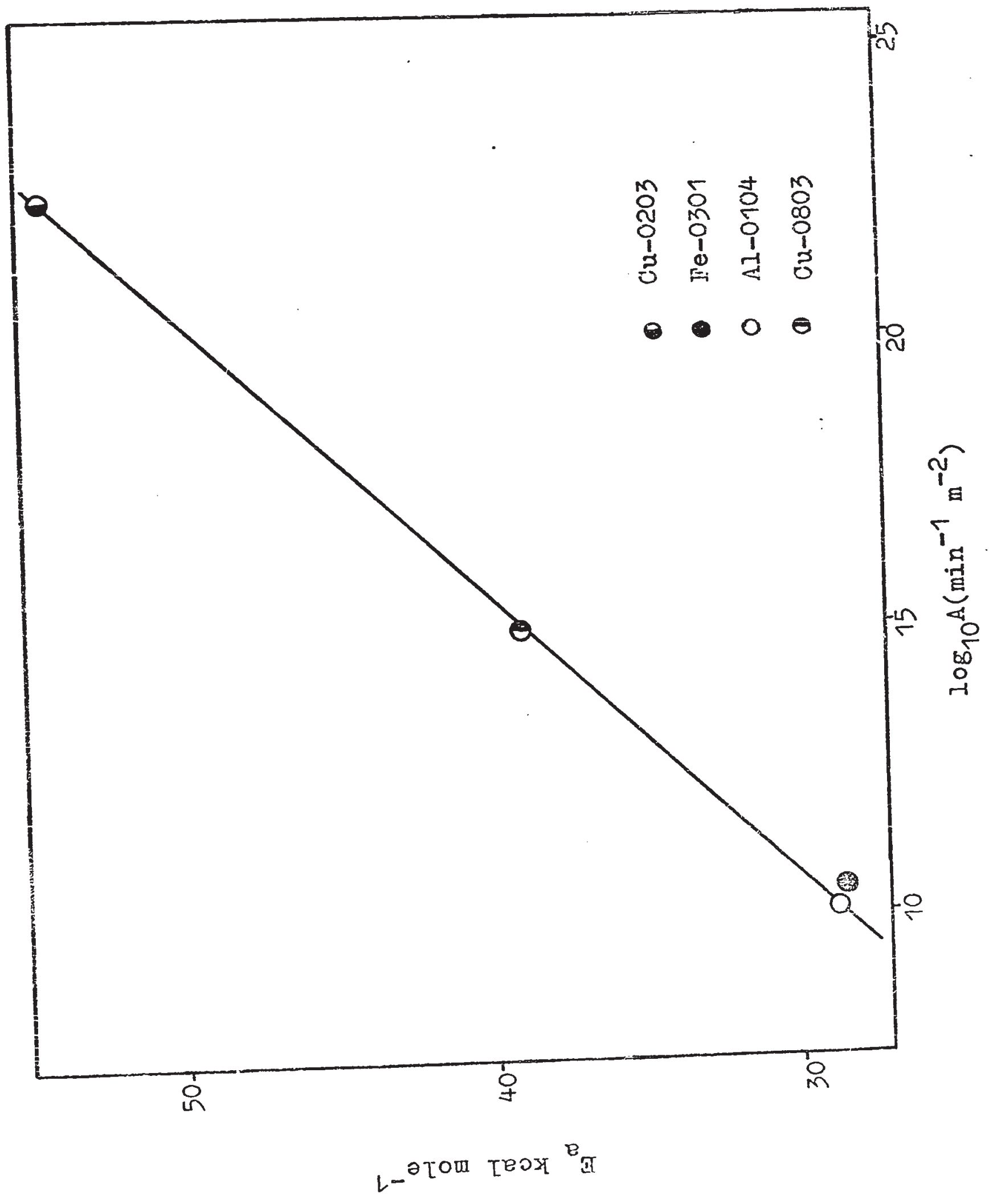




\section{REFERENCES}

1. P.W.M. Jacobs and H.M. Whitenead, Chern. Rev., 69, 551 $(1969)$.

2. C.U. Pittman, "The Nechanism of Decomposition of Amonium Perchlorate: i Review," U.S. Army Missile Command, Redstone Arsenal, RK-TR-66-13, August 1966.

3. A.R. Hall and G.S. Pearson, "Ammonium Perchlorate: A Review of its Role in Composite Propellant Combustion," R.P.E. Technical Report $67 / 1,1967$; Oxidation Combust. Rev., 3, 129 (1968).

4. A.G. Keenan and R.F. Siegmund, Quart. Rev., 23, 430 (1959).

5. G.S. Pearson, "Perchloric Acid: A Review of the Pingsical and Inorganic Chemistry," RPE Technicat Miemo 352 , March 1965; Advan. Inorg. Radiochem., 8 , 177 (1966).

6. C.C. Addison, "Mellor's Comprehensive Treatise on Inorganic and Theoretical Chemistry," Supplement II, Part I, Longmans, Green and Co., London, 1956, Cinapter II, p 598.

7. J.C. Schumacher, Ed., "Perchlorates, Their Properties, Manufacture and Uses," Reinhold Publishing Corp。, New York, H.Y., 1960, p 11 .

8. A.A. Zinov'ev, Usp. Khim., 32, 590 (1963); Russ. Ghem. Rev., 32, 268 (1963).

9. V.Ya. Rosolovskii, "The Chemistry of Anhydrous Perchloric Acid," Nauka, Noscow, 1966.

10. J.B. Levy, "The Thermal Decomposition of Perchloric Acid," Atlantic Research Corp., Alexandria, Va. 
ATOSR lN 1555, oct 1961 (AD 265 051); J. Phys= Cnem., 66, 1092 (1962)." 11. A.H. Clark, B. Beagley and D. W.J. Cruickshank, Chem.

12. G.A. Heath and J.R. Majer:, "A Preliminary Investigation by Mass Spectrometry of the Thermal Decomposition of Ammonium Perchlorate," RPE Technical Note No.219, April 1963; Trans. Faraday Soc., 60, 1783 (1964)。

13. V.H. Dibeler, R.M. Reese and D.F. Mann, J. Chem. Phys., 27, 176 (1957)。

14. I.P. Pisher, "Some Intermediates in the Pyrolysis and ilectron Impact of Chlorine Monoxide and Cnlorine Heptoxide," Ii. D. Techrical Report 67/10, Oct 1967; Trans. Paraday Soc., 64, 1852 (1968).

15. G.A. Cummings and G.S. Pearson, "Perchloric Acid: A Review of Its Thermal Decomposition and Thermochemistry," RPE Technical Note No.224, Oct 1963.

16. G.S. Pearson, Oxidation Combust. Rev., 4, 1 (1969).

17. D.J. Sibbett and J.M. Lobato, "Investieation of the Mechanism of Combustion of Composite Solid Propellants," Aerojet-General Corp. Azusa, Calif., Aerojet Report No. 1782, April 1960 (AD 240 274). position of Anhyarous Perc 'oric Acid," AerojetGeneral Ciorp., Azusa, Calif., Report 0372-01F, Appendix $C$.

19. D.J. Sibbett, $\mathbb{H} . J$. Cheselke, I. Geller, J.M. Iobato, F. E. Sutheriand and R. T. Chaiken, Combustion and jetonation Calif̂, ADstracted in AFOSR General Corp. Aprij 1962 (AD 274 132).

20. F. Solynosi, S. Boresol and H.E. Lazarn, Miagy Kem. Foly. 23, 329 (1957); Combust. Flame, 12, 398 (1968). 21. V.I.Gritson and V.M. Panilov, Kinet. Katal. 11, 
22. I.P. Fisher, "A Iiass Spectrometric Study of the Thermal Decomposition of Perchloric Acid and chlorine Dioxide," R.P. t. Technical Report 56/13, Tov 1956; Trans. Faraday Soc., 63, 684 (1967).

23. I.H. Studier, J. American Chem. Soc., 90, 1901 (1968).

24. Ii.F. Cordes and S.2. Smith, J. Chem. Ing. Data, 15, $158(1970)$

25. G.I. Pellett and A.R. Saunders, Heterogeneous Decomposition of Ammonium Perchlorate-Catalyst Fixtures Using Pulsed Laser Nass Spectrometry," AIAA Sixth Aerospace Sciences Ieeting, New York, i:.Y., Jan 1968, AIAA Preprint 68-149.

26. W. A. Guillory and i. King, J. Phys Cinem., 73, 4367 (1969).

27. F. Solymosi and S. Borcsok, J. Chem. Soc., 601
$(1970)$.

28. W. Dietz, Angew. Chem., 52, 616 (1939).

29. G. A. HCD. Cummings and G.S. Pearson, "illames Supported by Perchloric scid. II. The Decomosition Flame," RPE Technical Note 226, Oct 1963; Combust. Flame, 8, 199 (1964).

30. M. H. Evans, Chem. Rev., 51, 363 (1952).

31. A.P. Hall, G.S. Pearson, J. Combourieu and R. Noreau, "Perchloric Acid and Chlorine Dioxide Flames," R.P.E. Technical Report No.69/4, Feb 1969; Combust. Flame, 13, 596 (1969).

32. J. Powling, unpublished results quoted by G.3. Pearson in reference 5 .

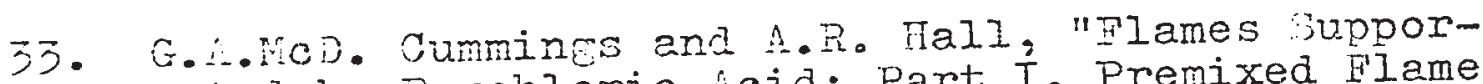
ted by Perchloric Acid: Part $\dot{I}$. Premixed Flames with Nethane," RPE Technical Note No.222, June 1953.

34. G.A.riCD. Cummines and A.R. Hall, "Tenth itmposium (International) on combustion," The Combustion Institute, Pjttsburoh, Pa., 1955, pp 1355-1372. 
35. G.A.McD. Cummines and A.R. Hall, "Perchloric Acid Flames: Part III, Some Flame Temperatures and Burning Velocities," R.P.T. Technical Report No.65/5, Sept 1965 .

36. G.S. Pearson, Nature, 208, 283 (1965).

37. G.i. Pearson, "Perchloric Aicid Planes: Part IV, Niethane-Rich Flames, "R.P.E. Technical Report No.65/6, AuE 1965.

38. G.i. Heath and G.B. Pearson, "The Chemical Structure of riethane-Perchioric Acid Plames," RPE llechnicaI Memo 399, April 1966: "The Pleventi Bymposium (International) on Combustion," The Combustion Institute, Pittsburgh, Pa., 1967, pp 967-977.

39. G.S. Pearson, Combust. Flame, 11, 89 (1967).

40. G.S. Pearson, "Perchloric Acid Fiames: Part V. Sthylene-Rich Flames," R.P. . Technical Report No. 6661 , March 1966.

41. G.s. Pearson, Combust. Flame, 11, 97 (1967).

42. G.S. Pearson, "Perchloric Acid Flames: Part VI. ithane-Rich Flames," R.P.E. Technical Report No. $66 / 2$, March 1966.

43. G.3. Pearson, Combust. Flame, 11, 103 (1957).

44. G.3. Pearson, "Perchloric Acid Flames: Part VII. Mixed Fuel-Rich Flames," R.P.i. Technical Report No.67/3, Iarch 1967; Combust. Flame, 11, 471 (1967).

45. G.D. Pearson, "Perchloric Acid Flames: Part VIII, Viethane-Rich Flames with Oxysen," R.P. .. Technical Report ivo.67/5i May 1967; Comoust. Flame, 12, 54 (1968).

46. A.R. Hall and G.S. Pearson, "Perchloric Acid Flames: Part IX. A TwO-Plame Structure with Hyarocarbons," R.P.i. Technical Report No.68/4, March 1958; "Twelfth Symposium (International) on Combustion," The Combustion Institute, Pittsburgh, Pa., 1968 $p p$

47. P. Lafitte, J. Combourieu, I. Majal, M. Ben Caid and R. Moreau, "ileventh Bymposium (International) cn 
Combustion," The Combustion Institute, Pittsburgh, Pa., 1967, pp 941-950.

48. M. Ben Caid, Doctorate Thesis, Paris (1966).

49. R. Moreau and J. Combourieu, Compt. Rend., C265, 440 (1967).

50. J. Combourieu and R. Moreau, "Twelfth Symposium (International) on Combustion," The Combustion Institute, Pittsburgh, Pa., 1968, pp

51. R. Moreau, Doctorate Thesis, Paris (1968).

52. R. Friedman and J.B. Levy, "Research on Solid Propellant Combustion," Atlantic Research Corp., Alexandria, Va., Final Technical Report AFOSR 2005, Dec 1961.

53. J.B. Levy, Comment on a paper by G.AoHeD. Cummings and A.R. Hall, see reference 34.

54. R.V. Figini, E. Coloccia and H.J. Schumacher, Z. Phys. Chem. (Frankfurt am Main), 14, 32 (1958).

55. E. Coloccia, R.V. Figini and E.J. Schumacher, Angew. Chem., 68, 492 (1956).

56. A.J. Arvia, W.H. Basualdo and H.J. Schumacher, Z. Anorg. Allg. Chem., 286, 58 (1956).

57. G.F. Goodeve and F.D. Richardson, J. Chem. Soc., 294 (1937).

58. J. Farquharson, C.F. Goodeve and F.D. Richardson, Trans. Faraday soc., 32, 790 (1936).

59. Z.G. Szabo, J. Chem. Soc., 1356 (1950).

60. H.J. Schumacher, Z. Phys. Chem. (Frankfurt am Main), $13,353(1957)$.

61. H.J. Schumacher and G. Stieger, Z. Physik. Chem., B?; $353(1930)$.

62. E.T. MeHale and G. von Elbe, J. Phys. Chem., 72, 1849 (1968).

63. H. Martin, W. Meise and E. Engelmann, Z. Phys. Chem. (Frankfurt am Main), 24, 285 (1960). 
54. P.J. Aymonino, J.E. Sicre and H.J. Schumacher, J. Chem. Phys., 22, 756 (1954); Anaies Asoc. Quim. Argentina, 43,26 (1955).

65. N. A=A Clyne and J.A. Coxon, Trans. Faraday Soc., $62,1175(1966)$

50. W.Ä.A. Clyne and J.A. Coxon, Proc. Roy. Soc. (London), A303, 207 (1968).

67. W.A.A. Clyne and J.A. Coxon, Proc. Roy. Soc. (Iondon), A298, 424 (1967)。

ㅊ. P.A. Durie and D.A. Ramsay, Can. J. Phys., 36, 35

59. G. Porter and F.J. Wright, Discussions Faraday Soc., 14, 23 (1953).

70. I.F.R. Cafferata, J.E. Sicre and H.J. Schumacher, 2 Phys. Chem.' (Frankfurt am Main), 루, 188 (1961).

71. P.W.M. Jacobs and A. Russel-Jones, "Eleventh Symposium (International) on Combustion," The Combustion Institute, Pittsburgh, Pa., 1966, pp 457-462.

72. I.i. Kolthoff and E.B. Sandell, "Textbook of Quantitative Analysis," The MacMillan Co., New York, N.Y., 1961, p 559.

73. Iojd., p 545.

24. Angelbrecht, E. Nachbauer and E. Meyer, J.
Chromatography, 15, $228(1964)$.

75. Anon., Anal. Chem., 29, 23A and 26A (1957).

7. H.A.A. Clyne, "Reaction Kinetics Related to Ammonium Perchlorate Decomposition: Part 1," Extramural Research Contract Report No.3, Department of Chemistry, Queen Mary College, London, April 1970.

7. ir.A.A. Clyne, "Reaction Kinetics Related to Ammonium Perchlorate Decomposition: Part 2," Extramural Research Contract Report No.3, Department of Chemistry, Queen Mary College, London, May 1970. 